\title{
Decision support systems for personalized and participative radiation oncology
}

Citation for published version (APA):

Lambin, P., Zindler, J., Vanneste, B. G. L., Van De Voorde, L., Eekers, D., Compter, I., Panth, K. M., Peerlings, J., Larue, R. T. H. M., Deist, T. M., Jochems, A., Lustberg, T., van Soest, J., de Jong, E. E. C., Even, A. J. G., Reymen, B., Rekers, N., van Gisbergen, M., Roelofs, E., ... Walsh, S. (2017). Decision support systems for personalized and participative radiation oncology. Advanced Drug Delivery Reviews, 109, 131-153. https://doi.org/10.1016/j.addr.2016.01.006

Document status and date:

Published: 15/01/2017

DOI:

10.1016/j.addr.2016.01.006

Document Version:

Publisher's PDF, also known as Version of record

Document license:

Taverne

Please check the document version of this publication:

- A submitted manuscript is the version of the article upon submission and before peer-review. There can be important differences between the submitted version and the official published version of record.

People interested in the research are advised to contact the author for the final version of the publication, or visit the DOI to the publisher's website.

- The final author version and the galley proof are versions of the publication after peer review.

- The final published version features the final layout of the paper including the volume, issue and page numbers.

Link to publication

\footnotetext{
General rights rights.

- You may freely distribute the URL identifying the publication in the public portal. please follow below link for the End User Agreement:

www.umlib.nl/taverne-license

Take down policy

If you believe that this document breaches copyright please contact us at:

repository@maastrichtuniversity.nl

providing details and we will investigate your claim.
}

Copyright and moral rights for the publications made accessible in the public portal are retained by the authors and/or other copyright owners and it is a condition of accessing publications that users recognise and abide by the legal requirements associated with these

- Users may download and print one copy of any publication from the public portal for the purpose of private study or research.

- You may not further distribute the material or use it for any profit-making activity or commercial gain

If the publication is distributed under the terms of Article $25 \mathrm{fa}$ of the Dutch Copyright Act, indicated by the "Taverne" license above, 


\title{
Decision support systems for personalized and participative radiation oncology is
}

\author{
Philippe Lambin *, Jaap Zindler, Ben G.L. Vanneste, Lien Van De Voorde, Daniëlle Eekers, Inge Compter, \\ Kranthi Marella Panth, Jurgen Peerlings, Ruben T.H.M. Larue, Timo M. Deist, Arthur Jochems, Tim Lustberg, \\ Johan van Soest, Evelyn E.C. de Jong, Aniek J.G. Even, Bart Reymen, Nicolle Rekers, Marike van Gisbergen, \\ Erik Roelofs, Sara Carvalho, Ralph T.H. Leijenaar, Catharina M.L. Zegers, Maria Jacobs, Janita van Timmeren, \\ Patricia Brouwers, Jonathan A. Lal, Ludwig Dubois, Ala Yaromina, Evert Jan Van Limbergen, Maaike Berbee, \\ Wouter van Elmpt, Cary Oberije, Bram Ramaekers, Andre Dekker, Liesbeth J. Boersma, Frank Hoebers, \\ Kim M. Smits, Adriana J. Berlanga, Sean Walsh
}

Department of Radiation Oncology (MAASTRO), GROW, School for Oncology and Developmental Biology, Maastricht University Medical Centre +, Maastricht, The Netherlands

\section{A R T I C L E I N F O}

\section{Article history}

Received 15 September 2015

Received in revised form 8 December 2015

Accepted 6 January 2016

Available online 14 January 2016

\section{Keywords:}

Radiotherapy

Decision support systems

Prediction models

Shared decision making

\begin{abstract}
A B S T R A C T
A paradigm shift from current population based medicine to personalized and participative medicine is underway. This transition is being supported by the development of clinical decision support systems based on prediction models of treatment outcome. In radiation oncology, these models 'learn' using advanced and innovative information technologies (ideally in a distributed fashion - please watch the animation: http://youtu.be/ ZDJFOxpwqEA) from all available/appropriate medical data (clinical, treatment, imaging, biological/genetic, etc.) to achieve the highest possible accuracy with respect to prediction of tumor response and normal tissue toxicity. In this position paper, we deliver an overview of the factors that are associated with outcome in radiation oncology and discuss the methodology behind the development of accurate prediction models, which is a multifaceted process. Subsequent to initial development/validation and clinical introduction, decision support systems should be constantly re-evaluated (through quality assurance procedures) in different patient datasets in order to refine and re-optimize the models, ensuring the continuous utility of the models. In the reasonably near future, decision support systems will be fully integrated within the clinic, with data and knowledge being shared in a standardized, dynamic, and potentially global manner enabling truly personalized and participative medicine.
\end{abstract}

(C) 2016 Published by Elsevier B.V.

\section{Contents}

1. Introduction..., 132

2. Rapid learning healthcare . . . . . . . . . . . . . . . . . . . . . . . . . . . . . . . . . . . . . . . . . . 132

2.1. The four phases of rapid learning healthcare . . . . . . . . . . . . . . . . . . . . . . . . . . . . . . . . . . . 132

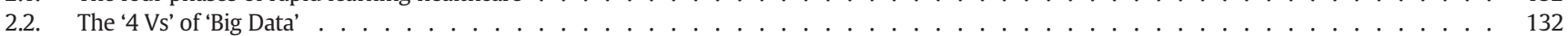

2.3. Knowledge . . . . . . . . . . . . . . . . . . . . . . . . . . . . . . . . . . . 133

2.4. Application . . . . . . . . . . . . . . . . . . . . . . . . . . . . . . . . . . . . 134

2.5. Evaluation .. . . . . . . . . . . . . . . . . . . . . . . . . . . . . . . . . . . . . . . 134

3. Producing a clinical decision support system . . . . . . . . . . . . . . . . . . . . . . . . . . . . . . . . . . . 135

3.1. Factors for prediction . . . . . . . . . . . . . . . . . . . . . . . . . . . . . . . . . . . . . 135

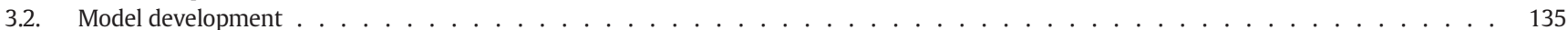

3.3. Predicting outcomes . . . . . . . . . . . . . . . . . . . . . . . . . . . . . . . . . . . . . . 136

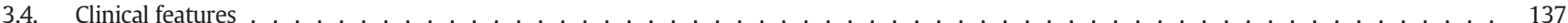

3.5. Treatment features . . . . . . . . . . . . . . . . . . . . . . . . . . . . . . . . . . 137

3.6. Imaging features: from tumor size to radiomics . . . . . . . . . . . . . . . . . . . . . . . . . . . . . . . . 138

it This review is part of the Advanced Drug Delivery Reviews theme issue on "Radiotherapy for Cancer: Present and Future".

* Corresponding author at: MAASTRO Clinic, Dr Tanslaan 12, PO Box 1588, 6201 BN Maastricht, The Netherlands. Tel.: + 31884455666 ; fax: + 31884455667.

E-mail address: philippe.lambin@maastro.nl (P. Lambin). 
3.7. Biological/genetic features . . . . . . . . . . . . . . . . . . . . . . . . . . . 140

3.8. Visualization of clinical decision support systems . . . . . . . . . . . . . . . . . . . . . . . . . . . . . . . 142

3.9. Cost effectiveness for decision support systems ～. . . . . . . . . . . . . . . . . . . . . . . . . . . . . . 142

3.10. Shared decision making . . . . . . . . . . . . . . . . . . . . . . . . . . . . . . . . . . . . 142

3.11. An example of personalized therapy in radiation oncology . . . . . . . . . . . . . . . . . . . . . . . . . . . 144

3.12. A vision of decision support systems for personalized and participative radiation oncology in practice . . . . . . . . . . . . . . . . . . 144

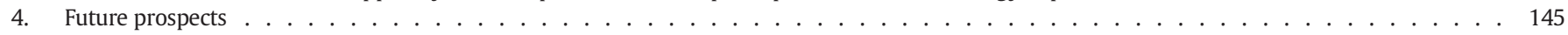

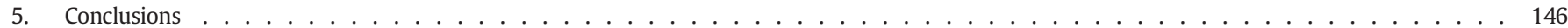

Disclosures of potential conflicts of interest . . . . . . . . . . . . . . . . . . . . . . . . . . . . . 146

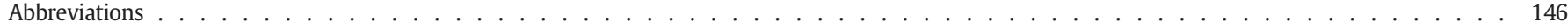

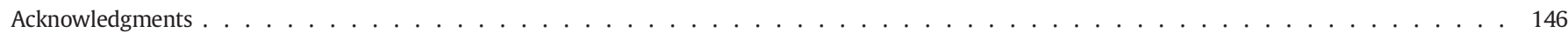

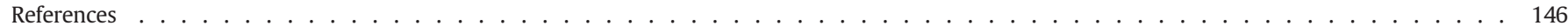

\section{Introduction}

Several major advances in cancer care (including radiation oncology) have been made in the last 5-10 years, with many new diagnostic techniques and treatment modalities becoming available [1]. This wealth of choice, however, has brought with it new challenges. Attaining level I evidence is increasingly difficult given the copious disease, patient and treatment parameters that exist, resulting in ever-increasing data heterogeneity [2]. This new reality is somewhat at odds with traditional evidence based medicine, whereby randomized trials are designed for large populations of homogenous patients. Consequently, new approaches are required to build evidence for clinical decision making based upon this wealth of patient, disease and treatment characteristics [3].

The challenge can be exemplified as follows: For each patient, the physicians must consider biology (mutations, translations, etc.), pathology, state-of-the-art imaging (including guidance techniques), blood tests, drugs/hormones, improved radiotherapy planning systems, dose, fractionation, radiation type, and, in the near future, radiogenomic data [4]. Medical decisions should balance cure rate, median survival, toxicity, comorbidity, quality of life, patient preferences (inform and involve the patient) and (in most healthcare systems) cost effectiveness [5]. This myriad of factors renders clinical decision making a dauntingly complex, and perhaps inhuman, task as human cognitive capacity is limited to roughly five factors per decision [2]. Furthermore, dramatic genetic [6], epigenetic [7], transcriptomic [8], histological [9] and microenvironmental [10] heterogeneity exists within individual tumors, and even greater heterogeneity exists between patients [11]. In radiation oncology there is heterogeneity in dose prescription, treatment margins and plan quality (i.e., 3DCRT, IMRT, VMAT, etc.). Moreover, there is a growing availability of targeted agents and immunotherapy which also may affect outcome. Despite these enormous complexities, individualized cancer therapy is realizable. Indeed, intra- and intertumoral variability can be potentially exploited advantageously to maximize the therapeutic ratio, i.e. increasing the effects of therapy upon the tumor while decreasing those effects on healthy tissues [12-14].

The principal challenge is how best to collect and integrate diverse multimodal data sources (clinical, treatment, imaging, biological/genetic, etc.) in a quantitative fashion that can provide specific clinical predictions that accurately and robustly estimate outcomes as a function of the possible decisions $[15,16]$. Presently, numerous published prediction models are available that account for factors related to both disease and treatment, but lack standardized evaluation of their robustness, reproducibility and/or clinical utility [17]. Consequently, these models may not be suitable (let alone optimal) for clinical decision support systems.

In this position paper we highlight the recent advances in decision support systems (DSS) for personalized radiation oncology, with a focus on the methodological aspects of prediction model development/validation as well as the sophisticated and innovative information technologies which are fundamental to the implementation and success of DSS. The benefits and accompanying challenges of DSS are also discussed as well as the steps required for the continued progression and wide spread acceptance of DSS within the clinic.

\section{Rapid learning healthcare}

\subsection{The four phases of rapid learning healthcare}

Rapid learning health care (RLHC) [2] (also known as: knowledgedriven medicine, computer assisted theragnostics, intelligent medical networks, etc.) is the (re)use of medical data (from both standard clinical practice and clinical trials) to aid in decision making with respect to new patients and/or to investigate novel hypotheses [18-22] (Fig. 1a). RLHC is comprised of four sequential infinitely reiterated phases [2] (Fig. 1b) that culminates in model development/validation which can be clinically implemented through DSS [23] (Fig. 1c). The Data phase handles the attainment and mining of prior data (e.g., patient, disease, treatment, outcome, etc.). The Knowledge phase utilizes sophisticated analytical methods, (e.g., machine learning), to harness knowledge from the aggregated data. The Application phase exploits this knowledge to improve clinical practice. The Evaluation phase assesses DSS performance with respect to outcomes, subsequently the initial phase commences once more. For each phase, current best practice coupled with the latest scientific understanding is used to optimize the process. The sections below describe each phase in detail.

\subsection{The '4 Vs' of 'Big Data'}

Perfect RLHC demands the ' 4 Vs' of 'Big Data'; veracity, velocity, variety, and volume of data (http://www.ibmbigdatahub.com/infographic/ four-vs-big-data). The veracity of data is critical to the amount of trust that can be placed in the knowledge acquired. The velocity of data is essential to guarantee that knowledge is gathered as continuously and constantly as practicable. The variety of data (predominantly with respect to treatment modalities as well as patient and disease characteristics) is fundamental to ultimately conclude which treatment is optimal for an individual patient. The volume of data is key: A) to obtain enhanced knowledge (the fidelity of knowledge is directly related to the number of patients upon which that knowledge is founded); and B) to gain knowledge regarding rarer, less heterogeneous patient cohorts and/or to increase the number of variables in the knowledge phase.

Accessing data with adequate fidelity in relation to the ' $4 \mathrm{Vs}$ ' is the largest obstacle in RLHC. It is recognized that both the clinical and research communities need to embrace a data sharing ethos [24], traversing institutional and national boundaries, so as to realize this goal [25]. One initiative to accomplish this goal is CancerLinQ [26] (http://cancerlinq.org/), of the American Society of Clinical Oncology (ASCO). It is a RLHC system designed to monitor, coordinate, and improve the quality of care provided to patients with cancer through the collection, aggregation, and analysis of data extracted from the electronic health records (EHRs) and practice management systems at 

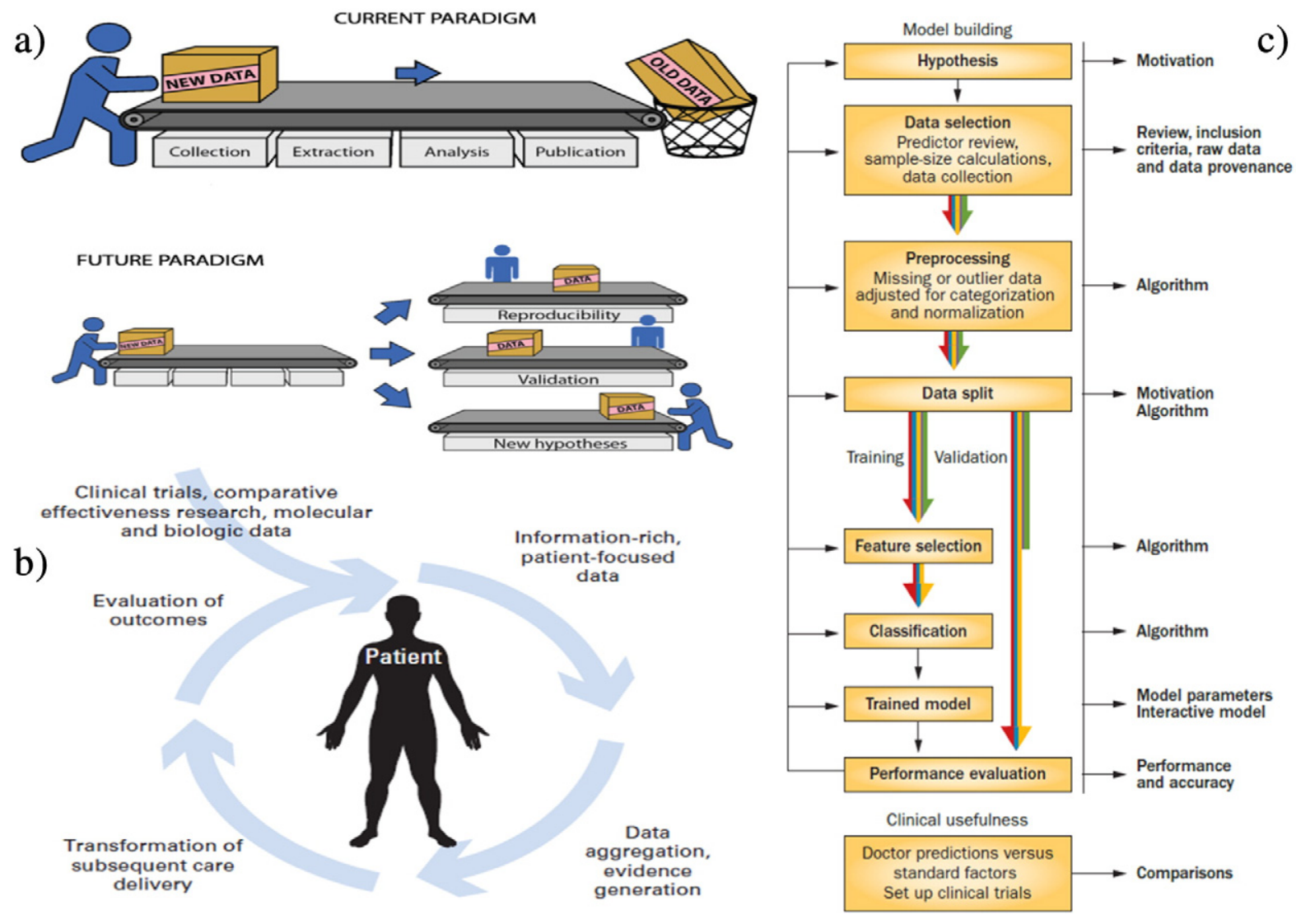

Fig. 1. Overview of the methodological aspects of clinical DSS development/validation, including assessment of clinical utility.

participating oncology practices. Unlike registries that collect prespecified data elements from a defined cohort, CancerLinQ collects the complete EHR of all patients in a participating practice. This necessitates an established secure connection to CancerLinQ from the EHRs and practice management systems, to periodically transfer a range of information. The data proposed to be transferred includes; provider and patient demographics, appointments, billing codes, patient visit/encounter details, medical history and physical examination, family and social histories, consult reports, surgery reports, pathology and laboratory data, and medication administration and prescription history. Through the use of natural language processing, CancerLinQ will also be able to collect and process information from clinician notes. This traditional data centralization approach faces the following classical barriers to data sharing [27], which come in the form of: human resources or insufficient time; cultural and language difficulties along with data recording methods; the political and academic worth of data; hazards to reputation; legal and privacy issue, etc. These are all significant issues to address and are not easily overcome. However, a cooperative endeavor linking radiotherapy institutes in the Netherlands, Germany and Belgium (Fig. 2: now extended to the UK, Italy, Denmark, Australia, China, India, and the USA - Canada, South Africa and Ireland are currently prospective partners) successfully realized RLHC through a novel data federated approach in the euroCAT project (www.eurocat.info, please see the animation: http://youtu.be/ZDJFOxpwqEA). Novel applications for advanced information communication technologies were central to the realization of the endeavor (Fig. 3), facilitating synchronized RLHC in each center without any data needing to leave the institution (thus overcoming the classical barriers to data sharing aforementioned), known as 'distributed learning' (please see the animation: https://www.youtube.com/watch?v=nQpqMIuHyOk). This forced the development of data with semantic interoperability (also called 'data with linguistic unity' or 'machine-readable data'), wherein local terms are matched to concepts from a well-defined ontology (e.g. NCI Thesaurus). Utilizing this technique, the ontology terms function as a common interface for the data at each institutional site, allowing a unified process for information retrieval and reasoning facilitated by a semantic gateway to the data. An advantage of such initiatives is that they encourage harmonization with regard to what data necessities collection and how (i.e., disease specific 'umbrella' protocols: NCT01855191 https://www.cancerdata.org/ protocols/eurocat-umbrella-protocol-nsclc) [28].

\subsection{Knowledge}

Machine learning is a method to transform data into knowledge. In machine learning, models/algorithms are utilized to optimally characterize data and generate knowledge which can be exploited to make predictions with respect to new, unobserved data. Models trained on past data can be employed to predict the outcomes (e.g., control, toxicity, quality of life, etc.) of numerous treatments using data from a new patient. With evermore patient characteristics becoming available (clinical, treatment, imaging, biological/genetic, etc.) there is more heterogeneity in the data and consequently greater opportunity to garner superior knowledge. However, an un-validated model is of highly limited worth and it is thus essential that models are properly validated. The TRIPOD (transparent reporting of a multivariable prediction model for individual prognosis or diagnosis) statement is an excellent template for this - exemplifying increased model accuracy and robustness stemming from proper data management [29-33]; Therefore, a validation dataset must be readily obtainable, if possible from an external institute(s) dissimilar (but not inappropriately different) than that from which the data was used to train the model. 


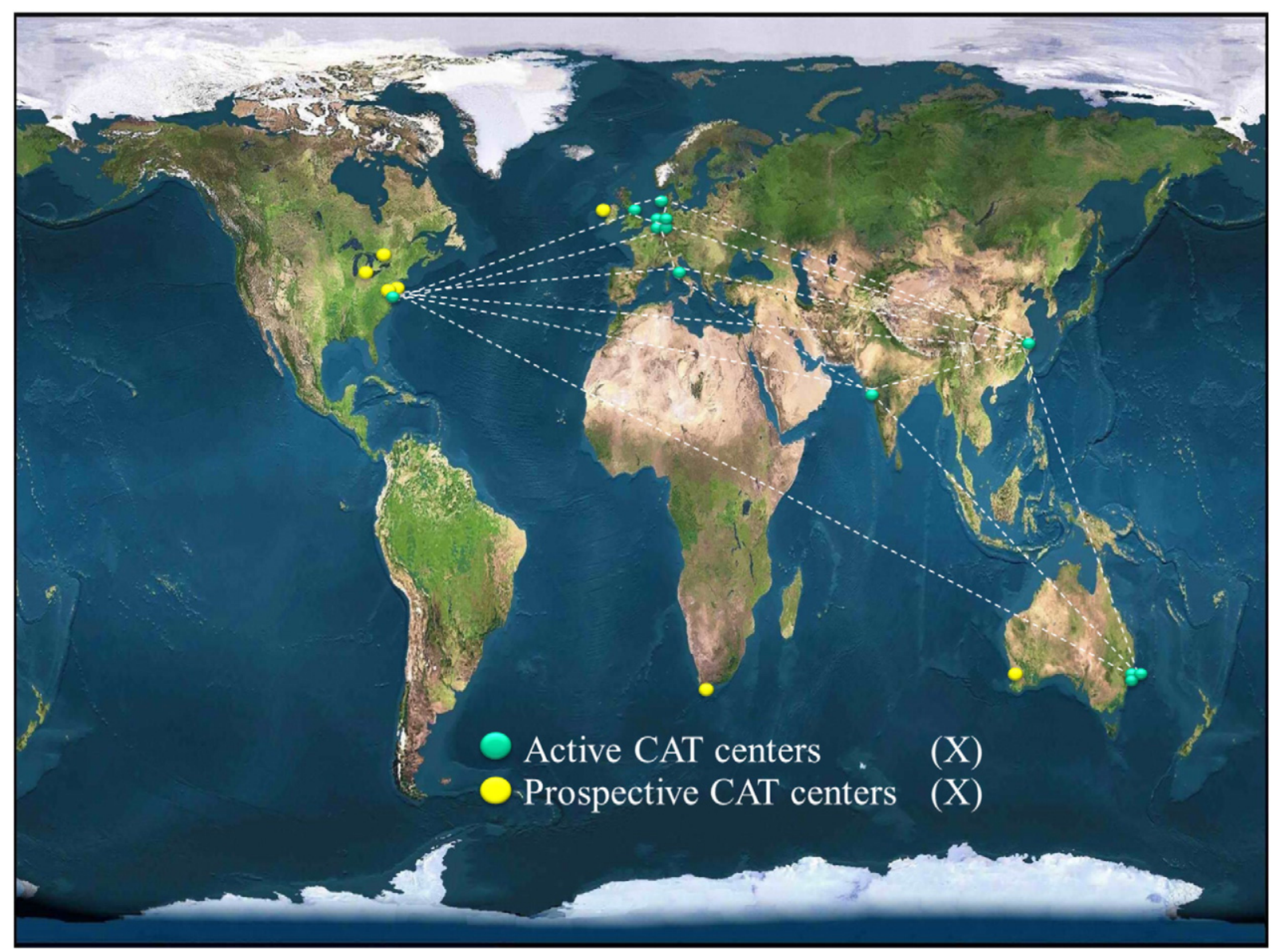

Fig. 2. Overview of the current 'worldCAT' network: Active and prospective partner sites.

Examples of radiotherapy models (on the basis of both clinical trials and routine clinical care data) are available for non-small cell lung, rectal and head-and-neck cancer on http://www.predictcancer.org, breast cancer on http://research.nki.nl/ibr/, prostate cancer on https://www. mskcc.org/nomograms/prostate, and glioblastoma on http://www. eortc.be/tools/gbmcalculator/.

\subsection{Application}

Clinical trials are vital in informing routine clinical care; however, current designs have considerable deficiencies, such as selection bias (e.g. under-representation of elderly patients) [34-37]. RLHC helps meet this challenge as the knowledge gained from RLHC is drawn directly from the routine clinical care population. This knowledge is applied with the aid of DSS. These are archetypally software applications that may be utilized to apply RLHC in practice. Examples include nomograms (Fig. 4) [38-40], recursive partitioning analysis models [41], and websites, such as those given above. DSS are proposed to support the physician and the patient in taking the most knowledgeable decision possible with respect to treatment options (they are neither proposed nor appropriate as a substitute to the physician). Healthcare professionals leveraging computer models in radiation oncology are not novel. Physics-based models for dose calculation along with radiobiology-based normal tissue complication probability (NTCP) [42] and tumor control probability (TCP) [43] models to link dose with toxicity and tumor control, are all accepted within the radiotherapy community. The emergent models from RLHC [44] are a natural evolution of this practice. An important attribute of RLHC models is their 'holistic' and multifactorial structure, integrating the current physics- and/or radiobiology-based models, along with accounting for patient, tumor and non-radiotherapy factors [23]. For instance, a RLHC model of radiation-induced esophagitis predicts that the risk for this toxicity depends not simply on just the dose to which the esophagus is exposed, but also significantly increases if concomitant chemotherapy is delivered [45]. Another example is that for non-metastatic unresectable non-small cell lung carcinoma, the prognostic value in relation to survival is inferiorly predicted by tumor-node-metastasis (TNM) classification than a multifactorial model built upon clinical, imaging and biomarkers variables [46].

\subsection{Evaluation}

The primary idea in RLHC is that the utilization of knowledge obtained from clinical data results in comprehensive understanding and subsequently improved predictability of treatment outcomes, suggesting that these outcomes can be improved both in terms of effectiveness (attaining the desired outcome) and efficiency (the resources needed to attain the outcome). While adding features may result in enhanced outcome prediction, this is not always the case and therefore critical appraisal of complex multifactorial models with comparatively simple generally accepted models is crucial to define the precise worth of added features [32]. Indeed, RLHC models ought to be repeatedly (re-)evaluated, fixed on the questions 'Is the outcome of treatment as expected, and if so, how does this relate to consensus and/or evidence based guideline knowledge?'. This appraisal ought to if possible be performed with (meta-analysis of) robust data that is independently interpreted by multiple interested stakeholders (researchers, physicians, economists and patients/representatives). 


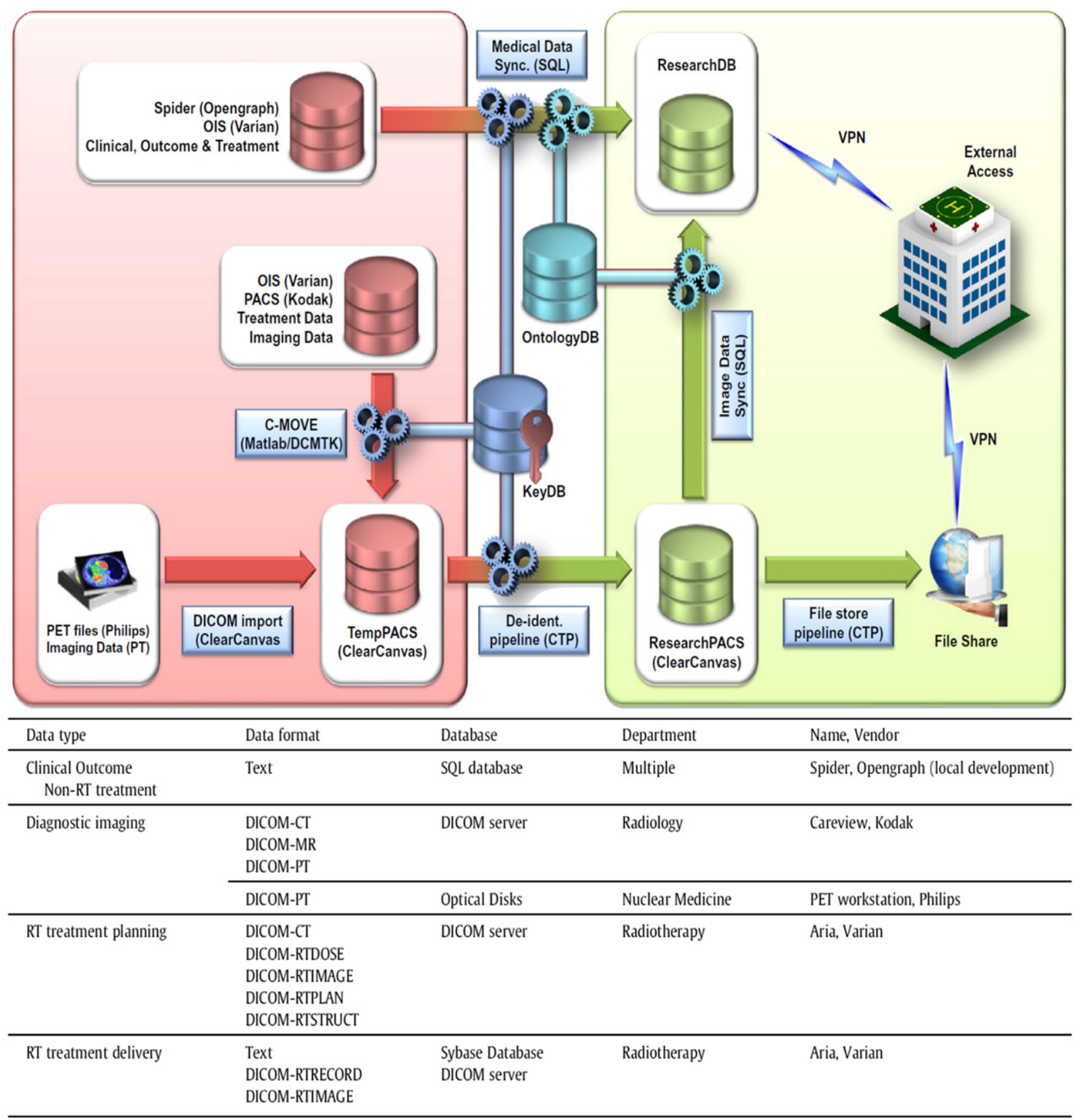

Fig. 3. Overview of data sources, flow and external access of the current network infrastructure installed at each partner site within 'worldCAT'.

\section{Producing a clinical decision support system}

\subsection{Factors for prediction}

The primary goal of producing DSS is to discover, based upon the available information, a combination of factors that accurately and robustly predict an individual patient's outcome [47] (e.g., clinical, treatment, imaging, biological/genetic, etc.). Outcomes can be categorized coarsely as either control (rates of local recurrence, evolution to metastatic disease, overall survival, etc.) or toxicity (acute, late, moderate, severe toxicity induction, etc.), or a combination of these end points (cost effectiveness can also be considered [48]). Although predictive factors (i.e., factors that influence response to certain treatments) are essential for DSS, prognostic factors (i.e., factors that influence response without treatment) [49] are equally significant in illuminating the complex relationship with outcome. Henceforth, we refer to both of these terms commonly as 'features' because for a predictive model correlation with outcome must be demonstrable.

\subsection{Model development}

The process of feature selection for model development is comparable to that of biomarker assays [50]. In that framework, we can distinguish qualification and validation. Qualification demonstrates that the data is predictive of an end point, while validation establishes that a combination of features is both reliable and suitable for the envisioned purpose. i.e., features must be identified and tested in independent datasets to determine if treatment decisions made based upon these features would improve outcomes. The complete cycle of model development entails several stages (Fig. 1c).

In the hypothesis-generation stage, the end point to predict must be considered along with the timing of the treatment decision and the 


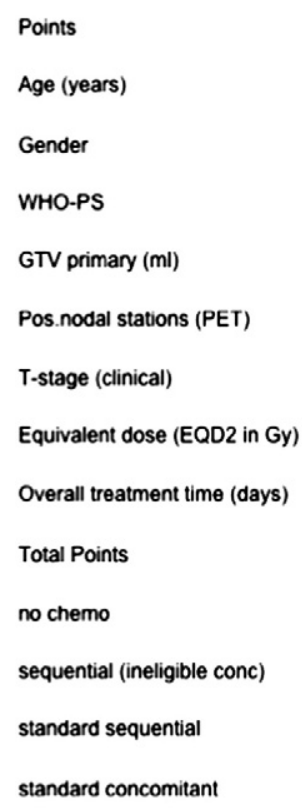

Points

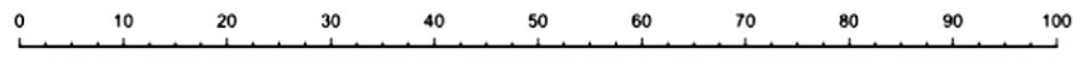

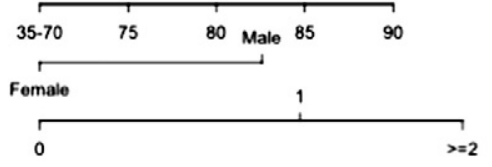

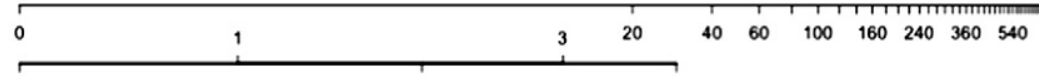

0

T0.T1

T2

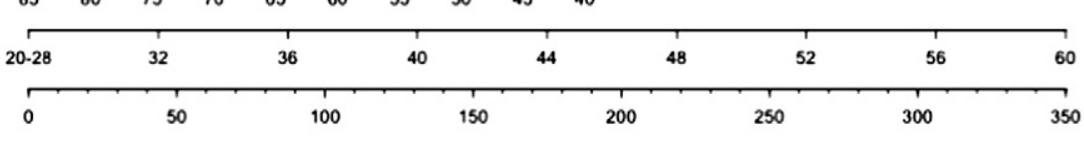

50

$\begin{array}{llllllll}0.8 & 0.7 & 0.6 & 0.5 & 0.4 & 0.3 & 0.2 & 0.1\end{array}$$$
0.8
$$

$\begin{array}{lllllll}0.7 & 0.6 & 0.5 & 0.4 & 0.3 & 0.2 & 0.1\end{array}$

0.8

\begin{tabular}{|c|c|c|c|c|c|c|}
\hline 0.7 & 0.6 & 0.5 & 0.4 & 0.3 & 0.2 & 0.1 \\
\hline & 0.7 & 0.6 & 0.5 & 0.4 & 0.3 & 0.2 \\
\hline
\end{tabular}

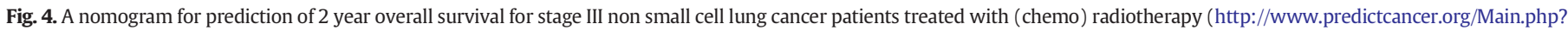
page $=$ LungSurvivalModel3).

available data at these time points. In the data-selection stage, a review of possible features is performed, by either expert panel or by mathematical approaches such as a Bayesian network (which has been shown to be superior to expert panels [51]). Sample-size calculations are recommended, particularly for the validation phase [52,53]. Data from both clinical trials (high quality, low quantity, controlled/biased selection) and clinical practice (low quality, high quantity, uncontrolled/unbiased selection) are useful, however selection biases should be accounted for in both instances and inclusion criteria ought to be equivalent. For all features, data heterogeneity is a key requirement to identify predictive features which enable the personalization of treatment.

Preprocessing manages various issues such as missing data (imputation) [54], incorrectly measured or entered data (sanity checks) [55] as well as discretizing and normalizing data (if applicable) to avoid sensitivity for different orders of data scales [56]. If an external, independent dataset is not available for validation, the available data must be split (in a separate stage) into a model training dataset and a validation dataset. In the feature selection stage, the ratio of the number of evaluated features to number of outcome events must be kept as low as possible to avoid overfitting [57-59]. When a model is overfitted, it is specifically and exclusively trained for the training data (including its data noise) and consequently performs poorly on new data. Data-driven preselection of features is therefore recommended [60]. Univariate analyses are commonly used to prioritize the features - that is, testing each feature individually and ranking them on their strength of correlation with outcome. Next, performance measures for the model are determined on both the training and validation datasets. These measures are typically the area under the receiver operating characteristic curve (AUC) or the c-index for censored data [32]. The AUC and c-index quantify the sensitivity and specificity of the model and have values between 0 and 1 (with 1 denoting a perfect model, 0.5 randomness, and 0 the inverse of a perfect model).

\subsection{Predicting outcomes}

Training data is employed to train a model, classifying all potential outcomes. Classical statistical [61] as well as machine-learning models [62] can be considered. For two or more classes (e.g., survival vs death), logistic regression, support vector machines, decision trees, Bayesian networks or Naive Bayes algorithms can all be utilized [63,
64]. For time-to-event outcomes (irrespective of censorship), Cox proportional hazards models or the Fine and Gray model [65] of competing risks are typical. Model selection is dependent on the nature of the outcome (e.g., logistic regression for two or more outcomes, or Cox regression for survival-type data) and the nature of the training data (e.g., Bayesian networks necessitate categorized data, while supportvector machines are appropriate for continuous data). As a general rule, several models should be evaluated to ascertain which model is optimal for the available data. This also includes investigation of nonlinear associations and interactions. Akaike's information criterion can be used to deal with the trade-off between goodness of fit and model complexity [66] (i.e., a simpler model is expected to be more robust than a more complex model to a wider range of data).

Performance in the training dataset is always upwards-biased because the features were selected from the training dataset. Therefore, a validation dataset is essential to establish the likely performance in the clinic. Preferably, validation data should come from an external independent institution or trial. When data is scarce, internal validation can be conducted using random split, temporal split or k-fold crossvalidation techniques [67]. The developed model should demonstrate a clear benefit with respect to decision making, and must be evaluated prospectively in the clinic in the penultimate stage of model development. Predictions forecast by the model and clinicians must be compared $[45,68]$ along with standard prognostic and predictive factors [69]. Application of models in clinical practice often requires an extra step in the development process. While most models provide a predicted probability for an outcome, clinical decision making usually relies on threshold values for treatment choices. Depending on the consequences a threshold value is chosen to minimize either false positives or false negatives. So a wide range of tools exist, ranging from informative, by providing a probability, to prescriptive tools, that use a fixed threshold, and even tools that are capable of identifying patient-specific thresholds. Irrespective of their nature, it is crucial to confirm improvements in patient outcome, quality of life and/or reduced toxicity [70], by performing clinical trials and impact studies whereby the random allocation of patients is predicated by the model. Satisfying this requisite will produce the ultimate evidence that the model is enhancing health care by comparing, in a controlled way, the personalized therapy with standard therapy in the clinic. 
Lastly, the prediction models and development data can be published, allowing the broader oncological community to assess them. Full transparency of the data as well as methodology is vital to the global implementation of the model within DSS. This proposition is analogous to clinical 'omics' publications for which the raw data, the code used to analyze the data, evidence for data provenance (the procedure that led to a piece of data) and a written report of nonscriptable analysis steps are customarily made available [71].

\subsection{Clinical features}

Decision making in radiotherapy is largely built on clinical features, such as the patient performance status, organ function and grade of the cancer based on histologic assessment, the extent of the tumor (defined by the TNM system), age, comorbidity of the patient, etc. Such features have been repeatedly found to be prognostic for survival and toxicity [72,73]. Accordingly, such features should be assessed/incorporated when developing robust and clinically acceptable models for DSS. Measurement of some clinical features can be captured with minimal effort (e.g., performance status). Even a simple questionnaire should be validated as is the case for laboratory measurements of organ function or parameters measured from blood $[74,75]$.

A standardized protocol should be established (e.g., the 'Umbrella' protocol NCT01855191 https://www.cancerdata.org/protocols/ eurocat-umbrella-protocol-nsclc [28]) to guarantee that comparisons are possible and appropriate between centers and questionnaires over time [76]. Additionally, why particular features were selected for measurement should be clearly explained (e.g., if hemoglobin measurements were only recorded for patients with fatigue, the subsequent bias would dictate caution when including and interpreting the measurements). Only when clinical parameters are recorded prospectively with a level of scrutiny equivalent to laboratory measurements will observational studies become as trustworthy as randomized trials $[77,78]$.

Toxicity measurements and grading should also be based upon validated systems, such as the common terminology criteria for adverse events (CTCAE: http://evs.nci.nih.gov/ftp1/CTCAE/CTCAE_4.03_201006-14_QuickReference_5x7.pdf) [79], which can be reported by the physician or patient $[80,81]$. Indeed, a recent meta-analysis revealed that high-quality toxicity assessments from observational trials are comparable to those of randomized trials $[82,83]$. However, a prospective protocol must clarify which system was used and how changes in toxicity grade over time with respect to treatment were managed.

Finally, to ensure standardized interpretation, the reporting of clinical and toxicity data and their analyses should be conducted in line with the STROBE (strengthening the reporting of observational studies in epidemiology) statement for observational studies and genetic-association studies, which is essentially a checklist of items that should be addressed in reports to simplify critical appraisal and interpretation of these type of studies [84-86].

\subsection{Treatment features}

A delicate balance exists between tumor control and treatmentrelated toxicity. Presently, image-guided radiotherapy (IGRT) is a highly precise cancer treatment modality in delivering its agent (radiation) to the tumor [87]. Additionally, broad knowledge of the effects of radiation upon normal tissue has been obtained [88-90]. Utilizing modern radiotherapy techniques - such as Brachytherapy (low dose or High dose rate), intensity-modulated radiotherapy (IMRT), volumetric arc therapy (VMAT) or particle-beam therapy - the treatment dose can be sculpted around the target volume with dosimetric accuracy of a few percentage points delivering millimeter precision to spare as much as possible the organs at risk [91] (Fig. 5).

For modeling purposes, features that are derived from planned spatial and temporal dose distributions are significant. Furthermore, a description of the efforts undertaken during treatment to safeguard that the prescribed dose is in fact delivered as planned (e.g., in-vivo dosimetry) is also required [92]. Additional therapies, such as hormonal therapy, chemotherapy, targeted agents and surgery, and their respective features must also be detailed because these also influence to varying degrees outcome. A prime example of this is concurrent versus sequential chemoradiation, which has a major impact on the incidence of acute esophagitis and induces dysphagia [93].

With respect to the spatial dimension of radiotherapy, how to combine information about the spatially variable dose distribution for every subvolume of the tumor or organ remains an open question. Dose-response relationships for tumor and healthy tissues are frequently reported as mean dose, though voxel-based measures have also been reported [94]. Mean doses or point doses (e.g., max/ min dose) inside the tumor or healthy tissue are easily quantified and are sufficient for numerous applications. However, spatial characteristics might be more relevant in personalized approaches to ensure radioresistant/sensitive areas of the tumor or healthy tissue receive higher/lower doses [95].

Clinical dose volume histogram analysis was first described in 1991 for radiation pneumonitis and proctitis after treatments for non-smallcell lung and prostate cancers [96]. In 2010, a series of comprehensive reviews of all commonly irradiated organs (the QUANTEC project) was published [89], illustrating that, similar to the tumor, care must be taken when assessing dose at the organ level. For example, in some organs the volume receiving a certain dose is important (such as the esophagus or lung $[97,98])$, while in other organs it is the maximum dose which is most important (such as for the spinal cord [99]). Predicting toxicity in healthy tissues is an active research area with ongoing, large, prospective multicenter studies [100-107].

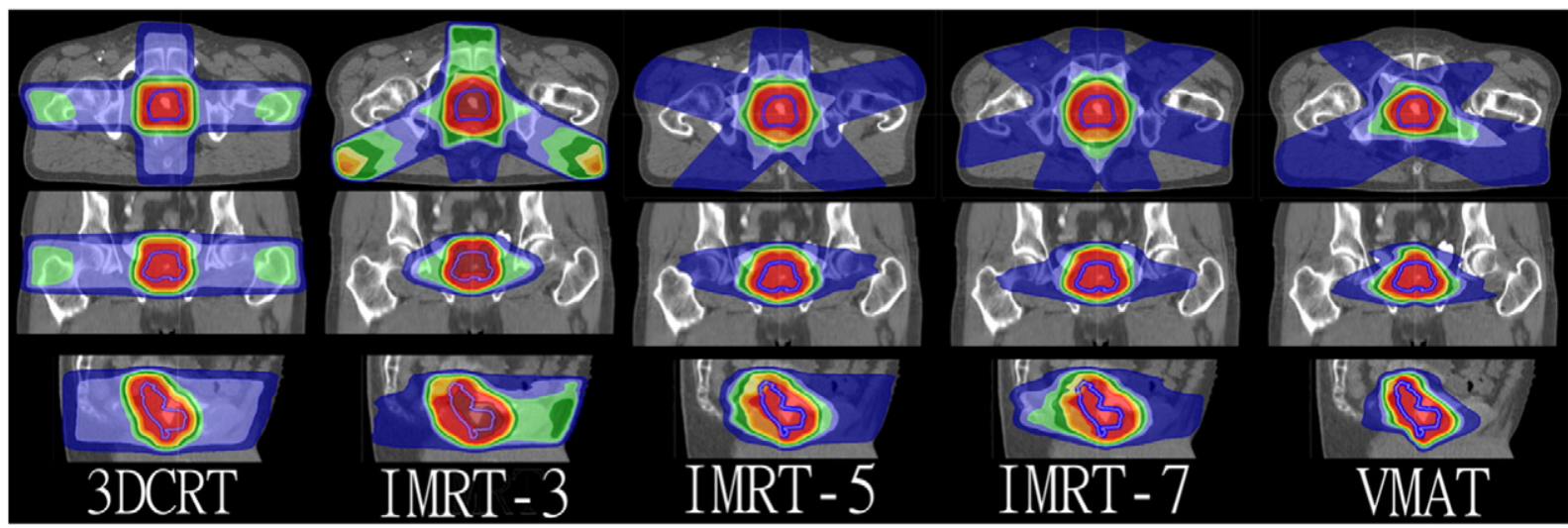

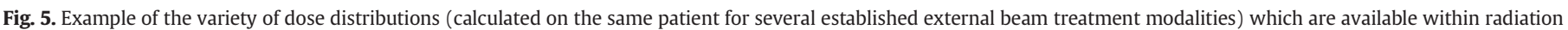
oncology for the treatment of prostate cancer. The number following IMRT-3/5/7 refers to the number of beams. 
Though significant, relying solely on dose-based predictions is illadvised due to the large variability in toxicity which patients' exhibit. The cause of this variability includes several recognized clinical and biological/genetic-based features as well as the quality of the treatment execution (i.e., planned vs delivered dose [108]). The overemphasis on the planned radiotherapy dose distribution as the primary factor of outcome is possibly the most common hazard in prediction modeling as substantial deviations from the original plan during treatment often occur [109]. The accuracy of prediction models is anticipated to improve when measured dose is used, as this quantity reveals the effect of radiotherapy most truthfully. Delivered dose reconstructions (2D and 3D [110]), Gamma-Index calculations and dose volume histograms (DVH) aid identification of increasingly accurate dose-related features [111, $112]$, such as radiation pneumonitis and esophagitis [98,113].

When considering dose as a treatment feature, it is important to be aware of the concept of biologically effective dose (BED) [114,115]. The BED concept is an inherent part of the linear quadratic (LQ) model which is derived from sound biophysical principles of radiation effect [116], with the consequence that BED is accurate and robust in a reasonably wide range of scenarios and can be expressed as:

$\mathrm{BED}=\mathrm{nd}\left(1+\frac{\mathrm{d}}{\alpha / \beta}\right)$

where $\alpha$ and $\beta$ are the radiosensitivity coefficients associated with lethal (linear) cell damage and potentially lethal/repairable (quadratic) cell damage respectively, $\mathrm{n}$ the number of fractions and $\mathrm{d}$ the dose per fraction, such that the total treatment dose is equivalent to nd. BED is viewed as an important biological measure of the physical dose delivered to tissue (characterized by the $\alpha / \beta$ ratio). Therefore, nearby tissues with different $\alpha / \beta$ ratio values (e.g., bladder, prostate, rectum), each receiving identical dose and fractionation, will be associated with different BEDs. It follows that, for a specified value of the $\alpha / \beta$ ratio, a particular BED can be attained by numerous different (yet isoeffective) fractionation schedules. Thus, BED is a powerful comparator of competing fractionation schedules. A limitation of this concept is that precise values for $\alpha / \beta$ ratios (of both the tumor(s) and healthy tissues) are seldom known in individual patients.

The temporal properties of fractionated treatment are also a vibrant field of research. Treatment dose is rarely increased to compensate for increases in treatment course duration (especially outside of squamous cell carcinoma of the head-and-neck or cervix), however, there is a growing body of evidence which advocates that reduced treatment times, while delivering the same total dose, improve outcome [117, 118]. A multicenter head-and-neck cancer study of patients treated with radiotherapy alone showed that the potential doubling time of the tumor prior to treatment was not predictive of local control [119]. Classic processes such as accelerated repopulation [120], fluctuations in cell loss, hypoxia and radioresistant tumor stem cells have each been advocated as the principal origins of this observation, the potential implications of which include shorter overall treatment times with increased doses per fraction and the avoidance of treatment gaps [121, 122]. Generally, treatment time is an available feature that is associated with local failure in numerous tumor sites [123-125].

In the ideal scenario, both the spatial and temporal properties of radiotherapy would be leveraged by monitoring/knowing the cumulative/fractional dose distribution in a tumor and/or healthy tissue (i.e., a radioresistance/sensitivity map that is continuously updated during treatment). Regrettably, such a comprehensive maps of radioresistance/sensitivity do not yet exist, although progress is being made [126,127]. With the provision of such a map, DSS would support the planning and adaptation of the spatial and temporal dose distribution in such a manner as to conserve or improve the therapeutic ratio continuously during treatment, as opposed to the present method that attempts to deliver the dose to the tumor as planned. Currently, a randomized phase II trial (RTOG 1106/ ACRIN 6697) of individualized adaptive radiotherapy using duringtreatment $18 \mathrm{~F}$-fluorodeoxyglucose (FDG)-positron emission tomography (PET)/computed tomography (CT) and modern technology in locally advanced non-small cell lung cancer is underway to answer important questions with respect to realizing this goal. The hypothesis of the trial is that the during-radiotherapy FDG-PET/CT-based adaptive therapy will allow increased daily dose to the reduced target volume for the remainder of the treatment in the majority of patients and meet the dose limits of organs at risk (OARs), thus improving loco-regional control without increasing normal tissue toxicity.

\subsection{Imaging features: from tumor size to radiomics}

Imaging plays a pivotal role in oncology, especially in radiotherapy it dominates treatment planning and response monitoring roles [128, 129]. Technological progress in imaging - including enhanced temporal and spatial resolution, faster scanners and protocol standardization has rapidly advanced the area towards the identification of quantitative noninvasive imaging biomarkers, also known as "Radiomics". [21,130, 131] (Fig. 6).

Metrics built on tumor volume and location are the most frequently employed image derived features of tumor response to therapy and survival [132-139], and utilize CT or magnetic resonance imaging (MRI) technology for 3D measurement [140-142]. Although used in clinical practice, tumor volume and location are subject to inter-observer variability that can be ascribed to variances in tumor delineations [143, 144]. Furthermore, the optimal techniques for measurement and definitions of appropriate response criteria are still to be definitely determined [145-149]. In addition, tumor motion and image artifacts are further sources of uncertainty [150,151]. To meet these challenges, computerized tumor delineation algorithms have been developed [152-155] based upon image properties such as the range of Hounsfield units (which characterize the linear attenuation coefficient of the tissue) on the CT which represent a specific tissue type, or calculation of the gradient across the $\mathrm{CT}$ (mathematical filter) to reveal the borders between tissue types. Thorough assessment, however, is required before these approaches can be routinely used in the clinic [156-158].

A typical tracer for the metabolic uptake of the tumor is FDG for PET imaging $[159,160]$. The pretreatment maximum standardized uptake value (SUV, which is the normalized FDG uptake for an injected dose according to the patient's body weight) is strongly linked with tumor recurrence as well as overall survival in a number of tumor sites, such as the lung, head and neck, rectum, esophagus and cervix [161-167]. Additionally, numerous studies have revealed that variations in SUV during and after treatment are initial predictors of tumor recurrence [168171]. However, FDG-PET measurements are dependent on a several factors, including injected dose, FDG clearance, baseline glucose concentration, image reconstruction methods used and partial-volume effects $[172,173]$. Global standardization of these factors is therefore essential to enable comparisons and validation of data from FDG-PET imaging across institutions [174-178].

Multiple studies have demonstrated that diffusion-weighted MRI parameters, such as the apparent diffusion coefficient (ADC), which quantifies water mobility in tissues, can accurately predict response and survival in multiple tumor sites [179-182]. However, issues concerning reproducibility of ADC measurements - which can be attributed to the dearth of standardization of instrumentation among vendors and of internationally recognized calibration protocols - remain a challenge for these kinds of investigations [183]. Assessments of varying time points in dynamic contrast-enhanced MRI have also been employed to quantify tumor perfusion [184-186]. Indeed, hypothesis-driven preclinical and xenograft studies support these clinical studies [187-189]. An example of this is that assessment of 
a)

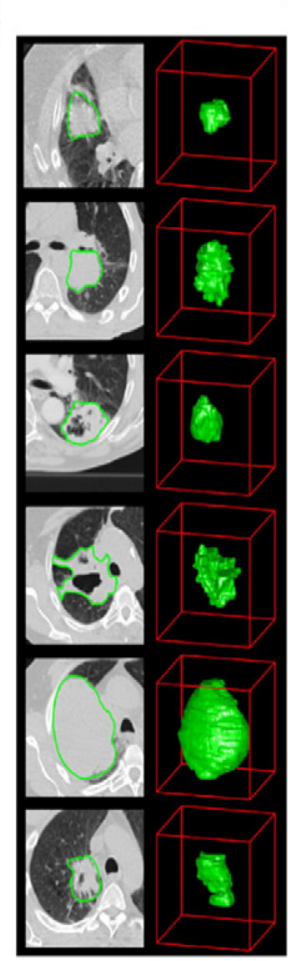

b)

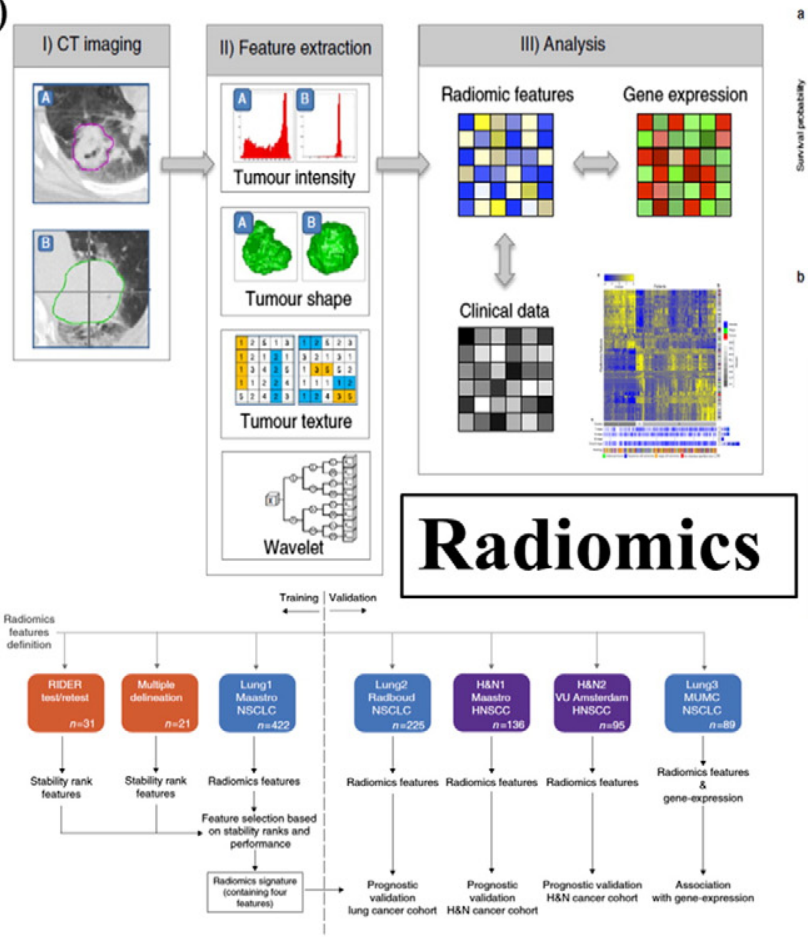

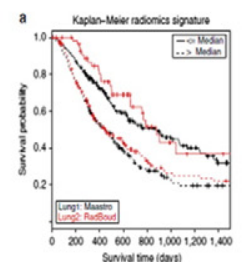
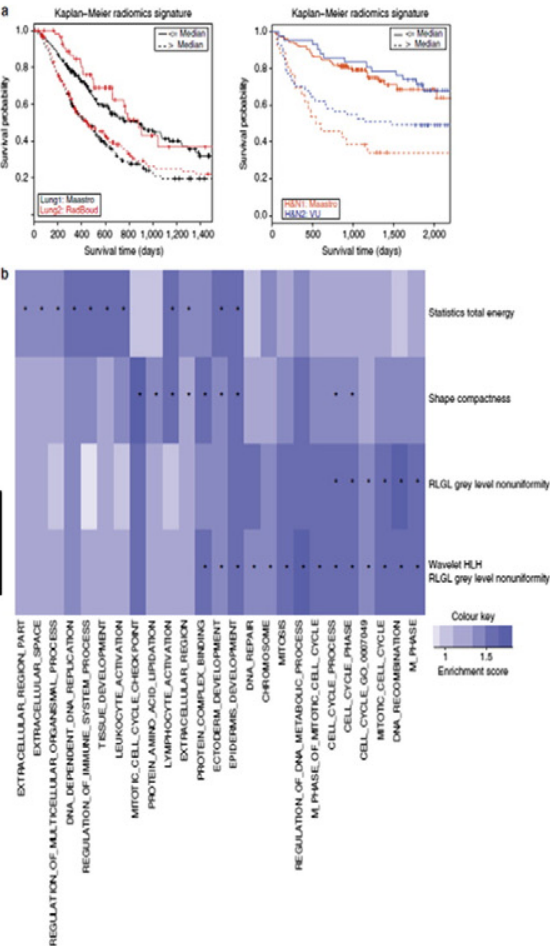

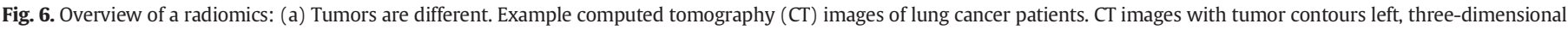

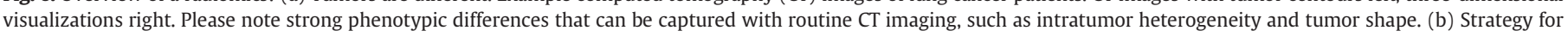

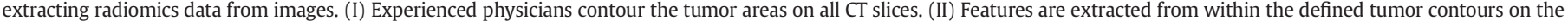
CT images, quantifying tumor intensity, shape, texture and wavelet texture. (III) For the analysis the radiomic features are compared with clinical data and gene-expression data.

the correlation of features from imaging, such as the extent of reoxygenation and lactate level, with tumor control is possible.

Increasingly sophisticated image derived features are presently being explored. It is currently possible with routine clinical imaging to capture both tumor heterogeneity and post-treatment changes, which can be processed to detect functional biomarkers. For instance, a surrogate for tumor perfusion can be directly related between variations in Hounsfield units in contrast-enhanced CT and the quantity of contrast agent present in the tissue [190,191] (corresponding perfusion defects can be detected by dual energy CT [192]). Indeed, decreasing magnitude of CT Hounsfield units after treatment has been used to assess treatment response in pulmonary, hepatic and rectal cancers $[193,194]$.

Standardization of image analysis to obtain a large number of features derived from imaging is now being considered for novel imaging biomarker approaches [21] with innovative image processing techniques, descriptors of tumor heterogeneity (such as variance or entropy of the voxel values) and the relationship of the tumor with adjacent tissues can be objectively quantified [195-197]. These systematic methods facilitate high-throughput assessment of imaging features which can be correlated with treatment outcome and, potentially, with biological data [198].

As a proof-of-concept it was shown that underlying genetic changes and early treatment responses influenced image derived radiomic features in a preclinical study [199]. In glioblastoma patients, MR imaging features have strongly corresponded to cancer related and drug targetable mutational status [200]. Indeed, qualitative imaging features from CT and MRI images have successfully predicted mRNA abundance variation in hepatocellular carcinomas and brain tumors [201-203]. Additionally, a composite of anatomical, functional and metabolic imaging may capture pathophysiological/morphological tumor characteristics in a noninvasive fashion, quantifying intra-tumoral heterogeneity [204-206].
The arrival of radiomics has increased the scope, purpose and potential for medical imaging within oncology. Radiomics mines and deciphers numerous medical imaging features. The hypothesis being that these imaging features are augmented with critical and interchangeable information regarding tumor phenotype [207]. Additionally, radiomic features provide a complete and full representation of the entire tumor and hence adeptly capture intratumor heterogeneity. It is thought that intra-tumor heterogeneity has potentially profound implications for clinical predictions (i.e., treatment response, survival outcomes, disease progression, etc.) and consequently it is deemed to be an essential element of precision oncology (i.e., a subset of the larger concept of precision medicine - prevention and treatment strategies that take individual variability into account) and related research [208-211]. The concept of precision medicine [212] is not new (e.g., a century of blood typing to guide blood transfusions), however, the prospect of applying this concept broadly has been radically enhanced with the modern development of powerful methods for characterizing patients, such as radiomics together with large-scale/ interconnected databases and computational tools for analyzing large complex datasets. Several studies have reported the significant predictive/prognostic power of radiomic features. It has been demonstrated that radiomic features are related to tumor histology, tumor grade/stage, patient survival, metabolism, and several additional clinical outcomes [213-218]. Furthermore, some radiogenomic studies have reported the associations between radiomic features and the underlying gene expression patterns [219]. Different radiomic features have been evaluated in various cancer types with respect to diverse imaging technologies [220224 ] and the reproducibility/variability of radiomic features in disparate clinical settings has also been examined [225-227]. These results suggest that radiomics can enhance individualized treatment selection and monitoring. Furthermore, unlike genomics 
a)

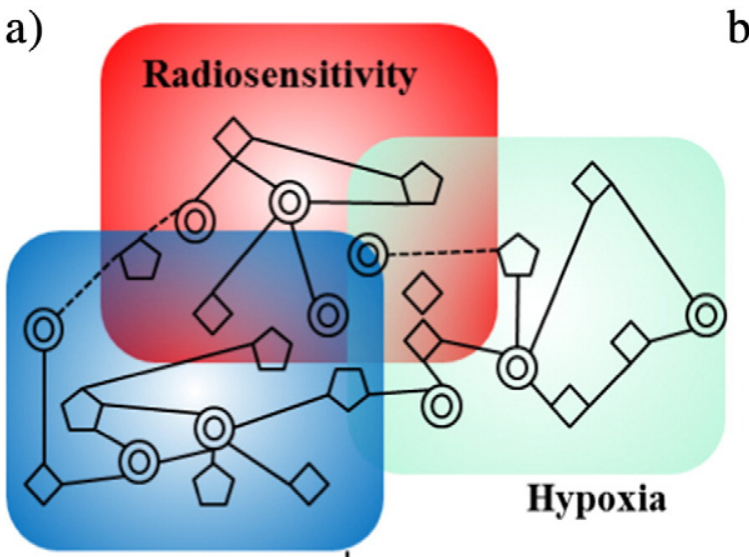

b)
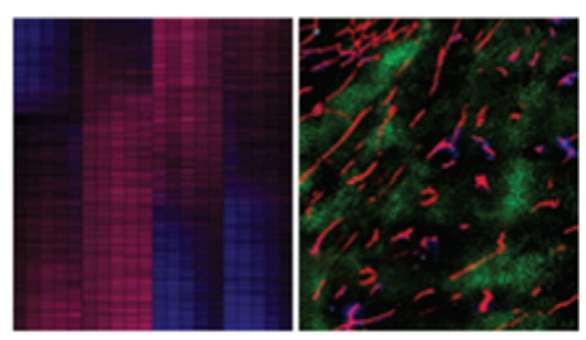

$\mathrm{A} \mathrm{C} \mathrm{T} \mathrm{T} \mathrm{A} \mathrm{A} \mathrm{C}$

A $\mathrm{G}$ A $\mathrm{T}$ G $\mathrm{A}$ C C $\mathrm{C}$

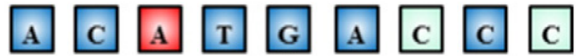

Proliferation

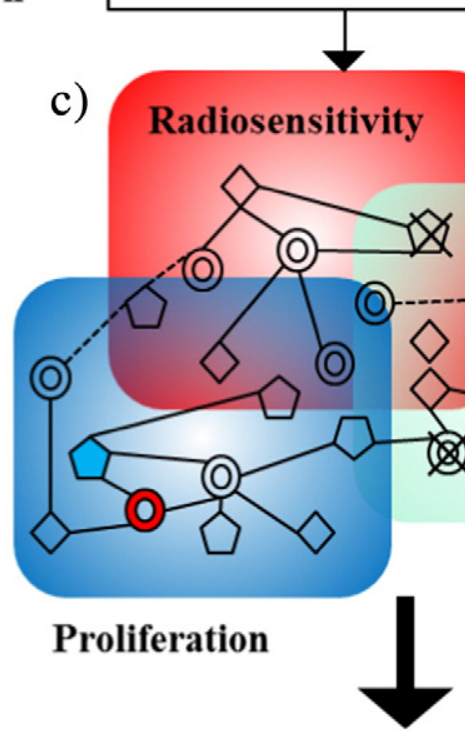

\section{Predict relative radioresistance and need for dose escalation / most potent targeted therapy}

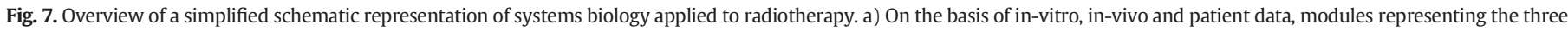

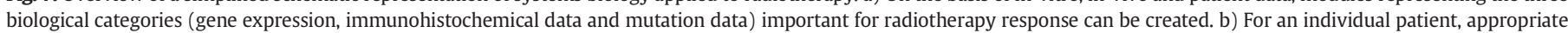

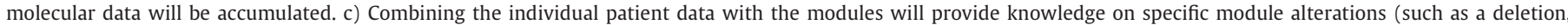

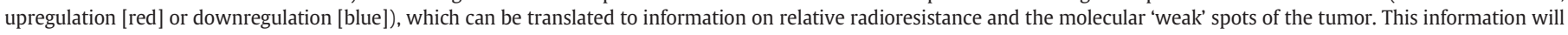
subsequently indicate whether dose escalation is necessary and which targeted drug is most effective for the patient.

based approaches, radiomics is non-invasive and comparatively cost effective. Radiomics is an innovative and encouraging breakthrough towards the realization of precision oncology.

\subsection{Biological/genetic features}

Biological/genetic features provide valuable biomarkers for DSS [228-231]; these include prognostic and predictive factors for outcomes [232], such as tumor response and normal-tissue tolerance. Notwithstanding these virtues, trials of biological/genetic biomarkers are susceptible to experimental inconsistency; therefore standardization of assay criteria, trial design as well as analysis is vital if biological/genetic biomarkers are to be effective prognostic/predictive tools in oncology [50] (Fig. 7).
Tumor control following treatment is largely determined by the criteria: the number of cancer stem cells (as often reflected by tumor volume prior to treatment) and their intrinsic radiosensitivity, the hypoxic fraction, repopulation and reoxygenation capacity during the course of radiotherapy [233-235]. Numerous methods have been developed to quantify the additional features which are predictive of tumor response.

Tumors exhibit large variability in intrinsic radiosensitivity, including among tumors of similar origin and histological type [236238]. Efforts to measure the radiosensitivity of human tumors are currently based upon the ex-vivo tumor survival fraction, detection of unrepaired DNA double strand breaks, e.g. using phosphorylated histone $\gamma \mathrm{H} 2 \mathrm{AX}[239,240]$. These investigations have established that tumor cell radiosensitivity is a major feature for radiotherapy outcome in prostate, lung, brain, cervical, and head-and-neck 
carcinomas [241-245]. However, these colony assays suffer from technical drawbacks which include a low success rate $(<70 \%)$ for human tumors and the time required to produce data, which can be up to several weeks. Studies have shown promising results that immunohistochemically staining $\gamma$-histone H2AX, a marker of DNA damage, can potentially gauge intrinsic radiosensitivity very early after commencement of treatment [246,247]. Double-stranded breaks are produced when cells are exposed to ionizing radiation or DNA-damaging chemotherapeutic agents, which swiftly results in the phosphorylation of $\gamma$-histone H2AX. $\gamma$-Histone H2AX is the most sensitive marker that can be employed to examine the DNA damage and its ensuing repair, and it can be identified by immunoblotting and immunostaining using microscopic or flow cytometric detection. Clinically, two biopsies (prior to and after treatment) are required to evaluate the $\gamma$-histone H2AX status, which can be difficult to implement in practice.

Previous research has also assessed chromosome damage, DNA damage, genetic and epigenetic alterations, mitochondrial DNA abnormalities, glutathione levels, and apoptosis [248,249]. Indeed, some clinical studies using such assays have demonstrated correlations with radiotherapy outcome, whereas others have not [250,251]. Despite the ability to quantify a feature that is fundamental to the response of tumors to radiotherapy, these cell-based functional assays have restricted clinical utility as a predictive tool.

Hypoxia is the key feature in assessing likely radioresistance and malignant progression; it is a negative prognostic factor after treatment with radiotherapy, chemotherapy and surgery [252,253]. Indeed, data exists which not only demonstrates the requirement of oxygen for radiation-induced cytotoxic DNA damage or decreased proliferation of hypoxic cells limiting cytotoxicity of many chemotherapeutic agents but also suggests that hypoxia stimulates both angiogenesis and metastasis and therefore plays a crucial role in tumor progression [254]. While a strong correlation has been shown between pimonidazole (a chemical probe of hypoxia) staining and outcome after radiotherapy in headand-neck cancer [255], the same relationship has not been confirmed in cervical cancer [256]. One hypothesis put forward to reconcile these contrasting results is that hypoxia tolerance is more important than hypoxia itself [257].

The use of fluorinated derivatives of such chemical probes also enables their detection by noninvasive PET [258-261]. While this method does require the administration of a drug, it benefits from sampling the entire tumor and not just a subvolume of it. An additional potential surrogate marker of tumor hypoxia is vasculature; the predictive worth of tumor vascularity has been quantified by both intercapillary distance (assumed to reflect tumor oxygenation) and microvessel density (the 'hotspot' technique that offers a histological evaluation of tumor angiogenesis). Studies have shown positive correlations with outcome largely using microvessel density in cervical cancer - although others have demonstrated negative correlations [262]. Reservations have been expressed regarding the degree to which biopsies (random sampling of tissue) correctly characterize the typically large, heterogeneous tumors [263].

When the overall treatment time is protracted, (e.g., equipment malfunction or poor tolerance by the patient), an increase in the prescription dose is necessary to compensate for the effect of tumor proliferation [264]. While proliferation during fractionated radiotherapy is evidently a significant factor in determining outcome, accurate measurement methods are currently unavailable [265]. A deeper comprehension of the response at both the cellular and molecular level is required along with an answer to the question of why radiation induces accelerated repopulation response in some but not all tumors [266].

Innate differences in cellular radiosensitivity (within the patient population) govern normal tissue reactions toxicity more than any other causal factor [267]. The implication being that the majority of prescribed doses may in fact be too conservative (i.e., because $5-10 \%$ of patients are highly sensitive; they skew what is 'optimal' treatment towards the lower tier of the tolerance spectrum, to the detriment of most patients whom are less sensitive). Future DSS should accurately identify highly sensitive patients and classify them accordingly so they receive appropriate treatments, facilitating improved/escalated treatments for the less sensitive patients.

Several small and large in vitro studies reported a correlation between severity of toxicity and radiosensitivity (e.g., radiation-induced fibrosis of the breast) $[268,269]$, however these studies contain inconsistencies due to a lack of standardized quality assurance for in-vivo radiotherapy [270,271]. Corresponding results have also been reported through rapid assays which quantify chromosomal damage, DNA damage and clonogenic cell survival [272-274]. The lymphocyte apoptosis assay has been utilized within a prospective breast cancer trial to stratify patients and assess late toxicity using letrozole as a radiosensitizer [275]. Cytokines such as TGF- $\beta$, which influence fibroblast proliferation and differentiation, are known to play an important role in fibrosis and senescence [276,277]. However presently, the relationship between late complications and the lymphocyte predictive assay, TGF- $\beta$ is strictly correlative and a mechanistic molecular explanation is missing. Analyses of single nucleotide polymorphisms (SNPs) and genome-wide association studies (GWAS) in candidate genes have demonstrated capacity in classification of normal tissue toxicity [278-284], identifying possible SNPs associated with the development of late radiation-induced toxicity. Recently, the identification of the TANC1 risk allele (SNP rs264663) suggesting that carriers of this allele have 6 times greater risk of developing late toxicity, underscores the potential of adding these features to predictive models. However, validation of SNP or GWAS studies has turned out to be difficult emphasizing the complex mechanisms behind radiation-induced toxicity in normal tissue $[285,286]$. In general, the weakness of all these approaches has been the large experimental variability as opposed to the inter-patient variations in radiosensitivity. Normal tissue toxicity is the dose-limiting factor in the field radiation oncology; therefore, a comprehensive DSS should be built upon predictors of tumor control and normal tissue toxicity.

An additional important and promising development in the field of radiation oncology is that of biomarkers for immunotherapy. It is recognized that ionizing radiation provokes an anti-tumor immune response and that the clinical potential of these immunogenic effects in combination with different immunotherapies is substantial [287]. For a durable and vigorous immune response, activation of T-cells, endowed with antigen specificity and memory effects, is generally a prerequisite [288]. In such a response several factors are of key importance. Paramount, the tumor must contain antigens which are different from the healthy tissue, in order to be recognizable to the immune system. Such neoantigens are derived from mutated proteins from a tumor cell. Recent data shows that the success rate of immunotherapies is dependent on the presence of neoantigen-specific T-cells [289]. Consistently, it is shown that the mutational load of a large series of human tumors correlates with the cytolytic activity of natural killer cells and T-cells [290].

When a tumor has the potential to be recognized by the immune system, an adequate immune response can be orchestrated. In this process it is of essential importance that neoantigens are taken up by antigen presenting cells (APCs) or dendritic cells (DCs) and subsequently cross-presented to naïve T-cells [291]. The latter is then transformed into tumor killing cytotoxic T-cells. In this context the ability of radiation to boost immune responses seems to be critically dependent on the quantity and quality of DCs present [292,293].

Tumors have variable ways to protect them from adequate cytotoxic T-cell responses, such as interfering with various immune checkpoints. Depending on the type of interference several specific molecules have biomarker potential. One example of this is the expression of PD-1L. PD-1L binds PD-1 on the cytotoxic T-cell, preventing it to conduct its cytolytic action. Regarding the effects of anti-PD-1 mediated immunotherapy, not only the mutational load shows a strong correlation with clinical responses but also the expression of PD-1L in non-small lung cancer patients [294,295]. 
Such biological/genetic features hold great potential and will undoubtedly be included in future DSS.

\subsection{Visualization of clinical decision support systems}

The process of developing a predictive model defines the characteristics of the DSS (e.g., features selection, overall prediction accuracy, robustness, etc.). However, the success/appeal of the DSS depends on other dynamics, such as its utility, availability, interactivity, adaptability, etc. which increases the acceptability. Even DSS with models developed in large patient populations, with appropriate external validation, may fail to be accepted within the health-care community if the DSS is difficult to interpret, if there is little opportunity for application of the DSS or if the clinical usefulness has not been clearly demonstrated [296]. While some DSS (e.g., decision trees, nomograms, Bayesian networks) fundamentally have a visual representation that is readily comprehensible, many DSS do not. Another method of increasing the acceptability of DSS for personalized medicine is to make peer-reviewed DSS interactively available online (with sufficient background information); clinicians can subsequently scrutinize them using their own patient data. Such an approach affords retrospective validation of the DSS by the broader community, as well as providing a gauge of the clinical utility of the DSS. A website that focuses on DSS for radiotherapy has been established: www.predictcancer.org. The purpose of this website is to enable clinicians, researchers, and patients to utilize, develop, and validate the DSS for cancer patients treated with radiotherapy. This contributes to DSS advancement in general by showing the potential and limitations of these predictions as well as raising awareness

\subsection{Cost effectiveness for decision support systems}

Traditionally, DSS have been focused on clinical endpoints. However, considering the almost exponential rising costs of healthcare, it is increasingly important to consider cost and cost-effectiveness in clinical decision making. Consequently, future DSS should include cost and/or cost-effectiveness as supplementary endpoints (Fig. 8).

\subsection{Shared decision making}

DSS can greatly assist in the choice of the most appropriate therapeutic and/or diagnostic modality. Yet, deciding the most appropriate care pathway for each patient is a very complex process which is dependent upon unique personal patient characteristics and preferences. However, hitherto now, DSS do not take patient preferences and personal values explicitly into account. This stems from the traditional healthcare approach, which is more paternalistic than participative. Clinicians may utilize DSS to determine treatment without considering the distinctive and important personal predilections of patients, as patients will seldom question or challenge the clinician's opinion. However recently, this paternalistic approach is more and more shifting towards a more participative patient-centered approach. The ramifications of this shift are that clinicians should proactively provide additional, appropriate, and relevant information to patients thereby realizing shared decision making (SDM) practice (Fig. 9).

SDM is an interactive process in which patients and practitioners collaborate in choosing healthcare [297], based upon the best available evidence $[298,299]$ (e.g., radical or palliative treatment, brachytherapy or surgery, etc.). Several studies have demonstrated that patients involved decision making, experience less decisional conflict, improved compliance with treatment and greater quality of life [300]. A significant barrier to the implementation of SDM comes in the form of effective patient-clinician communication. Clinicians often unintentionally use difficult language (from the patient's perspective) and may dominate the conversation, while patients may lack the courage to ask questions. To involve patients in SDM it is crucial to communicate effectively with them by providing information and encouraging substantial feedback. Another important obstacle is that some patients may not be receptive to the information provided as anxiety or emotional distress can impair the patient's ability to coherently process information [301]. To help

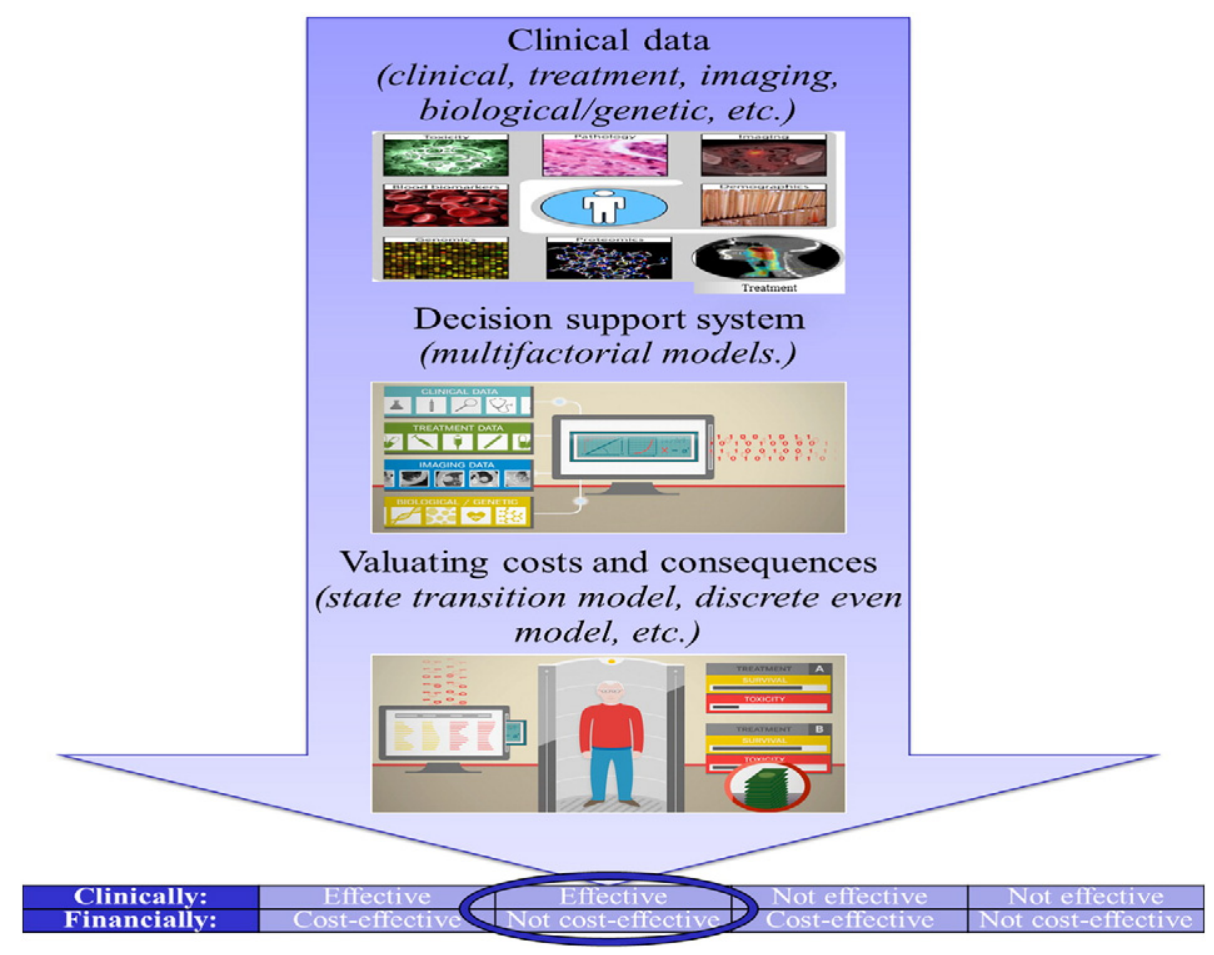

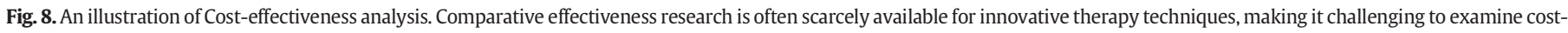

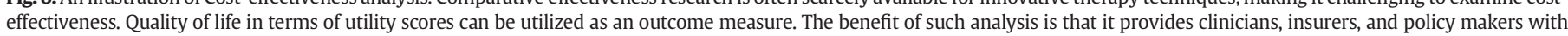
quantitative estimates of the financial impact of therapy and therefore greatly facilitates budgeting and allocation of resources. 
CONVENTIONAL DECISION MAKING: non-personalized \& non-participative a)

GUIDELINES
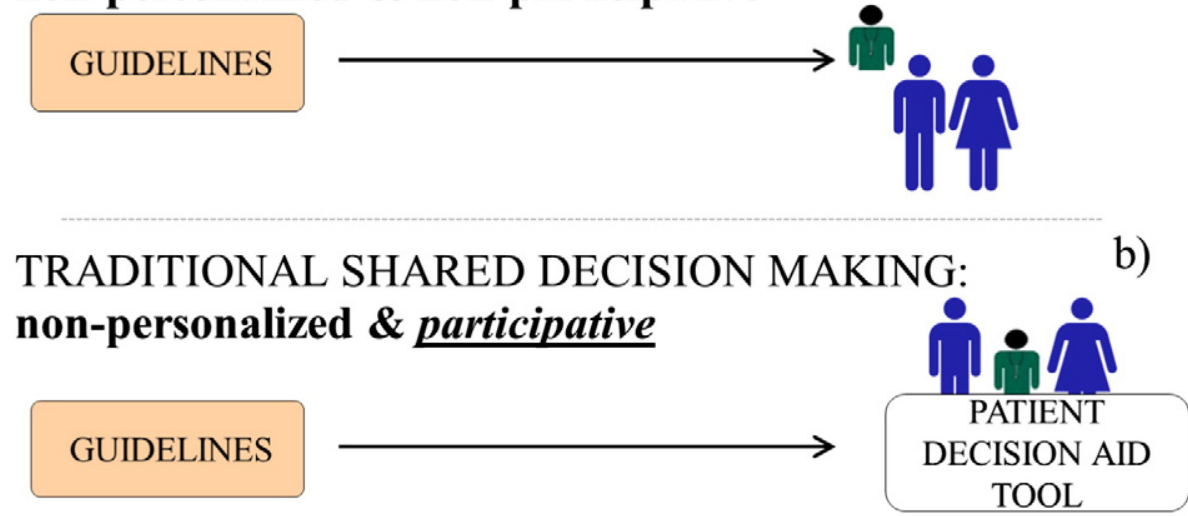

NOVEL SHARED DECISION MAKING:

c)

\section{personalized \& participative}

\section{GUIDELINES}

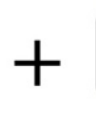

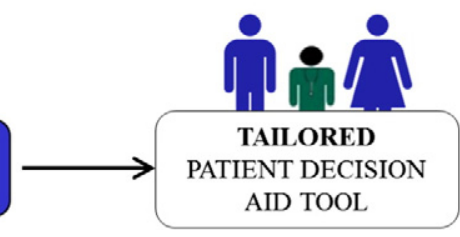

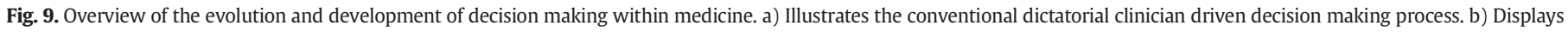

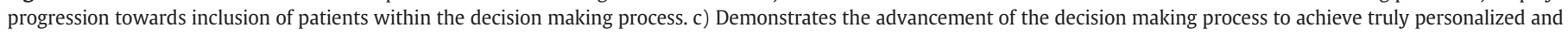
participative components.

overcome these challenges patient decision aids (PDAs) have been developed [302,303]. PDAs provide patients with disease-specific information and treatment options, through various multimedia, helping patients to recognize and clarify their personal values [304-306] (Fig. 10).
PDAs do not promote one option over another, nor are they meant to replace clinician consultation. Instead, they prepare patients to make informed, values-based decisions with clinicians (http://ipdas.ohri.ca/). A recent Cochrane review [307] reported level I evidence that PDAs improve patient's knowledge about
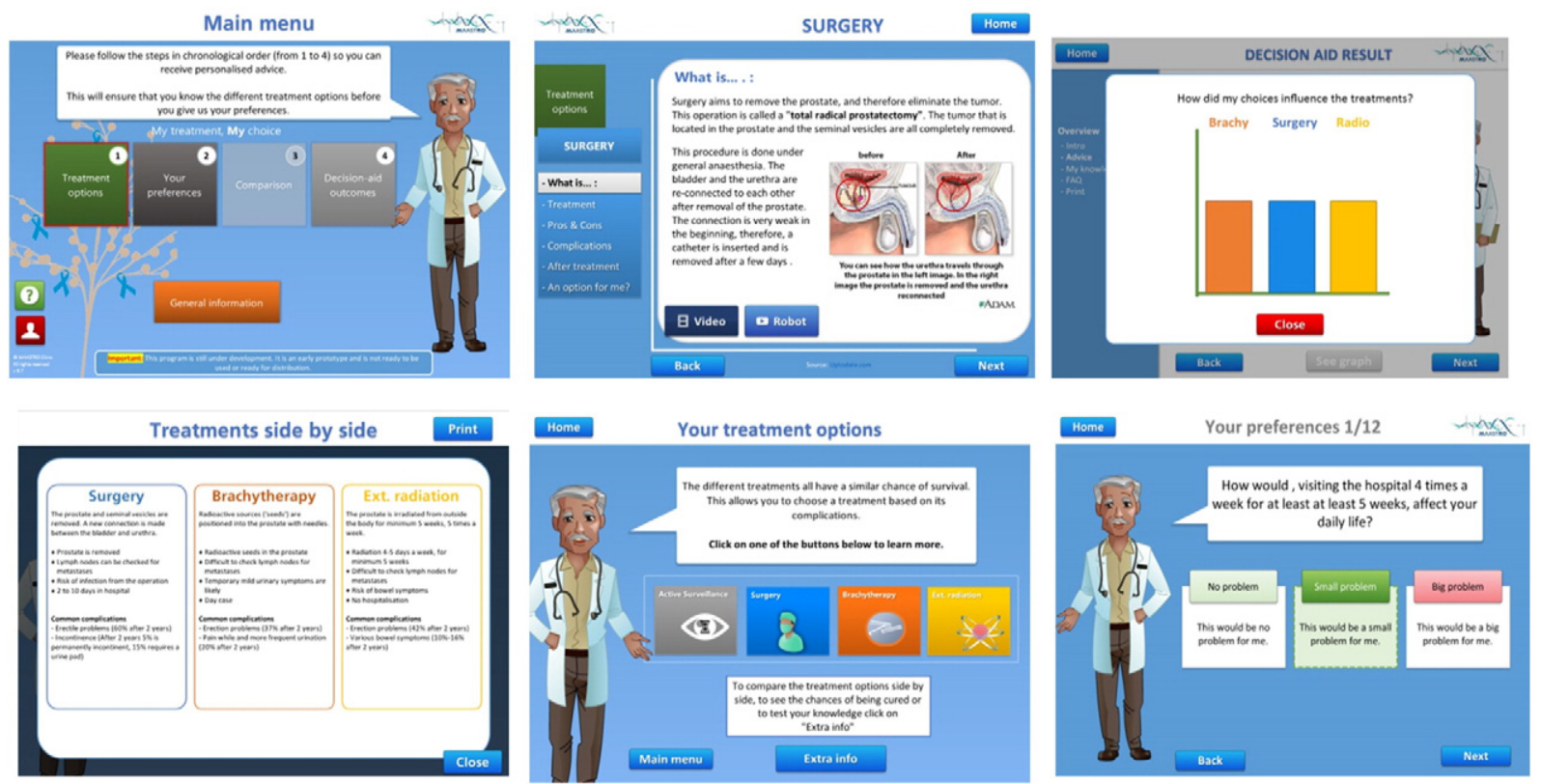

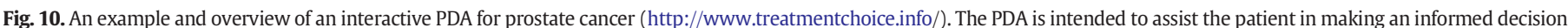

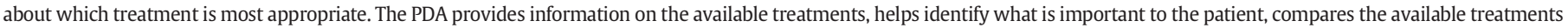

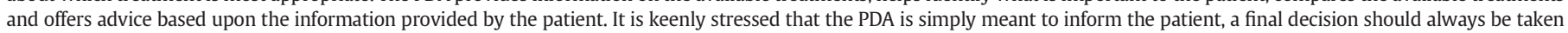
together with the clinician. 
treatments, involvement in the decision process, and accurate risk perceptions. Appropriate SDM within modern medicine requires the integration of PDAs and DSS. This will genuinely deliver personalized and participative therapy that supports both clinicians and patients.

\subsection{An example of personalized therapy in radiation oncology}

With deeper knowledge of the complexities of cancer, a realization that optimal cancer therapy most likely requires increasingly personalized treatment has taken hold. Personalized therapy has huge potential in cancer care. Within medical oncology the search for personalized therapy has produced many targeted agents. New medications have revealed substantial activity within subsets of tumors harboring particular targetable mutations. Trastuzumab is well recognized for HER2positive breast cancer, and recent novel targeted agents such as crizotin$\mathrm{ib}$ and vemurafenib have been successful in increasing survival in anaplastic lymphoma kinase rearranged lung cancers and BRAF (V600E) mutationepositive melanomas, respectively. This underscores the significance of the individual patients' biology, enabling correct patient and tumor stratification. The progress of genetic assays has enabled improved prediction of patient sensitivity to different chemotherapy agents, and there is mounting clinical validation of these models. An OncotypeDX21-gene assay has been validated to predict both the recurrence risk and the magnitude of adjuvant chemotherapy benefit for breast cancer [308]. However, an OncotypeDX21-gene assay for stage II colon cancer has been found to be prognostic but not predictive of an adjuvant chemotherapeutic benefit [309].

The central issues regarding the personalization of radiotherapy are those of dose, fractionation and target volumes. A type of personalized therapy is presently ongoing in the form of de-escalating dose for human papillomavirus positive oropharyngeal cancers. Contrastingly, considerable research efforts into dose escalation are also underway, despite negative phase III dose escalation trials for several malignancies. These efforts could be significantly augmented by genetic analysis, providing superior selection of the target population, and therefore increasing the likelihood of success. At the vanguard to personalized therapy within radiation oncology is the development of a radiation sensitivity index (RSI), a multigene expression model proposed to predict radiation responsiveness (a high RSI indicates radioresistance) [310-313]. The RSI signature has been previously validated [313], and was recently applied to primary and metastatic colon cancer samples [310]. Large differences in RSI based on anatomical site of metastases $(\mathrm{P}<.0001)$ were observed, which persisted when the analysis was restricted to lesions from the same patient $(\mathrm{P}<.0001)$. Initial clinical validation in a cohort of 29 liver and lung metastases patients treated with stereotactic body radiation therapy confirmed these results [310]. Appreciation of the strengths and weaknesses of the RSI is essential when evaluating these results and the implications. The surviving fraction following 2 Gy (SF2) was ascertained in breast, central nervous system, colon, melanoma, non-small cell lung cancer, ovarian, prostate, renal, and leukemia cell lines [311]. Linear regression analysis correlated ten hub genes with SF2, and the relative expression of these genes forms the basis of the RSI. An important point of consideration here is that SF2 experiments are typically conducted under normoxic conditions, dissimilarities in local environments of metastatic sites may produce variances in radiosensitivity undetected in the current assay. Furthermore, the clinical applicability of the RSI model to differing fractionation regimes (e.g., hypofractionation) is uncertain. Data supporting clinical validation of the RSI model is provided in the form of 14 rectal and 12 esophageal cancer patients treated with neoadjuvant chemoradiation and 92 head and neck cancer patients treated with definitive chemoradiation [313]. Potential caveats to accepting this as RSI substantiation include small cohort sizes and the contribution of concurrent chemotherapy. Additional data supporting clinical validation of the RSI model is provided in the form of 503 breast cancer patients, reporting that radiosensitive patients had improved 5-year relapse free-survival and distant metastasis free survival rates than radioresistant patients, when treated with radiotherapy and surgery [312]. Differences in outcome vanished for (radiosensitive/radioresistant) patients only receiving surgery, suggesting that the RSI is a radiotherapy biomarker. The most recent data supporting clinical validation of the RSI model is provided by the differences in radiosensitivity between colon primaries (704 patients) and sites of metastases (1362 patients), in a further demonstration of the potential to personalize therapy [310]. RSI ranking by anatomic site revealed large differences: ovary (0.48), abdomen (0.47), liver (0.43), brain (0.42), lung (0.32), and lymph nodes (0.31); $\mathrm{P}<.001$ (Recall that a high RSI indicates radioresistance). These results were substantiated in analyses restricted to lesions within the same patient. The conclusion being that in the treatment of oligometastatic disease, prescribed doses should be contingent on the metastatic site, with lung (the second most frequent site of metastases) being more radiosensitive than liver (the most frequent site of metastases). Finally, data supporting indirect clinical validation of the RSI model is provided in the form of clinical outcomes for lung (9 patients) and liver (14 patients) metastases patients (RSI data unavailable) treated with stereotactic body radiotherapy (SBRT) to $60 \mathrm{~Gy}$ in 5 fractions. The rate of 2-year local control was noted to be significantly higher for lung than for liver metastases ( $100 \%$ vs $73 \%$, respectively, $\mathrm{P}=.026$ ). While these results demonstrate real progress in terms of personalized therapy, clinical applicability of the RSI model as DSS is hampered by the critical limitations in both the lack of clinical and treatment characteristics and the treatment-related outcomes available to correlate with the RSI analysis and the low patient numbers. These initial results warrant validation in a larger clinical cohort. Ultimately, notwithstanding these criticisms, the RSI represents a significant and important advance towards further personalizing radiotherapy [314].

\subsection{A vision of decision support systems for personalized and participative radiation oncology in practice}

In a clinic two patients diagnosed with non-small cell lung cancer stage IIIB receive an appointment for a consultation in the same week. In the year 2010, these two patients would probably have gone through the same diagnostic procedure receiving identical treatment. With RLHC these two patients can potentially receive personalized and participative treatment resulting in two different care paths.

Case A). A 75-year-old male patient has an inoperable squamous cell carcinoma of the lung stage IIIB. The patient is a heavy smoker and has limited lung function as well as angina pectoris. His principal wish is to be able to celebrate, in a reasonable condition, his 40th wedding anniversary, which is scheduled to take place in 6 months. Long term survival is not a priority for him; he does not want to stop smoking and refuses any heavy treatment which might induce hair loss.

Case B). A 55-year-old female patient, non-smoker, has an adenocarcinoma of the lung stage IIIB. She is of Asian origin and has 4 children (between 11 and 18 years). She is a company director and wishes to be cured at all costs. She insists on the most accurate information on her prognosis, as she wants to schedule her absence and quality time with her company and children, respectively. Assuming a fully mature RLHC network (access to more than 20,000 lung cancer patients' clinical, treatment, imaging, biological/genetic, records as well as a followup data documenting complications and scoring based on the CTCAE system of the $\mathrm{NCI}$ ) with integrated DSS and PDAs, the following care paths are feasible: first advanced computer vision and pattern recognition tools localize, segment and characterize the thorax images (lung, tumors and heart) of the patients (CT and FDG-PET). Second, DSS aid in the selection of the most beneficial diagnostic procedure (the most likely procedure to improve prognosis and/or prediction and/or cost efficiency). Third, DSS with PDAs help the clinician and patient 
determine the most appropriate treatment (the most probable treatment to achieve the desired survival, toxicity, and/or cost efficiency). Both patients receive a full history/anamnesis, a physical examination, CT-thorax and a CT-abdomen, a blood sample, and a bronchoscopy with biopsy. For Cases A) and B) a PET scan with FDG is recommended by the DSS. After the patients have received a FDG-PET-CT, the DSS then suggest the following: For Case A) a blood marker for tumor hypoxia, which demonstrates elevated levels. Thus, a PET-CT scan with FMISO as the tracer for hypoxia is performed which visualizes a limited zone of hypoxia in $3 \mathrm{~cm}^{3}$ within the tumor. For Case B) a mutation analysis of the EGFR gene, a SNP analysis and a gene expression array. The analyses reveal a mutation of the tyrosine kinase domain of the EGFR, no polymorphism of the TGF beta gene and a rapidly proliferating tumor without hypoxia. The missing polymorphism predicts no increased risk for a radiation induced pneumonitis. The DSS suggests a Thymidine PET-CT scan, enabling visualization of the heterogeneity of the tumor proliferation, which might suggest a radiation boost of a sub-volume of the tumor. Before treatment begins the various outcomes for each treatment, based on the pretreatment prediction module, are discussed with the patient. Case A) after discussion with his doctor he decides to accept a high dose radiotherapy treatment including a concomitant boost of the hypoxic region within the tumor but refuses the addition of chemotherapy drugs. The polymorphism analysis of the TGF beta gene reveals an increased risk for radiation-induced pneumonitis. The DSS therefore advise an early follow-up extensive vaccination program against influenza and pneumonia. As a consequence of this care pathway, the patient decides to move into an apartment on the ground floor without stairs. Finally, he and his wife are able to celebrate their 40th wedding anniversary with no major toxicity. One and a half years later, the patient passes away due to progressive liver metastases. Case B) after discussion with her doctor, she agrees to undergo a concomitant accelerated chemo-radiotherapy treatment together with the combined adjuvant treatment of an anti-EGFR drug (due to the positive EGFR mutation analysis). Two weeks into treatment, the risk of esophagitis together with weight loss (taking into account neutropenia) is reevaluated. Using the pre-treatment DSS it is suggested that the risk for the development of severe esophagitis is higher than $70 \%$. Consequently, an esophageal feeding tube is transiently positioned. A second posttreatment DSS prediction of survival and pneumonitis is than performed which takes into account the quality of treatment (set-up error, in vivo dosimetry, treatment duration, drug effectively given) and the metabolic response at 3 months (based on a FDG-PET). In this particular case, the probability of survival at 2 years is predicted to be $85 \%$. Consequently, the patient decides not to sell her company. The follow-up DSS identify her case as high risk for the development of brain metastases and advise either regular repeated brain MRI or preventive total brain irradiation, which in this case was favored by the patient. Five years later, the patient remains free of disease. An update of the system integrating new data on cancer risk and gene polymorphisms reveals an increased risk for the development of breast cancer together with her thorax irradiation. This convinced her to begin yearly mammography screening.

The above treatments described are not the standard of care and are hypothetically the optimal treatments with the goal of personalizing care (e.g., concurrent treatment with an anti-EGFR drug is currently under investigation (RTOG 1306) and is not routinely performed in all patients with a mutation.).

\section{Future prospects}

Enthusiasm for the great potential of the future must be tempered by the pragmatic reality of the present. Currently, most of the 'eHealth' analytics effort is focused on monitoring and improving hospital costs, quality of healthcare management, and productivity. The initial impact and widespread adoption of RLHC together with DSS will probably be felt first in an administrative/business sense rather than a scientific/ clinical sense within institutions. When RLHC together with DSS eventually do make it to the clinical setting, there is the potential risk of the misuse of such technologies/tools (e.g., generation of artifacts, false signals, data corruption, etc.). These genuine concerns can be averted by implementing and adherence to stringent universal dataquality assurance programs and semantic interoperability harmonization, coupled with automated data correction, imputation and/or rejection procedures.

The need for very complex DSS should be relativized as recently approved novel anti-cancer therapies, such as immunologics, are yielding major therapeutic gains which massively outweigh the small gains of former anti-cancer approaches. Thus the need for complex DSS when the gains of treatment A versus B differ massively, does not have the same implication for the decision making process as with classical $4-7 \%$ gains.

The primary focus of this position paper has been model development/validation for DSS along with the cutting-edge information technologies which are essential for the realization of such DSS. While an accurate model forms the foundation of a DSS, further concerns must be addressed prior to a new DSS being utilized in routine clinical practice.

Foremost, all decisions taken by a physician (or patient) can be distilled into a balance between harm (toxic effects, complications, quality of life and financial cost) and benefit (survival, local control and quality of life). For instance, larger dose typically results in a greater probability of normal tissue toxicity, but also a parallel greater probability of tumor control. Determining the correct balance between harm and benefit is a profoundly personal choice that varies considerably among patients. Therefore, an ideal DSS should comprehensively predict local control, survival, toxicity, quality of life and cost. The DSS should present these estimates and the balance between them in a manner that is easily interpreted by both the physician and the patient, enabling shared decision making.

Furthermore, all predictions made by a DSS must include confidence intervals. Correctly estimating confidence intervals is a dynamic and challenging field of research due to the unique uncertainties associated with the process e.g., feature noise, missing features, size and quality of the training dataset, as well as the inherent uncertainty of cancer; must all be combined to specify the uncertainty in the prediction for any given individual patient. DSS are deficient when deprived of certainty with respect to potential choices that may or may not have a statistically significant and/or clinically meaningful difference in outcome. Distributed learning of appropriate data upon which the model was developed is a key ingredient to achieve sufficient certainty in DSS. Despite the ethical, administrative, political and technical boundaries, the continuing development, interconnection, and growth of RLHC networks towards full maturity are of vital importance to modern medicine, as the future performance of DSS is dependent upon both the number and heterogeneity of available patients to learn from. However, there are still difficulties to be addressed with regard to distributed learning within RLHC networks. For example, model developers cannot access and curate all available data within a RLHC network, consequently stringent quality assurance protocols coupled with automated data correction, imputation and/or rejection procedures need to be developed and standardized.

Notwithstanding these challenges, the dream of accurate robust patient specific predictive models leading to DSS that are dynamically updated through global RLHC networks is becoming an ever increasingly tangible reality, and many important milestones have already been reached. These include the aforementioned universal data-quality assurance programs and semantic interoperability harmonization. Indeed, investment is already underway in research and innovation for health-informatics systems (Apple, Google, IBM, etc.), which indicates that 'eHealth' will be among the major health-care innovations of the coming decades. 
It is our firm belief that this genuinely innovative approach will lead to urgently necessary improvements in both healthcare effectiveness and efficiency.

This position paper has thus far focused on the predictive, personalized, and participative elements of medicine, however, medicine will transition (even farther) from a reactive to a proactive discipline over the coming decade - a discipline that is predictive, personalized, participative and preventive (P4) [315-317]. P4 medicine will be driven by system approaches to disease/health, utilizing emerging technologies and analytical tools. Preventive medicine can become a reality as fully matured RLHC networks expose the opportunity to apply therapies intended to prevent or halt disease progression. Importantly, invoking the P4 medicine concept will enable a paradigm-shift in health care from an emphasis on disease to a focus on health - with vast associated cost savings for society resulting in a decreased absenteeism from work and a parallel increase in productivity. P4 medicine is a potentially catalyzing revolution of modern medicine that offers solutions to manage the heretofore overwhelming obstacles of incredible complexities of disease/health via systems approaches, innovative technologies and sophisticated analytical tools. The ultimate goal is that the emphasis of medicine will be lifted from disease and placed onto health. In the not too distant future, there is the very real possibility that billions of data points for each individual within fully matured RLHC networks will define with exquisite exactitude the precise nature of their health - and any transitions into disease.

\section{Conclusions}

Truly personalized cancer therapy is the goal in modern oncology. However, personalized cancer therapy is also a colossal challenge. The immense diversity of both cancer patients and therapy choices makes it tremendously problematic to decide which choices are best for the individual patient. Nevertheless, DSS produced by RLHC can contribute to the realization of this goal. Accurate robust validated prediction models are being swiftly developed, whereby multiple features related to the patient, disease, and treatment are combined into an integrated prediction. The key, however, is standardization - mainly in data acquisition across all areas (clinical, treatment, imaging, biological/genetic, etc.). Standardization requires harmonized clinical guidelines, regulated image acquisition and analysis parameters, validated biomarker assay criteria and data-sharing methods that use identical ontologies. Assessing the clinical utility of any DSS is just as important as standardizing the development of externally validated accurate and robust prediction models with high-quality data, preferably by standardizing the design of clinical trials. These crucial steps are the basis of validating DSS, which in turn, will stimulate developments in RLHC and will enable the next major advances in personalized and participative medicine.

\section{Disclosures of potential conflicts of interest}

Andre Dekker, leader of the Knowledge Engineering division at MAASTRO (Timo Deist, Arthur Jochems, Tim Lustberg, Johan van Soest, and Sean Walsh) discloses a conflict of interest due to financial support from Varian Medical Systems who are developing a rapid learning health care system.

$\begin{array}{ll}\text { Abbreviations } \\ \text { 3D } & \text { Three dimensional } \\ \text { 3DCRT } & \text { Three dimensional conformal radiotherapy } \\ \text { 4 Vs } & \text { Velocity, veracity, volume, and variety of data } \\ \text { ACRIN } & \text { American College of Radiology Imaging Network } \\ \text { ADC } & \text { Apparent diffusion coefficient } \\ \text { ASCO } & \text { The American Society of Clinical Oncology } \\ \text { AUC } & \text { Area under the curve } \\ \text { BRAF } & \text { Serine/threonine-protein kinase }\end{array}$

CT Computed tomography

CTCAE Common terminology criteria for adverse events

DC Dendritic cell

DNA Deoxyribonucleic acid

DSS Decision supports systems

DVH Dose volume histogram

EGFR Epidermal growth factor receptor

EHR Electronic health record

FDG Fluorodeoxyglucose - $18 \mathrm{~F}$

FMISO Fluoromisonidazole - 18F

GWAS Genome-wide association studies

H2AX H2A histone family, member X

HER2 Human epidermal growth factor receptor 2

IGRT Image guided radiotherapy

IMRT Intensity modulated radiotherapy

MR Magnetic resonance

MRI Magnetic resonance imaging

mRNA Messenger ribonucleic acid

$\mathrm{NCI} \quad$ National cancer institute

NTCP Normal tissue complication probability

P4 Predictive, personalized, participative and preventive medicine

PD-1L Programmed death-ligand 1

PDA Patient decision aid

PET Positron emission tomography

QUANTEC Quantitative analysis of normal tissue effects in the clinic

RLHC Rapid learning heath care

RSI Radiation sensitivity index

RTOG The Radiation Therapy Oncology Group

SBRT Stereotactic body radiotherapy

SDM Shared decision making

SF2 Surviving fraction following $2 \mathrm{~Gy}$

SNP Single nucleotide polymorphisms

STROBE Strengthening the reporting of observational studies in epidemiology

SUV Standardized uptake value

TCP Tumor control probability

TGF- $\beta$ Transforming growth factor beta

TNM Tumor-node-metastasis

TRIPOD Transparent reporting of a multivariable prediction model for individual prognosis or diagnosis

VMAT Volumetric arc therapy

\section{Acknowledgments}

The authors acknowledge financial support from the QuIC-ConCePT project, which is partly funded by EFPI A companies and the Innovative Medicine Initiative Joint Undertaking (IMI JU) under Grant Agreement No. 115151. This research is also supported by the Dutch technology Foundation STW (grant no. 10696 DuCAT), which is the applied science division of NWO, and the Technology Programme of the Ministry of Economic Affairs. Authors also acknowledge financial support from the National Institute of Health (NIH-USA U01 CA 143062-01, Radiomics of NSCLC), EU 7th framework program (EURECA, ARTFORCE - no. 257144, REQUITE - no. 601826), SME Phase 2 (EU proposal 673780 RAIL), the European Program H2020-PHC-2015 (BD2decide $\left.\mathrm{n}^{\circ} 210274050\right)$, Kankeronderzoekfonds Limburg from the Health Foundation Limburg and the Dutch Cancer Society (KWF UM 2011-5020, KWF UM 2009-4454, KWF MAC 2013-6425, KWF MAC 2013-6089) and Alpe d'HuZes-KWF (DESIGN), Center for Translational Molecular Medicine (TraIT), EUROSTARS (SeDI and CloudAtlas) and Varian Medical Systems (VATE).

\section{References}

[1] N. Vogelzang, S. Benowitz, S. Adams, C. Aghajanian, S. Chang, Z. Dreyer, P. Janne, A Ko, G. Masters, O. Odenike, J. Patel, B. Roth, W. Samlowski, A. Seidman, W. Tap, J. 
Temel, J. Von Roenn, M. Kris, Clinical cancer advances 2011: annual report on prog ress against cancer from the American Society of Clinical Oncology, J. Clin. Oncol. 30 (2012) 88-109.

[2] A. Abernethy, L. Etheredge, P. Ganz, P. Wallace, R. German, C. Neti, P. Bach, S Murphy, Rapid-learning system for cancer care, J. Clin. Oncol. 28 (2010) 4268-4274.

[3] L. Maitland, L. Schilsky, Clinical trials in the era of personalized oncology, CA Cancer J. Clin. 61 (2011) 365-381.

[4] B. Rosenstein, C. West, S. Bentzen, J. Alsner, C. Andreassen, D. Azria, G. Barnett, M. Baumann, N. Burnet, J. Chang-Claude, E. Chuang, C. Coles, A. Dekker, K.D. Ruyck, D. De Ruysscher, K. Drumea, A. Dunning, D. Easton, R. Eeles, L. Fachal, S. GutierrezEnrıquez, K. Haustermans, L. Henrıquez-Hernandez, T. Imai, G. Jones, S. Kerns, Z. Liao, K. Onel, H. Ostrer, M. Parliament, P. Pharoah, T. Rebbeck, C. Talbot, H. Thierens, A. Vega, J. Witte, P. Wong, F. Zenhausern, Radiogenomics: radiobiology enters the era of big data and team science, Int. J. Radiat. Oncol. Biol. Phys. 89 (2014) 710-713.

[5] R. Sullivan, J. Peppercorn, K. Sikora, J. Zalcberg, N.J. Meropol, E. Amir, D. Khayat, P. Boyle, P. Autier, I.F. Tannock, T. Fojo, J. Siderov, S. Williamson, S. Camporesi, J.G. McVie, A.D. Purushotham, P. Naredi, A. Eggermont, M.F. Brennan, M.L. Steinberg, M.D. Ridder, S.A. McCloskey, D. Verellen, T. Roberts, G. Storme, R.J. Hicks, P.J. Ell, B.R. Hirsch, D.P. Carbone, K.A. Schulman, P. Catchpole, D. Taylor, J. Geissler, N.G. Brinker, D. Meltzer, D. Kerr, M. Aapro, Delivering affordable cancer care in highincome countries, Lancet Oncol. 12 (2011) 933-980.

[6] M. Gerlinger, A. Rowan, S. Horswell, J. Larkin, D. Endesfelder, E. Gronroos, P. Martinez, N. Matthews, A. Stewart, P. Tarpey, I. Varela, B. Phillimore, S. Begum, N McDonald, A. Butler, D. Jones, K. Raine, C. Latimer, C. Santos, M. Nohadani, A Eklund, B. Spencer-Dene, G. Clark, L. Pickering, G. Stamp, M. Gore, Z. Szallasi, J. Downward, A. Futreal, C. Swanton, Intratumor heterogeneity and branched evolution revealed by multiregion sequencing, N. Engl. J. Med. 366 (2012) 883-892.

[7] A.A. Alizadeh, V. Aranda, A. Bardelli, C. Blanpain, C. Bock, C. Borowski, C. Caldas, A Califano, M. Doherty, M. Elsner, M. Esteller, R. Fitzgerald, J.O. Korbel, P. Lichter, C.E. Mason, N. Navin, D. Pe'er, K. Polyak, C.W. Roberts, L. Siu, A. Snyder, H. Stower, C. Swanton, R.G. Verhaak, J.C. Zenklusen, J. Zuber, J. Zucman-Rossi, Toward understanding and exploiting tumor heterogeneity, Nat. Med. 21 (2015) 846-853.

[8] B. Bachtiary, P. Boutros, M. Pintilie, W. Shi, C. Bastianutto, J. Li, J. Schwock, W. Zhang, L. Penn, I. Jurisica, A. Fyles, F. Liu, Gene expression profiling in cervical cancer: an exploration of intratumor heterogeneity, Clin. Cancer Res. 12 (2006) $5632-5640$

[9] C. Boyd, J. Benarroch-Gampel, K. Sheffield, C. Cooksley, T. Riall, 415 patients with adenosquamous carcinoma of the pancreas: a population-based analysis of prognosis and survival, J. Surg. Res. 174 (2012) 12-19.

[10] M. Milosevic, A. Fyles, R. Wong, M. Pintilie, M. Kavanagh, W. Levin, L. Manchul, T. Keane, R. Hill, Interstitial fluid pressure in cervical carcinoma: within tumor heterogeneity, and relation to oxygen tension, Cancer 82 (1998) 2418-2426.

[11] C. Curtis, S. Shah, C. Suet-Feung, G. Turashvili, O. Rueda, M. Dunning, D. Speed, A. Lynch, S. Samarajiwa, Y. Yuan, S. Gräf, G. Ha, G. Haffari, A. Bashashati, R. Russell, S. McKinney, A. Langerød, A. Green, E. Provenzano, G. Wishart, S. Pinder, P. Watson, F. Markowetz, L. Murphy, I. Ellis, A. Purushotham, A. Børresen-Dale, J. Brenton, S. Tavaré, C. Caldas, S. Aparicio, The genomic and transcriptomic architecture of 2,000 breast tumours reveals novel subgroups, Nature 468 (2012) 346-352.

[12] H. Aerts, J. Bussink, W. Oyen, W. van Elmpt, A. Folgering, D. Emans, M. Velders, P. Lambin, D. De Ruysscher, Identification of residual metabolic-active areas within NSCLC tumours using a pre-radiotherapy FDG-PET-CT scan: a prospective validation, Lung Cancer 75 (2012) 73-76.

[13] H. Aerts, A. van Baardwijk, S. Petit, C. Offermann, J. Loon, R. Houben, A. Dingemans, R. Wanders, L. Boersma, J. Borger, G. Bootsma, W. Geraedts, C. Pitz, J. Simons, B. Wouters, M. Oellers, P. Lambin, G. Bosmans, A. Dekker, D. De Ruysscher, Identification of residual metabolic-active areas within individual NSCLC tumours using a pre-radiotherapy (18)Fluorodeoxyglucose-PET-CT scan, Radiother. Oncol. 91 (2009) 386-392.

[14] H. Suit, S. Skates, A. Taghian, P. Okunieff, J. Efird, Clinical implications of heterogeneity of tumor response to radiation therapy, Radiother. Oncol. 25 (1992) 251-260.

[15] E. Roelofs, L. Persoon, S. Nijsten, W. Wiessler, A. Dekker, P. Lambin, Benefits of a clinical data warehouse with data mining tools to collect data for a radiotherapy trial, Radiother. Oncol. 108 (2013) 174-179.

[16] E. Roelofs, A. Dekker, E. Meldolesi, R.G. van Stiphout, V. Valentini, P. Lambin, International data-sharing for radiotherapy research: an open-source based infrastructure for multicentric clinical data mining, Radiother. Oncol. 110 (2014) 370-374.

[17] A. Vickers, Prediction models: revolutionary in principle, but do they do more good than harm? J. Clin. Oncol. 29 (2011) 2951-2952.

[18] C. Dehing-Oberije, S. Yu, D. De Ruysscher, S. Meersschout, K. van Beek, Y. Lievens, J. van Meerbeeck, W. De Neve, B. Rao, H. van der Weide, P. Lambin, Development and external validation of a prognostic model for 2-year survival of non-small cell lung cancer patients treated with chemoradiotherapy, Int. J. Radiat. Oncol. Biol. Phys. 74 (2009) 8.

[19] A. Egelmeer, E. Velazquez, J. de Jong, C. Oberije, Y. Geussens, S. Nuyts, B. Kremer, D. Rietveld, C. Leemans, M. de Jong, C. Rasch, F. Hoebers, J. Homer, N. Slevin, C. West, L. P ., Development and validation of a nomogram for prediction of survival and local control in laryngeal carcinoma patients treated with radiotherapy alone: a cohort study based on 994 patients, Radiother. Oncol. 100 (2011) 108-115.

[20] M. Jimenez, A. van Baardwijk, H. Aerts, D. De Ruysscher, N. Novoa, G. Varela, L. P . Effectiveness of surgery and individualized high-dose hyperfractionated accelerated radiotherapy on survival in clinical stage I non-small cell lung cancer. A propensity score matched analysis, Radiother. Oncol. 97 (93) (2010) 413-417.
[21] P. Lambin, E. Rios-Velazquez, R. Leijenaar, S. Carvalho, R.G. van Stiphout, P. Granton, C.M. Zegers, R. Gillies, R. Boellard, A. Dekker, H.J. Aerts, Radiomics: extracting more information from medical images using advanced feature analysis, Eur. J. Cancer 48 (2012) 441-446.

[22] E. Roelofs, M. Engelsman, R. Coen, L. Persoon, Q. Sima, D. de Ruysscher, F. Verhaegen, M. Pijls-Johannesma, P. Lambin, Results of a multicentric in silico clinical trial (ROCOCO) comparing radiotherapy with photons and protons for nonsmall cell lung cancer, J. Thorac. Oncol. 7 (2012).

[23] P. Lambin, R. van Stiphout, M. Starmans, E. Rios-Velazquez, G. Nalbantov, H. Aerts, Predicting outcomes in radiation oncology-multifactorial decision support systems, Nat. Rev. Clin. Oncol. 10 (2013).

[24] J.O. Deasy, S.M. Bentzen, A. Jackson, R.K. Ten Haken, E.D. Yorke, L.S. Constine, A. Sharma, L.B. Marks, Improving normal tissue complication probability models: the need to adopt a "data-pooling" culture, Int. J. Radiat. Oncol. Biol. Phys. 76 (2010) S151-S154

[25] T. Skripcak, C. Belka, W. Bosch, C. Brink, T. Brunner, V. Budach, D. Büttner, J. Debus, A. Dekker, C. Grau, S. Gulliford, C. Hurkmans, U. Just, M. Krause, P. Lambin, J. Langendijk, R. Lewensohn, A. Lühr, P. Maingon, M. Masucci, M. Niyazi, P. Poortmans, M. Simon, H. Schmidberger, E. Spezi, M. Stuschke, V. Valentini, M. Verheij, G. Whitfield, B. Zackrisson, D. Zips, M. Baumann, Creating a data exchange strategy for radiotherapy research: towards federated databases and anonymised public datasets, Radiother. Oncol. 113 (2014) 303-309.

[26] R.L. Schilsky, D.L. Michels, A.H. Kearbey, P.P. Yu, C.A. Hudis, Building a rapid learning health care system for oncology: the regulatory framework of CancerLinQ, J. Clin. Oncol. Off. J. Am. Soc. Clin. Oncol. 32 (2014) 2373-2379.

[27] I. Budin-Ljosne, P. Burton, J. Isaeva, A. Gaye, A. Turner, M.J. Murtagh, S. Wallace, V. Ferretti, J.R. Harris, DataSHIELD: an ethically robust solution to multiple-site individual-level data analysis, Public Health Genomics 18 (2015) 87-96.

[28] E. Meldolesi, J. van Soest, N. Dinapoli, A. Dekker, A. Damiani, M. Gambacorta, V. Valentini, An umbrella protocol for standardized data collection (SDC) in rectal cancer: a prospective uniform naming and procedure convention to support personalized medicine, Radiother. Oncol. 112 (2014) 59-62.

[29] G. Collins, J. Reitsma, D. Altman, K. Moons, Transparent reporting of a multivariable prediction model for individual prognosis or diagnosis (TRIPOD): the TRIPOD statement, Ann. Intern. Med. 162 (2015) 55-63.

[30] D. De Ruysscher, C. Dehing S. Yu, R. Wanders, M. Ollers, A. Dingemans, G. Bootsma, M. Hochstenbag, W. Geraedts, C. Pitz, J. Simons, L. Boersma, J. Borger, A. Dekker, P. Lambin, Dyspnea evolution after high-dose radiotherapy in patients with nonsmall cell lung cancer, Radiother. Oncol. (2009).

[31] D. De Ruysscher, A. Houben, H. Aerts, C. Dehing, R. Wanders, M. Ollers, A. Dingemans, M. Hochstenbag, L. Boersma, J. Borger, A. Dekker, L. P ., Increased (18)F-deoxyglucose uptake in the lung during the first weeks of radiotherapy is correlated with subsequent Radiation-Induced Lung Toxicity (RILT): a prospective pilot study, Radiother. Oncol. 91 (2009) 415-420.

[32] E. Steyerberg, A. Vickers, N. Cook, T. Gerds, M. Gonen, N. Obuchowski, M. Pencina, M. Kattan, Assessing the performance of prediction models: a framework for traditional and novel measures, Epidemiology 21 (2010) 128-138.

[33] V. Valentini, R. van Stiphout, G. Lammering, M. Gambacorta, M. Barba, M. Bebenek, F. Bonnetain, J. Bosset, K. Bujko, L. Cionini, J. Gerard, C. Rödel, A. Sainato, R. Sauer, B. Minsky, L. Collette, L. P ., Nomograms for predicting local recurrence, distant metastases, and overall survival for patients with locally advanced rectal cancer on the basis of European randomized clinical trials, J. Clin. Oncol. 29 (2011) 3163-3172.

[34] P. Lambin, J. Zindler, B. Vanneste, L. van de Voorde, M. Jacobs, D. Eekers, J. Peerlings, B. Reymen, R. Larue, T. Deist, E. de Jong, A. Even, A. Berlanga, E. Roelofs, Q. Cheng, S. Carvalho, R. Leijenaar, C. Zegers, E. van Limbergen, M. Berbee, W. van Elmpt, C. Oberije, R. Houben, A. Dekker, L. Boersma, F. Verhaegen, G. Bosmans, F. Hoebers, K. Smits, S. Walsh, Modern clinical research: how rapid learning health care and cohort multiple randomised clinical trials complement traditional evidence based medicine, Acta. Oncol. 54 (2015) 1289-1300.

[35] A.L. Dekker, S.L. Gulliford, M.A. Ebert, C.G. Orton, Point/Counterpoint. Future radiotherapy practice will be based on evidence from retrospective interrogation of linked clinical data sources rather than prospective randomized controlled clinical trials, Med. Phys. 41 (2014) 030601.

[36] M.M. Grand, P.C. O'Brien, Obstacles to participation in randomised cancer clinical trials: a systematic review of the literature, J. Med. Imaging Radiat. Oncol. 56 (2012) 31-39.

[37] V.H. Murthy, H.M. Krumholz, C.P. Gross, Participation in cancer clinical trials: race-, sex-, and age-based disparities, JAMA 291 (2004) 2720-2726.

[38] C. Dehing-Oberije, D. De Ruysscher, A. van Baardwijk, S. Yu, B. Rao, P. Lambin, The importance of patient characteristics for the prediction of radiation-induced lung toxicity, Radiother. Oncol. 91 (2009) 421-426.

[39] C. Oberije, D. De Ruysscher, R. Houben, M. van de Heuvel, W. Uyterlinde, J. Deasy, J. Belderbos, A. Dingemans, A. Rimner, S. Din, P. Lambin, A validated prediction model for overall survival from stage iii non-small cell lung cancer: toward survival prediction for individual patients, Int. J. Radiat. Oncol. Biol. Phys. 92 (2015) 935-944.

[40] D. Stacey, C. Bennett, M. Barry, N. Col, K. Eden, M. Holmes-Rovner, H. LlewellynThomas, A. Lyddiatt, F. Légaré, R. Thomson, Decision aids for people facing health treatment or screening decisions, Cochrane Database Syst. Rev. 5 (2011).

[41] J. Li, M. Wang, M. Won, E.G. Shaw, C. Coughlin, W.J. Curran Jr., M.P. Mehta, Validation and simplification of the Radiation Therapy Oncology Group recursive partitioning analysis classification for glioblastoma, Int. J. Radiat. Oncol. Biol. Phys. 81 (2011) 623-630.

[42] J.M. Michalski, H. Gay, A. Jackson, S.L. Tucker, J.O. Deasy, Radiation dose volume effects in radiation induced rectal injury, Int. J. Radiat. Oncol. Biol. Phys. 76 (2010) S123-S129. 
[43] S. Walsh, W. van der Putten, A TCP model for external beam treatment of intermediate-risk prostate cancer, Med. Phys. 40 (2013) 11.

[44] A. Dekker, S. Vinod, L. Holloway, C. Oberije, A. George, G. Goozee, G. Delaney, P. Lambin, D. Thwaites, Rapid learning in practice: a lung cancer survival decision support system in routine patient care data, Radiother. Oncol. 113 (2014) 7.

[45] C. Dehing-Oberije, D. De Ruysscher, S. Petit, J. Van Meerbeeck, K. Vandecasteele, W. De Neve, A.M. Dingemans, I. El Naqa, J. Deasy, J. Bradley, E. Huang, P. Lambin, Development, external validation and clinical usefulness of a practical prediction model for radiation-induced dysphagia in lung cancer patients, Radiother. Oncol. 97 (2010) 455-461.

[46] C. Dehing-Oberije, H. Aerts, S. Yu, D. De Ruysscher, P. Menheere, M. Hilvo, H. van der Weide, B. Rao, P. Lambin, Development and validation of a prognostic model using blood biomarker information for prediction of survival of non-small-cell lung cancer patients treated with combined chemotherapy and radiation or radiotherapy alone (NCT00181519, NCT00573040, and NCT00572325), Int. J. Radiat. Oncol. Biol. Phys. 81 (2011) 360-368.

[47] T.J. Bright, A. Wong, R. Dhurjati, E. Bristow, L. Bastian, R.R. Coeytaux, G. Samsa, V. Hasselblad, J.W. Williams, M.D. Musty, L. Wing, A.S. Kendrick, G.D. Sanders, D. Lobach, Effect of clinical decision-support systems: a systematic review, Ann. Intern. Med. 157 (2012) 29-43.

[48] B.L. Ramaekers, J.P. Grutters, M. Pijls-Johannesma, P. Lambin, M.A. Joore, J.A. Langendijk, Protons in head-and-neck cancer: bridging the gap of evidence, Int. J. Radiat. Oncol. Biol. Phys. 85 (2013) 1282-1288.

[49] G.M. Clark, Prognostic factors versus predictive factors: examples from a clinical trial of erlotinib, Mol. Oncol. 1 (2008) 406-412.

[50] J.E. Dancey, K.K. Dobbin, S. Groshen, J.M. Jessup, A.H. Hruszkewycz, M. Koehler, R. Parchment, M.J. Ratain, L.K. Shankar, W.M. Stadler, L.D. True, A. Gravell, M.R. Grever, Guidelines for the development and incorporation of biomarker studies in early clinical trials of novel agents, Clin. Cancer Res. 16 (2010) 1745-1755.

[51] M.B. Sesen, A.E. Nicholson, R. Banares-Alcantara, T. Kadir, M. Brady, Bayesian networks for clinical decision support in lung cancer care, PLoS One 8 (2013), e82349.

[52] N. Peek, D.G. Arts, R.J. Bosman, P.H. van der Voort, N.F. de Keizer, External validation of prognostic models for critically ill patients required substantial sample sizes, J. Clin. Epidemiol. 60 (2007) 491-501.

[53] Y. Vergouwe, E.W. Steyerberg, M.J. Eijkemans, J.D. Habbema, Substantial effective sample sizes were required for external validation studies of predictive logistic regression models, J. Clin. Epidemiol. 58 (2005) 475-483.

[54] T. Aittokallio, Dealing with missing values in large-scale studies: microarray data imputation and beyond, Brief. Bioinform. 11 (2010) 253-264.

[55] J. Ludbrook, Outlying observations and missing values: how should they be handled? Clin. Exp. Pharmacol. Physiol. 35 (2008) 670-678.

[56] T. Jayalakshmi, A. Santhakumaran, Statistical normalization and back propagation for classification, Int. J. Comput. Theory. Eng. 3 (2011) 89-93.

[57] M.A. Babyak, What you see may not be what you get: a brief, nontechnical introduction to overfitting in regression-type models, Psychosom. Med. 66 (2004) 411-421.

[58] F.E. Harrell Jr., K.L. Lee, R.M. Califf, D.B. Pryor, R.A. Rosati, Regression modelling strategies for improved prognostic prediction, Stat. Med. 3 (1984) 143-152.

[59] P. Peduzzi, J. Concato, E. Kemper, T.R. Holford, A.R. Feinstein, A simulation study of the number of events per variable in logistic regression analysis, J. Clin. Epidemiol. 49 (1996) 1373-1379.

[60] L. Huan, H. Motoda, Feature Selection for Knowledge Discovery and Data Mining, Kluwer Academic Publishers, Norwell, MA, 1998.

[61] F. Harrell, Regression Modeling Strategies, Springer, New York, 2011.

[62] C. Bishop, Pattern Recognition and Machine Learning, Springer, N. Y., 2007.

[63] K. Kourou, T.P. Exarchos, K.P. Exarchos, M.V. Karamouzis, D.I. Fotiadis, Machine learning applications in cancer prognosis and prediction, Comput. Struct. Biotechnol. J. 13 (2015) 8-17.

[64] S.M. Lee, P.A. Abbott, Bayesian networks for knowledge discovery in large datasets: basics for nurse researchers, J. Biomed. Inform. 36 (2003) 389-399.

[65] H. Putter, M. Fiocco, R.B. Geskus, Tutorial in biostatistics: competing risks and multi-state models, Stat. Med. 26 (2007) 2389-2430.

[66] H. Akaike, A new look at the statistical model indentification, IEEE Trans. Autom. Control 19 (1974) 716-723.

[67] K.G. Moons, A.P. Kengne, D.E. Grobbee, P. Royston, Y. Vergouwe, D.G. Altman, M. Woodward, Risk prediction models: II. External validation, model updating, and impact assessment, Heart 98 (2012) 691-698.

[68] M.C. Specht, M.W. Kattan, M. Gonen, J. Fey, K.J. Van Zee, Predicting nonsentinel node status after positive sentinel lymph biopsy for breast cancer: clinicians versus nomogram, Ann. Surg. Oncol. 12 (2005) 654-659.

[69] C. Dehing-Oberije, D. De Ruysscher, H. van der Weide, M. Hochstenbag, G. Bootsma, W. Geraedts, C. Pitz, J. Simons, J. Teule, A. Rahmy, P. Thimister, H. Steck, P. Lambin, Tumor volume combined with number of positive lymph node stations is a more important prognostic factor than TNM stage for survival of non-smallcell lung cancer patients treated with (chemo)radiotherapy, Int. J. Radiat. Oncol. Biol. Phys. 70 (2008) 1039-1044.

[70] A.J. Vickers, B.S. Kramer, S.G. Baker, Selecting patients for randomized trials: a systematic approach based on risk group, Trials 7 (2006) 30.

[71] K.A. Baggerly, K.R. Coombes, What information should be required to support clinical "omics" publications? Clin. Chem. 57 (2011) 688-690.

[72] A.H. Klopp, P.J. Eifel, Biological predictors of cervical cancer response to radiation therapy, Semin. Radiat. Oncol. 22 (2012) 143-150.

[73] G. Kristiansen, Diagnostic and prognostic molecular biomarkers for prostate cancer, Histopathology 60 (2012) 125-141.

[74] C.S. Ang, J. Phung, E.C. Nice, The discovery and validation of colorectal cancer biomarkers, Biomed. Chromatogr. 25 (2011) 82-99.
[75] M.E. Schmidt, K. Steindorf, Statistical methods for the validation of questionnaires-discrepancy between theory and practice, Methods Inf. Med. 45 (2006) 409-413.

[76] I. Garrido-Laguna, F. Janku, C. Vaklavas, G.S. Falchook, S. Fu, D.S. Hong, A. Naing A.M. Tsimberidou, S. Wen, R. Kurzrock, Validation of the Royal Marsden Hospital prognostic score in patients treated in the Phase I Clinical Trials Program at the MD Anderson Cancer Center, Cancer 118 (2012) 1422-1428.

[77] I. Shrier, J.F. Boivin, R.J. Steele, R.W. Platt, A. Furlan, R. Kakuma, J. Brophy, M. Rossignol, Should meta-analyses of interventions include observational studies in addition to randomized controlled trials? A critical examination of underlying principles, Am. J. Epidemiol. 166 (2007) 1203-1209.

[78] I. Tzoulaki, K.C. Siontis, J.P. Ioannidis, Prognostic effect size of cardiovascular biomarkers in datasets from observational studies versus randomised trials: metaepidemiology study, BMJ 343 (2011) d6829.

[79] N.C. Institute, in: N. NCI, DHHS (Eds.), Common Terminology Criteria for Adverse Events v4.0, National Cancer Institute, 2009.

[80] A. Trotti, A.D. Colevas, A. Setser, E. Basch, Patient-reported outcomes and the evolution of adverse event reporting in oncology, J. Clin. Oncol. Off. J. Am. Soc. Clin. Oncol. 25 (2007) 5121-5127.

[81] A. Trotti, A.D. Colevas, A. Setser, V. Rusch, D. Jaques, V. Budach, C. Langer, B. Murphy, R. Cumberlin, C.N. Coleman, P. Rubin, CTCAE v3.0: development of a comprehensive grading system for the adverse effects of cancer treatment, Semin. Radiat. Oncol. 13 (2003) 176-181.

[82] S. Golder, Y.K. Loke, M. Bland, Meta-analyses of adverse effects data derived from randomised controlled trials as compared to observational studies: methodological overview, PLoS Med. 8 (2011), e1001026.

[83] P.G. Steg, J. Lopez-Sendon, E. Lopez de Sa, S.G. Goodman, J.M. Gore, F.A. Anderson Jr., D. Himbert, J. Allegrone, F. Van de Werf, External validity of clinical trials in acute myocardial infarction, Arch. Intern. Med. 167 (2007) 68-73.

[84] J. Little, J.P. Higgins, J.P. Ioannidis, D. Moher, F. Gagnon, E.v. Elm, M.J. Khoury, B. Cohen, G. Davey-Smith, J. Grimshaw, P. Scheet, M. Gwinn, R.E. Williamson, G.Y. Zou, K. Hutchings, C.Y. Johnson, V. Tait, M. Wiens, J. Golding, C.v. Duijn, J. McLaughlin, A. Paterson, G. Wells, I. Fortier, M. Freedman, M. Zecevic, R. King, C. Infante-Rivard, A. Stewart, N. Birkett, STrengthening the REporting of Genetic Association studies (STREGA)-an extension of the STROBE statement, Eur. J. Clin. Investig. 39 (2009) 247-266.

[85] E. von Elm, D.G. Altman, M. Egger, S.J. Pocock, P.C. Gotzsche, J.P. Vandenbroucke, Strengthening the Reporting of Observational Studies in Epidemiology (STROBE) statement: guidelines for reporting observational studies, BMJ 335 (2007) 806-808.

[86] E. von Elm, D.G. Altman, M. Egger, S.J. Pocock, P.C. Gotzsche, J.P. Vandenbroucke The Strengthening the Reporting of Observational Studies in Epidemiology (STROBE) statement: guidelines for reporting observational studies, Lancet 370 (2007) 1453-1457.

[87] L.A. Dawson, M.B. Sharpe, Image-guided radiotherapy: rationale, benefits, and limitations, Lancet Oncol. 7 (2006) 848-858.

[88] A. Jackson, L.B. Marks, S.M. Bentzen, A. Eisbruch, E.D. Yorke, R.K. Ten Haken, L.S Constine, J.O. Deasy, The lessons of QUANTEC: recommendations for reporting and gathering data on dose-volume dependencies of treatment outcome, Int. J. Radiat. Oncol. Biol. Phys. 76 (2010) S155-S160.

[89] S.M. Bentzen, L.S. Constine, J.O. Deasy, A. Eisbruch, A. Jackson, L.B. Marks, R.K. Ten Haken, E.D. Yorke, Quantitative Analyses of Normal Tissue Effects in the Clinic (QUANTEC): an introduction to the scientific issues, Int. J. Radiat. Oncol. Biol. Phys. 76 (2010) S3-S9.

[90] D.A. Jaffray, P.E. Lindsay, K.K. Brock, J.O. Deasy, W.A. Tomé, Accurate accumulation of dose for improved understanding of radiation effects in normal tissue, Int. J. Radiat. Oncol. Biol. Phys. 76 (2010) S135-S139.

[91] D.A. Jaffray, Image-guided radiotherapy: from current concept to future perspectives, Nat. Rev. Clin. Oncol. 9 (2012) 688-699.

[92] B.C. Hermans, L.C. Persoon, M. Podesta, F.J. Hoebers, F. Verhaegen, E.G. Troost, Weekly kilovoltage cone-beam computed tomography for detection of dose discrepancies during (chemo)radiotherapy for head and neck cancer, Acta Oncol. (Stockh.) (2015) 1-7.

[93] J. Belderbos, L. Uitterhoeve, N. van Zandwijk, H. Belderbos, P. Rodrigus, P. van de Vaart, A. Price, N. van Walree, C. Legrand, S. Dussenne, H. Bartelink, G. Giaccone, C. Koning, Randomised trial of sequential versus concurrent chemo-radiotherapy in patients with inoperable non-small cell lung cancer (EORTC 08972-22973), Eur. J. Cancer 43 (2007) 114-121.

[94] P. Lambin, S.F. Petit, H.J. Aerts, W.J. van Elmpt, C.J. Oberije, M.H. Starmans, R.G. van Stiphout, G.A. van Dongen, K. Muylle, P. Flamen, A.L. Dekker, D. De Ruysscher, The ESTRO Breur Lecture 2009. From population to voxel-based radiotherapy: exploiting intra-tumour and intra-organ heterogeneity for advanced treatment of non-small cell lung cancer, Radiother. Oncol. 96 (2010) 145-152.

[95] S. Bentzen, Theragnostic imaging for radiation oncology: dose-painting by numbers, Lancet Oncol. 6 (2005) 112-117.

[96] B. Emami, J. Lyman, A. Brown, L. Coia, M. Goitein, J.E. Munzenrider, B. Shank, L.J. Solin, M. Wesson, Tolerance of normal tissue to therapeutic irradiation, Int. J. Radiat. Oncol. Biol. Phys. 21 (1991) 109-122.

[97] L.B. Marks, S.M. Bentzen, J.O. Deasy, F.M. Kong, J.D. Bradley, I.S. Vogelius, I. E Naqa, J.L. Hubbs, J.V. Lebesque, R.D. Timmerman, M.K. Martel, A. Jackson, Radiation dose-volume effects in the lung, Int. J. Radiat. Oncol. Biol. Phys. 76 (2010) S70-S76.

[98] M. Werner-Wasik, E. Yorke, J. Deasy, J. Nam, L.B. Marks, Radiation dose-volume effects in the esophagus, Int. J. Radiat. Oncol. Biol. Phys. 76 (2010) S86-S93.

[99] T.E. Schultheiss, The radiation dose-response of the human spinal cord, Int. J. Radiat. Oncol. Biol. Phys. 71 (2008) 1455-1459. 
[100] I. Beetz, C. Schilstra, A.v.d. Schaaf, E.R.v.d. Heuvel, P. Doornaert, P.v. Luijk, A. Vissink, B.F.v.d. Laan, C.R. Leemans, H.P. Bijl, M.E. Christianen, R.J. Steenbakkers, J.A Langendijk, NTCP models for patient-rated xerostomia and sticky saliva after treatment with intensity modulated radiotherapy for head and neck cancer: the role of dosimetric and clinical factors, Radiother. Oncol. 105 (2012) 101-106.

[101] I. Beetz, C. Schilstra, P. van Luijk, M.E. Christianen, P. Doornaert, H.P. Bijl, O. Chouvalova, E.R. van den Heuvel, R.J. Steenbakkers, J.A. Langendijk, External validation of three dimensional conformal radiotherapy based NTCP models for patient-rated xerostomia and sticky saliva among patients treated with intensity modulated radiotherapy, Radiother. Oncol. 105 (2012) 94-100.

[102] M.J. Boomsma, H.P. Bijl, M.E. Christianen, I. Beetz, O. Chouvalova, R.J. Steenbakkers, B.F. van der Laan, B.H. Wolffenbuttel, S.F. Oosting, C. Schilstra, J.A. Langendijk, A prospective cohort study on radiation-induced hypothyroidism: development of an NTCP model, Int. J. Radiat. Oncol. Biol. Phys. 84 (2012) e351-e356.

[103] M.E. Christianen, I.M. Verdonck-de Leeuw, P. Doornaert, O. Chouvalova, R.J. Steenbakkers, P.W. Koken, C. Rene Leemans, S.F. Oosting, J.L. Roodenburg, B.F. van der Laan, B.J. Slotman, H.P. Bijl, J.A. Langendijk, Patterns of long-term swallowing dysfunction after definitive radiotherapy or chemoradiation, Radiother. Oncol. (2015).

[104] B.L. Ramaekers, M.A. Joore, J.P. Grutters, P. van den Ende, J. Jong, R. Houben, P. Lambin, M. Christianen, I. Beetz, M. Pijls-Johannesma, J.A. Langendijk, The impact of late treatment-toxicity on generic health-related quality of life in head and neck cancer patients after radiotherapy, Oral Oncol. 47 (2011) 768-774.

[105] K. Wopken, H.P. Bijl, A. van der Schaaf, M.E. Christianen, O. Chouvalova, S.F. Oosting, B.F. van der Laan, J.L. Roodenburg, C.R. Leemans, B.J. Slotman, P. Doornaert, R.J. Steenbakkers, I.M. Verdonck-de Leeuw, J.A. Langendijk, Development and validation of a prediction model for tube feeding dependence after curative (chemo-) radiation in head and neck cancer, PLoS One 9 (2014), e94879.

[106] A. van der Schaaf, C.J. Xu, P. van Luijk, A.A. Van't Veld, J.A. Langendijk, C. Schilstra, Multivariate modeling of complications with data driven variable selection: guarding against overfitting and effects of data set size, Radiother. Oncol. 105 (2012) 115-121.

[107] C.J. Xu, A. van der Schaaf, A.A. Van't Veld, J.A. Langendijk, C. Schilstra, Statistical validation of normal tissue complication probability models, Int. J. Radiat. Oncol. Biol. Phys. 84 (2012) e123-e129.

[108] M. Podesta, S.M. Nijsten, L.C. Persoon, S.G. Scheib, C. Baltes, F. Verhaegen, Time dependent pre-treatment EPID dosimetry for standard and FFF VMAT, Phys. Med. Biol. 59 (2014) 4749-4768.

[109] S.M. Nijsten, B.J. Mijnheer, A.L. Dekker, P. Lambin, A.W. Minken, Routine individualised patient dosimetry using electronic portal imaging devices, Radiother. Oncol. 83 (2007) 65-75.

[110] M. Podesta, L.C. Persoon, F. Verhaegen, A novel time dependent gamma evaluation function for dynamic 2D and 3D dose distributions, Phys. Med. Biol. 59 (2014) 5973-5985.

[111] W. van Elmpt, S. Nijsten, S. Petit, B. Mijnheer, P. Lambin, A. Dekker, 3D in vivo dosimetry using megavoltage cone-beam CT and EPID dosimetry, Int. J. Radiat. Oncol. Biol. Phys. 73 (2009) 1580-1587.

[112] W. van Elmpt, S. Petit, D. De Ruysscher, P. Lambin, A. Dekker, 3D dose delivery verification using repeated cone-beam imaging and EPID dosimetry for stereotac tic body radiotherapy of non-small cell lung cancer, Radiother. Oncol. 94 (2010) 188-194.

[113] G. Rodrigues, M. Lock, D. D'Souza, E. Yu, J. Van Dyk, Prediction of radiation pneumonitis by dose-volume histogram parameters in lung cancer-a systematic review, Radiother. Oncol. 71 (2004) 127-138.

[114] B. Jones, R.G. Dale, C. Deehan, K.I. Hopkins, D.A. Morgan, The role of biologically effective dose (BED) in clinical oncology, Clin. Oncol. (R. Coll. Radiol.) 13 (2001) 71-81.

[115] J.F. Fowler, 21 years of biologically effective dose, Br. J. Radiol. 83 (2010) 554-568.

[116] J.F. Fowler, The linear-quadratic formula and progress in fractionated radiotherapy, Br. J. Radiol. 62 (1989) 679-694.

[117] M. Saunders, A.M. Rojas, S. Dische, CHART revisited: a conservative approach for advanced head and neck cancer, Clin. Oncol. (R. Coll. Radiol.) 20 (2008) 127-133.

[118] N. Turner, M.B. Lambros, H.M. Horlings, A. Pearson, R. Sharpe, R. Natrajan, F.C. Geyer, M. van Kouwenhove, B. Kreike, A. Mackay, A. Ashworth, M.J. van de Vijver, J.S. Reis-Filho, Integrative molecular profiling of triple negative breast cancers identifies amplicon drivers and potential therapeutic targets, Oncogene 29 (2010) 2013-2023

[119] A.C. Begg, K. Haustermans, A.A. Hart, S. Dische, M. Saunders, B. Zackrisson, H. Gustaffson, P. Coucke, N. Paschoud, M. Hoyer, J. Overgaard, P. Antognoni, A. Richetti, J. Bourhis, H. Bartelink, J.C. Horiot, R. Corvo, W. Giaretti, H. Awwad, T. Shouman, T. Jouffroy, Z. Maciorowski, W. Dobrowsky, H. Struikmans, G.D. Wilson, et al., The value of pretreatment cell kinetic parameters as predictors for radiotherapy outcome in head and neck cancer: a multicenter analysis, Radiother. Oncol. 50 (1999) 13-23.

[120] Z. Huang, N.A. Mayr, M. Gao, S.S. Lo, J.Z. Wang, G. Jia, W.T.C. Yuh, The onset time of tumor repopulation for cervical cancer - first evidence from clinical data, Int. J. Radiat. Oncol. Biol. Phys. 84 (2012) 478-484.

[121] M. Baumann, M. Krause, R. Hill, Exploring the role of cancer stem cells in radioresistance, Nat. Rev. Cancer 8 (2008) 545-554.

[122] F. Hessel, C. Petersen, D. Zips, M. Krause, D. Pfitzmann, H.D. Thames, M. Baumann, Impact of increased cell loss on the repopulation rate during fractionated irradiation in human FaDu squamous cell carcinoma growing in nude mice, Int. J. Radiat. Biol. 79 (2003) 479-486

[123] E. Ben-Josef, J. Moughan, J.A. Ajani, M. Flam, L. Gunderson, J. Pollock, R. Myerson, R. Anne, S.A. Rosenthal, C. Willett, Impact of overall treatment time on survival and local control in patients with anal cancer: a pooled data analysis of Radiation
Therapy Oncology Group trials 87-04 and 98-11, J. Clin. Oncol. Off. J. Am. Soc. Clin. Oncol. 28 (2010) 5061-5066.

[124] S. Song, S. Rudra, M.D. Hasselle, P.L. Dorn, L.K. Mell, A.J. Mundt, S.D. Yamada, N.K. Lee, Y. Hasan, The effect of treatment time in locally advanced cervical cancer in the era of concurrent chemoradiotherapy, Cancer 119 (2013) 325-331.

[125] H.D. Thames, D. Kuban, L.B. Levy, E.M. Horwitz, P. Kupelian, A. Martinez, J. Michalski, T. Pisansky, H. Sandler, W. Shipley, M. Zelefsky, A. Zietman, The role of overall treatment time in the outcome of radiotherapy of prostate cancer: an analysis of biochemical failure in 4839 men treated between 1987 and 1995, Radiother. Oncol. 96 (2010) 6-12.

[126] S.F. Petit, H.J. Aerts, J.G. van Loon, C. Offermann, R. Houben, B. Winkens, M.C. Ollers, P. Lambin, D. De Ruysscher, A.L. Dekker, Metabolic control probability in tumour subvolumes or how to guide tumour dose redistribution in non-small cell lung cancer (NSCLC): an exploratory clinical study, Radiother. Oncol. 91 (2009) 393-398.

[127] S.F. Petit, W.J. van Elmpt, C.J. Oberije, E. Vegt, A.M. Dingemans, P. Lambin, A.L. Dekker, D. De Ruysscher, [(1)(8)F]fluorodeoxyglucose uptake patterns in lung before radiotherapy identify areas more susceptible to radiation-induced lung toxicity in non-small-cell lung cancer patients, Int. J. Radiat. Oncol. Biol. Phys. 81 (2011) 698-705.

[128] L. Fass, Imaging and cancer: a review, Mol. Oncol. 2 (2008) 115-152.

[129] D.A. Torigian, S.S. Huang, M. Houseni, A. Alavi, Functional imaging of cancer with emphasis on molecular techniques, CA Cancer J. Clin. 57 (2007) 206-224.

[130] L.H. Eadie, P. Taylor, A.P. Gibson, A systematic review of computer-assisted diagnosis in diagnostic cancer imaging, Eur. J. Radiol. 81 (2012) e70-e76.

[131] R.J. Gillies, A.R. Anderson, R.A. Gatenby, D.L. Morse, The biology underlying molecular imaging in oncology: from genome to anatome and back again, Clin. Radiol. 65 (2010) 517-521.

[132] C.B. Caldwell, K. Mah, Y.C. Ung, C.E. Danjoux, J.M. Balogh, S.N. Ganguli, L.E. Ehrlich, Observer variation in contouring gross tumor volume in patients with poorly defined non-small-cell lung tumors on CT: the impact of 18FDG-hybrid PET fusion, Int. J. Radiat. Oncol. Biol. Phys. 51 (2001) 923-931.

[133] A.K. Cangir, H. Kutlay, M. Akal, A. Gungor, N. Ozdemir, H. Akay, Prognostic value of tumor size in non-small cell lung cancer larger than five centimeters in diameter, Lung Cancer 46 (2004) 325-331.

[134] C. Greco, K. Rosenzweig G.L. Cascini, O. Tamburrini, Current status of PET/CT for tumour volume definition in radiotherapy treatment planning for non-small cell lung cancer (NSCLC), Lung Cancer 57 (2007) 125-134

[135] J.S. Lam, T. Klatte, J.J. Patard, R.H. Goel, F. Guille, B. Lobel, C.C. Abbou, A. De La Taille, J. Tostain, L. Cindolo, V. Altieri, V. Ficarra, W. Artibani, T. Prayer-Galetti, L. Schips, R. Zigeuner, A.J. Pantuck, R.A. Figlin, A.S. Belldegrun, Prognostic relevance of tumour size in T3a renal cell carcinoma: a multicentre experience, Eur. Urol. 52 (2007) $155-162$.

[136] G. Pitson, A. Fyles, M. Milosevic, J. Wylie, M. Pintilie, R. Hill, Tumor size and oxygenation are independent predictors of nodal diseases in patients with cervix cancer, Int. J. Radiat. Oncol. Biol. Phys. 51 (2001) 699-703.

[137] R.J. Steenbakkers, J.C. Duppen, I. Fitton, K.E. Deurloo, L. Zijp, A.L. Uitterhoeve, P.T. Rodrigus, G.W. Kramer, J. Bussink, K. De Jaeger, J.S. Belderbos, A.A. Hart, P.J. Nowak, M. van Herk, C.R. Rasch, Observer variation in target volume delineation of lung cancer related to radiation oncologist-computer interaction: a 'Big Brother' evaluation, Radiother. Oncol. 77 (2005) 182-190.

[138] F. Thomas, R. Arriagada, H. Mouriesse, I. Sillet-Bach, I. Kunkler, F. Fontaine, T. Le Chevalier, G. Contesso, D. Sarrazin, Radical radiotherapy alone in non-operable breast cancer: the major impact of tumor size and histological grade on prognosis, Radiother. Oncol. 13 (1988) 267-276.

[139] E.R. Velazquez, H.J. Aerts, C. Oberije, D. De Ruysscher, P. Lambin, Prediction of residual metabolic activity after treatment in NSCLC patients, Acta Oncol. (Stockh.) 49 (2010) 1033-1039.

[140] P. Bowden, R. Fisher, M. Mac Manus, A. Wirth, G. Duchesne, M. Millward, A. McKenzie, J. Andrews, D. Ball, Measurement of lung tumor volumes using threedimensional computer planning software, Int. J. Radiat. Oncol. Biol. Phys. 53 (2002) 566-573.

[141] C.D. Marcus, V. Ladam-Marcus, C. Cucu, O. Bouche, L. Lucas, C. Hoeffel, Imaging techniques to evaluate the response to treatment in oncology: current standards and perspectives, Crit. Rev. Oncol. Hematol. 72 (2009) 217-238.

[142] M. Nishino, M. Guo, D.M. Jackman, P.J. DiPiro, J.T. Yap, T.K. Ho, H. Hatabu, P.A. Janne, A.D. Van den Abbeele, B.E. Johnson, CT tumor volume measurement in advanced non-small-cell lung cancer: performance characteristics of an emerging clinical tool, Acad. Radiol. 18 (2011) 54-62.

[143] J.J. Erasmus, G.W. Gladish, L. Broemeling, B.S. Sabloff, M.T. Truong, R.S. Herbst, R.F. Munden, Interobserver and intraobserver variability in measurement of nonsmall-cell carcinoma lung lesions: implications for assessment of tumor response, J. Clin. Oncol. Off. J. Am. Soc. Clin. Oncol. 21 (2003) 2574-2582.

[144] L.H. Schwartz, M. Mazumdar, W. Brown, A. Smith, D.M. Panicek, Variability in response assessment in solid tumors: effect of number of lesions chosen for measurement, Clin. Cancer Res. 9 (2003) 4318-4323.

[145] P. Therasse, Measuring the clinical response. What does it mean? Eur. J. Cancer 38 (2002) 1817-1823.

[146] I.M. Desar, C.M. van Herpen, H.W. van Laarhoven, J.O. Barentsz, W.J. Oyen, W.T. van der Graaf, Beyond RECIST: molecular and functional imaging techniques for evaluation of response to targeted therapy, Cancer Treat. Rev. 35 (2009) 309-321.

[147] C.G. Moertel, J.A. Hanley, The effect of measuring error on the results of therapeutic trials in advanced cancer, Cancer 38 (1976) 388-394.

[148] R.L. Wahl, H. Jacene, Y. Kasamon, M.A. Lodge, From RECIST to PERCIST: evolving considerations for PET response criteria in solid tumors, J. Nucl. Med. 50 (Suppl. 1) (2009) 122S-150S. 
[149] H. Young, R. Baum, U. Cremerius, K. Herholz, O. Hoekstra, A.A. Lammertsma, J. Pruim, P. Price, Measurement of clinical and subclinical tumour response using [18F]-fluorodeoxyglucose and positron emission tomography: review and 1999 EORTC recommendations. European Organization for Research and Treatment of Cancer (EORTC) PET Study Group, Eur. J. Cancer 35 (1999) 1773-1782.

[150] S.A. Nehmeh, Y.E. Erdi, Respiratory motion in positron emission tomography/computed tomography: a review, Semin. Nucl. Med. 38 (2008) 167-176.

[151] J.J. Sonke, J. Belderbos, Adaptive radiotherapy for lung cancer, Semin. Radiat. Oncol. 20 (2010) 94-106.

[152] G. Strassmann, S. Abdellaoui, D. Richter, F. Bekkaoui, M. Haderlein, E. Fokas, N. Timmesfeld, B. Vogel, M. Henzel, R. Engenhart-Cabillic, Atlas-based semiautomatic target volume definition (CTV) for head-and-neck tumors, Int. J. Radiat. Oncol. Biol. Phys. 78 (2010) 1270-1276.

[153] A. van Baardwijk, G. Bosmans, L. Boersma, J. Buijsen, S. Wanders, M. Hochstenbag, R.J. van Suylen, A. Dekker, C. Dehing-Oberije, R. Houben, S.M. Bentzen, M. van Kroonenburgh, P. Lambin, D. De Ruysscher, PET-CT-based auto-contouring in non-small-cell lung cancer correlates with pathology and reduces interobserver variability in the delineation of the primary tumor and involved nodal volumes, Int. J. Radiat. Oncol. Biol. Phys. 68 (2007) 771-778.

[154] M. Wanet, J.A. Lee, B. Weynand, M. De Bast, A. Poncelet, V. Lacroix, E. Coche, V. Gregoire, X. Geets, Gradient-based delineation of the primary GTV on FDG-PET in non-small cell lung cancer: a comparison with threshold-based approaches, CT and surgical specimens, Radiother. Oncol. 98 (2011) 117-125.

[155] K. Wu, Y.C. Ung, J. Hornby, M. Freeman, D. Hwang, M.S. Tsao, M. Dahele, G. Darling, D.E. Maziak, R. Tirona, K. Mah, C.S. Wong, PET CT thresholds for radiotherapy target definition in non-small-cell lung cancer: how close are we to the pathologic findings? Int. J. Radiat. Oncol. Biol. Phys. 77 (2010) 699-706.

[156] J.F. Daisne, T. Duprez, B. Weynand, M. Lonneux, M. Hamoir, H. Reychler, V. Gregoire, Tumor volume in pharyngolaryngeal squamous cell carcinoma: comparison at CT, MR imaging, and FDG PET and validation with surgical specimen, Radiology 233 (2004) 93-100.

[157] U. Nestle, S. Kremp, A. Schaefer-Schuler, C. Sebastian-Welsch, D. Hellwig, C. Rube, C.M. Kirsch, Comparison of different methods for delineation of 18F-FDG PETpositive tissue for target volume definition in radiotherapy of patients with nonsmall cell lung cancer, J. Nucl. Med. 46 (2005) 1342-1348.

[158] J. van Loon, A. van Baardwijk, L. Boersma, M. Ollers, P. Lambin, D. De Ruysscher, Therapeutic implications of molecular imaging with PET in the combined modality treatment of lung cancer, Cancer Treat. Rev. 37 (2011) 331-343.

[159] J.P. O'Connor, A. Jackson, M.C. Asselin, D.L. Buckley, G.J. Parker, G.C. Jayson, Quantitative imaging biomarkers in the clinical development of targeted therapeutics: current and future perspectives, Lancet Oncol. 9 (2008) 766-776.

[160] K.A. Wood, P.J. Hoskin, M.I. Saunders, Positron emission tomography in oncology: a review, Clin. Oncol. (R. Coll. Radiol.) 19 (2007) 237-255.

[161] G.R. Borst, J.S. Belderbos, R. Boellaard, E.F. Comans, K. De Jaeger, A.A. Lammertsma, J.V. Lebesque, Standardised FDG uptake: a prognostic factor for inoperable nonsmall cell lung cancer, Eur. J. Cancer 41 (2005) 1533-1541.

[162] H.H. Chung, J.W. Kim, K.H. Han, J.S. Eo, K.W. Kang, N.H. Park, Y.S. Song, J.K. Chung, S.B. Kang, Prognostic value of metabolic tumor volume measured by FDG-PET/CT in patients with cervical cancer, Gynecol. Oncol. 120 (2011) 270-274.

[163] S. Differding, F.X. Hanin, V. Gregoire, PET imaging biomarkers in head and neck cancer, Eur. J. Nucl. Med. Mol. Imaging 42 (2015) 613-622.

[164] C.J. Hoekstra, S.G. Stroobants, E.F. Smit, J. Vansteenkiste, H. van Tinteren, P.E. Postmus, R.P. Golding, B. Biesma, F.J. Schramel, N. van Zandwijk, A.A. Lammertsma, O.S. Hoekstra, Prognostic relevance of response evaluation using [18F]-2-fluoro-2-deoxy-D-glucose positron emission tomography in patients with locally advanced non-small-cell lung cancer, J. Clin. Oncol. Off. J. Am. Soc. Clin. Oncol. 23 (2005) 8362-8370.

[165] M.P. Mac Manus, R.J. Hicks, J.P. Matthews, A. Wirth, D. Rischin, D.L. Ball, Metabolic (FDG-PET) response after radical radiotherapy/chemoradiotherapy for non-small cell lung cancer correlates with patterns of failure, Lung Cancer 49 (2005) 95-108

[166] D.E. Soto, M.L. Kessler, M. Piert, A. Eisbruch, Correlation between pretreatment FDG-PET biological target volume and anatomical location of failure after radiation therapy for head and neck cancers, Radiother. Oncol. 89 (2008) 13-18.

[167] A. van Baardwijk, G. Bosmans, A. Dekker, M. van Kroonenburgh, L. Boersma, S. Wanders, M. Ollers, R. Houben, A. Minken, P. Lambin, D. De Ruysscher, Time trends in the maximal uptake of FDG on PET scan during thoracic radiotherapy. A prospective study in locally advanced non-small cell lung cancer (NSCLC) patients, Radiother. Oncol. 82 (2007) 145-152.

[168] G. Ceulemans, M. Voordeckers, A. Farrag, D. Verdries, G. Storme, H. Everaert, Can 18-FDG-PET during radiotherapy replace post-therapy scanning for detection/ demonstration of tumor response in head-and-neck cancer? Int. J. Radiat. Oncol. Biol. Phys. 81 (2011) 938-942.

[169] M.H. Janssen, M.C. Ollers, R.G. van Stiphout, J. Buijsen, J. van den Bogaard, D. de Ruysscher, P. Lambin, G. Lammering, Evaluation of early metabolic responses in rectal cancer during combined radiochemotherapy or radiotherapy alone: sequential FDG-PET-CT findings, Radiother. Oncol. 94 (2010) 151-155.

[170] M. Lambrecht, C. Deroose, S. Roels, V. Vandecaveye, F. Penninckx, X. Sagaert, E. van Cutsem, F. de Keyzer, K. Haustermans, The use of FDG-PET/CT and diffusionweighted magnetic resonance imaging for response prediction before, during and after preoperative chemoradiotherapy for rectal cancer, Acta Oncol. (Stockh.) 49 (2010) 956-963.

[171] J. van Loon, C. Offermann, M. Ollers, W. van Elmpt, E. Vegt, A. Rahmy, A.M. Dingemans, P. Lambin, D. De Ruysscher, Early CT and FDG-metabolic tumour volume changes show a significant correlation with survival in stage I-III small cell lung cancer: a hypothesis generating study, Radiother. Oncol. 99 (2011) 172-175.
[172] R. Boellaard, Need for standardization of 18F-FDG PET/CT for treatment response assessments, J. Nucl. Med. 52 (Suppl. 2) (2011) 93S-100S.

[173] J. Bussink, J.H. Kaanders, W.T. van der Graaf, W.J. Oyen, PET-CT for radiotherapy treatment planning and response monitoring in solid tumors, Nat. Rev. Clin. Oncol. 8 (2011) 233-242.

[174] R. Boellaard, M.J. O'Doherty, W.A. Weber, F.M. Mottaghy, M.N. Lonsdale, S.G. Stroobants, W.J. Oyen, J. Kotzerke, O.S. Hoekstra, J. Pruim, P.K. Marsden, K. Tatsch, C.J. Hoekstra, E.P. Visser, B. Arends, F.J. Verzijlbergen, J.M. Zijlstra, E.F. Comans, A.A. Lammertsma, A.M. Paans, A.T. Willemsen, T. Beyer, A. Bockisch, C. Schaefer-Prokop, D. Delbeke, R.P. Baum, A. Chiti, B.J. Krause, FDG PET and PET/ CT: EANM procedure guidelines for tumour PET imaging: version 1.0, Eur. J. Nucl. Med. Mol. Imaging 37 (2010) 181-200.

[175] S.G. Peeters, C.M. Zegers, N.G. Lieuwes, W. van Elmpt, J. Eriksson, G.A. van Dongen, L. Dubois, P. Lambin, A comparative study of the hypoxia PET tracers $[(1)(8) F] H X 4$ [(1)(8)F]FAZA, and [(1)(8)F]FMISO in a preclinical tumor model, Int. J. Radiat. Oncol. Biol. Phys. 91 (2015) 351-359.

[176] J. van Loon, M.H. Janssen, M. Ollers, H.J. Aerts, L. Dubois, M. Hochstenbag, A.M. Dingemans, R. Lalisang, B. Brans, B. Windhorst, G.A. van Dongen, H. Kolb, J. Zhang, D. De Ruysscher, P. Lambin, PET imaging of hypoxia using [18F]HX4: a phase I trial, Eur. J. Nucl. Med. Mol. Imaging 37 (2010) 1663-1668.

[177] C.M. Zegers, W. van Elmpt, B. Reymen, A.J. Even, E.G. Troost, M.C. Ollers, F.J Hoebers, R.M. Houben, J. Eriksson, A.D. Windhorst, F.M. Mottaghy, D. De Ruysscher, P. Lambin, In vivo quantification of hypoxic and metabolic status of NSCLC tumors using [18F]HX4 and [18F]FDG-PET/CT imaging, Clin. Cancer Res. 20 (2014) 6389-6397.

[178] R. Boellaard, W.J. Oyen, C.J. Hoekstra, O.S. Hoekstra, E.P. Visser, A.T. Willemsen, B. Arends, F.J. Verzijlbergen, J. Zijlstra, A.M. Paans, E.F. Comans, J. Pruim, The Netherlands protocol for standardisation and quantification of FDG whole body PET studies in multi-centre trials, Eur. J. Nucl. Med. Mol. Imaging 35 (2008) 2320-2333.

[179] J.E. Bayouth, T.L. Casavant, M.M. Graham, M. Sonka, M. Muruganandham, J.M Buatti, Image-based biomarkers in clinical practice, Semin. Radiat. Oncol. 21 (2011) 157-166.

[180] V.N. Harry, S.I. Semple, D.E. Parkin, F.J. Gilbert, Use of new imaging techniques to predict tumour response to therapy, Lancet Oncol. 11 (2010) 92-102.

[181] L. Heijmen, M.C. Verstappen, E.E. Ter Voert, C.J. Punt, W.J. Oyen, L.F. de Geus-Oei, J.J Hermans, A. Heerschap, H.W. van Laarhoven, Tumour response prediction by diffusion-weighted MR imaging: ready for clinical use? Crit. Rev. Oncol. Hematol. 83 (2012) 194-207.

[182] V. Vandecaveye, P. Dirix, F. De Keyzer, K. Op de Beeck, V. Vander Poorten, E. Hauben, M. Lambrecht, S. Nuyts, R. Hermans, Diffusion-weighted magnetic resonance imaging early after chemoradiotherapy to monitor treatment response in head-and-neck squamous cell carcinoma, Int. J. Radiat. Oncol. Biol. Phys. 82 (2012) 1098-1107.

[183] S.Y. Kim, S.S. Lee, J.H. Byun, S.H. Park, J.K. Kim, B. Park, N. Kim, M.G. Lee, Malignant hepatic tumors: short-term reproducibility of apparent diffusion coefficients with breath-hold and respiratory-triggered diffusion-weighted MR imaging, Radiology 255 (2010) 815-823.

[184] R.G. Kierkels, W.H. Backes, M.H. Janssen, J. Buijsen, R.G. Beets-Tan, P. Lambin, G. Lammering, M.C. Oellers, H.J. Aerts, Comparison between perfusion computed tomography and dynamic contrast-enhanced magnetic resonance imaging in rectal cancer, Int. J. Radiat. Oncol. Biol. Phys. 77 (2010) 400-408.

[185] A. Shukla-Dave, N.Y. Lee, J.F. Jansen, H.T. Thaler, H.E. Stambuk, M.G. Fury, S.G. Patel A.L. Moreira, E. Sherman, S. Karimi, Y. Wang, D. Kraus, J.P. Shah, D.G. Pfister, J.A Koutcher, Dynamic contrast-enhanced magnetic resonance imaging as a predictor of outcome in head-and-neck squamous cell carcinoma patients with nodal metastases, Int. J. Radiat. Oncol. Biol. Phys. 82 (2012) 1837-1844.

[186] R. Sinkus, B.E. Van Beers, V. Vilgrain, N. DeSouza, J.C. Waterton, Apparent diffusion coefficient from magnetic resonance imaging as a biomarker in oncology drug development, Eur. J. Cancer 48 (2012) 425-431.

[187] P. Morchel, G. Melkus, A. Yaromina, D. Zips, M. Baumann, P.M. Jakob, M. Flentje, Correlating quantitative MR measurements of standardized tumor lines with histological parameters and tumor control dose, Radiother. Oncol. 96 (2010) 123-130.

[188] V. Quennet, A. Yaromina, D. Zips, A. Rosner, S. Walenta, M. Baumann, W. MuellerKlieser, Tumor lactate content predicts for response to fractionated irradiation of human squamous cell carcinomas in nude mice, Radiother. Oncol. 81 (2006) 130-135.

[189] A. Yaromina, V. Quennet, D. Zips, S. Meyer, G. Shakirin, S. Walenta, W. MuellerKlieser, M. Baumann, Co-localisation of hypoxia and perfusion markers with parameters of glucose metabolism in human squamous cell carcinoma (hSCC) xenografts, Int. J. Radiat. Biol. 85 (2009) 972-980.

[190] Y.I. Kim, J.W. Chung, J.H. Park, G.H. Kang, M. Lee, K.S. Suh, K.G. Kim, Multiphase contrast-enhanced CT imaging in hepatocellular carcinoma correlation with immunohistochemical angiogenic activities, Acad. Radiol. 14 (2007) 1084-1091.

[191] K.A. Miles, Perfusion CT for the assessment of tumour vascularity: which protocol? Br. J. Radiol. 76 (Spec No 1) (2003) S36-S42.

[192] W. van Elmpt, C.M. Zegers, M. Das, D. De Ruysscher, Imaging techniques for tumour delineation and heterogeneity quantification of lung cancer: overview of current possibilities, J. Thorac. Dis. 6 (2014) 319-327.

[193] K.A. Miles, Molecular imaging with dynamic contrast-enhanced computed tomography, Clin. Radiol. 65 (2010) 549-556.

[194] G. Petralia, L. Bonello, S. Viotti, L. Preda, G. d'Andrea, M. Bellomi, CT perfusion in oncology: how to do it, Cancer Imaging 10 (2010) 8-19.

[195] M.C. Asselin, J.P. O'Connor, R. Boellaard, N.A. Thacker, A. Jackson, Quantifying heterogeneity in human tumours using MRI and PET, Eur. J. Cancer 48 (2012) 447-455. 
[196] J.F. Eary, F. O'Sullivan, J. O'Sullivan, E.U. Conrad, Spatial heterogeneity in sarcoma 18F-FDG uptake as a predictor of patient outcome, J. Nucl. Med. 49 (2008) 1973-1979.

197] F. Tixier, C.C. Le Rest, M. Hatt, N. Albarghach, O. Pradier, J.P. Metges, L. Corcos, D. Visvikis, Intratumor heterogeneity characterized by textural features on baseline 18 F-FDG PET images predicts response to concomitant radiochemotherapy in esophageal cancer, J. Nucl. Med. 52 (2011) 369-378.

[198] R. Pepperkok, J. Ellenberg, High-throughput fluorescence microscopy for systems biology, Nat. Rev. Mol. Cell Biol. 7 (2006) 690-696.

[199] K.M. Panth, R.T. Leijenaar, S. Carvalho, N.G. Lieuwes, A. Yaromina, L. Dubois, P. Lambin, Is there a causal relationship between genetic changes and radiomicsbased image features? An in vivo preclinical experiment with doxycycline inducible GADD34 tumor cells, Radiother. Oncol. (2015).

[200] D.A. Gutman, W.D. Dunn Jr., P. Grossmann, L.A. Cooper, C.A. Holder, K.L. Ligon, B.M. Alexander, H.J. Aerts, Somatic mutations associated with MRI-derived volumetric features in glioblastoma, Neuroradiology (2015).

[201] M. Diehn, C. Nardini, D.S. Wang, S. McGovern, M. Jayaraman, Y. Liang, K. Aldape, S Cha, M.D. Kuo, Identification of noninvasive imaging surrogates for brain tumo gene-expression modules, Proc. Natl. Acad. Sci. U. S. A. 105 (2008) 5213-5218.

[202] M.D. Kuo, J. Gollub, C.B. Sirlin, C. Ooi, X. Chen, Radiogenomic analysis to identify imaging phenotypes associated with drug response gene expression programs in hepatocellular carcinoma, J. Vasc. Interv. Radiol. 18 (2007) 821-831.

[203] E. Segal, C.B. Sirlin, C. Ooi, A.S. Adler, J. Gollub, X. Chen, B.K. Chan, G.R. Matcuk, C.T. Barry, H.Y. Chang, M.D. Kuo, Decoding global gene expression programs in liver cancer by noninvasive imaging, Nat. Biotechnol. 25 (2007) 675-680.

[204] A.M. Rutman, M.D. Kuo, Radiogenomics: creating a link between molecular diagnostics and diagnostic imaging, Eur. J. Radiol. 70 (2009) 232-241.

[205] W. van Elmpt, C.M. Zegers, B. Reymen, A.J. Even, A.C. Dingemans, M. Oellers, J.E. Wildberger, F.M. Mottaghy, M. Das, E.G. Troost, P. Lambin, Multiparametric imaging of patient and tumour heterogeneity in non-small-cell lung cancer: quantification of tumour hypoxia, metabolism and perfusion, Eur. J. Nucl. Med. Mol. Imaging (2015).

[206] T.E. Yankeelov, R.G. Abramson, C.C. Quarles, Quantitative multimodality imaging in cancer research and therapy, Nat. Rev. Clin. Oncol. 11 (2014) 670-680.

[207] H. Aerts, E. Rios-Velazquez, R. Leijenaar, C. Parmar, P. Grossmann, S. Carvalho, J. Bussink, R. Monshouwer, B. Haibe-Kains, D. Rietveld, F. Hoebers, M. Rietbergen, C. Leemans, A. Dekker, J. Quackenbush, R. Gillies, P. Lambin, Decoding tumour phenotype by noninvasive imaging using a quantitative radiomics approach, Nat Commun. 5 (2014)

[208] R. Fisher, L. Pusztai, C. Swanton, Cancer heterogeneity: implications for targeted therapeutics, Br. J. Cancer 108 (2013) 479-485.

[209] D.L. Longo, Tumor heterogeneity and personalized medicine, N. Engl. J. Med. 366 (2012) 956-957.

[210] N.J. Szerlip, A. Pedraza, D. Chakravarty, M. Azim, J. McGuire, Y. Fang, T. Ozawa, E.C. Holland, J.T. Huse, S. Jhanwar, M.A. Leversha, T. Mikkelsen, C.W. Brennan, Intratumoral heterogeneity of receptor tyrosine kinases EGFR and PDGFRA amplification in glioblastoma defines subpopulations with distinct growth factor response, Proc. Natl. Acad. Sci. U. S. A. 109 (2012) 3041-3046.

[211] C.K. Ng, H.N. Pemberton, J.S. Reis-Filho, Breast cancer intratumor genetic heterogeneity: causes and implications, Expert. Rev. Anticancer. Ther. 12 (2012) 1021-1032.

[212] F.S. Collins, H. Varmus, A new initiative on precision medicine, N. Engl. J. Med. 372 (2015) 793-795.

[213] A. Cistaro, N. Quartuccio, A. Mojtahedi, P. Fania, P.L. Filosso, A. Campenni, U. Ficola, S. Baldari, Prediction of 2 years-survival in patients with stage I and II non-small cell lung cancer utilizing (18)F-FDG PET/CT SUV quantification, Radiol. Oncol. 47 (2013) 219-223.

[214] G.J. Cook, C. Yip, M. Siddique, V. Goh, S. Chicklore, A. Roy, P. Marsden, S. Ahmad, D. Landau, Are pretreatment 18F-FDG PET tumor textural features in non-small cell lung cancer associated with response and survival after chemoradiotherapy? J. Nucl. Med. 54 (2013) 19-26.

[215] T.P. Coroller, P. Grossmann, Y. Hou, E. Rios Velazquez, R.T. Leijenaar, G. Hermann, P. Lambin, B. Haibe-Kains, R.H. Mak, H.J. Aerts, CT-based radiomic signature predicts distant metastasis in lung adenocarcinoma, Radiother. Oncol. 114 (2015) 345-350.

[216] B. Ganeshan, V. Goh, H.C. Mandeville, Q.S. Ng, P.J. Hoskin, K.A. Miles, Non-small cell lung cancer: histopathologic correlates for texture parameters at CT, Radiology 266 (2013) 326-336.

[217] O. Gevaert, J. Xu, C.D. Hoang, A.N. Leung, Y. Xu, A. Quon, D.L. Rubin, S. Napel, S.K Plevritis, Non-small cell lung cancer: identifying prognostic imaging biomarkers by leveraging public gene expression microarray data-methods and preliminary results, Radiology 264 (2012) 387-396.

[218] M.D. Pickles, D.J. Manton, M. Lowry, L.W. Turnbull, Prognostic value of pretreatment DCE-MRI parameters in predicting disease free and overall survival for breast cancer patients undergoing neoadjuvant chemotherapy, Eur. J. Radiol. 71 (2009) 498-505.

[219] M. Nicolasjilwan, Y. Hu, C. Yan, D. Meerzaman, C.A. Holder, D. Gutman, R. Jain, R. Colen, D.L. Rubin, P.O. Zinn, S.N. Hwang, P. Raghavan, D.A. Hammoud, L.M Scarpace, T. Mikkelsen, J. Chen, O. Gevaert, K. Buetow, J. Freymann, J. Kirby, A.E. Flanders, M. Wintermark, Addition of MR imaging features and genetic biomarkers strengthens glioblastoma survival prediction in TCGA patients, J. Neuroradiol. 42 (2015) 212-221.

[220] L. Alic, W.J. Niessen, J.F. Veenland, Quantification of heterogeneity as a biomarker in tumor imaging: a systematic review, PLoS One 9 (2014), e110300.

[221] S. Carvalho, R.T. Leijenaar, E.R. Velazquez, C. Oberije, C. Parmar, W. van Elmpt, B. Reymen, E.G. Troost, M. Oellers, A. Dekker, R. Gillies, H.J. Aerts, P. Lambin, Prognostic value of metabolic metrics extracted from baseline positron emission tomography images in non-small cell lung cancer, Acta Oncol. (Stockh.) 52 (2013) 1398-1404.

[222] O. Gevaert, L.A. Mitchell, A.S. Achrol, J. Xu, S. Echegaray, G.K. Steinberg, S.H. Cheshier, S. Napel, G. Zaharchuk, S.K. Plevritis, Glioblastoma multiforme: exploratory radiogenomic analysis by using quantitative image features, Radiology 276 (2015) 313.

[223] M. Hatt, F. Tixier, C. Cheze Le Rest, O. Pradier, D. Visvikis, Robustness of intratumour (1)(8)F-FDG PET uptake heterogeneity quantification for therapy response prediction in oesophageal carcinoma, Eur. J. Nucl. Med. Mol. Imaging 40 (2013) 1662-1671.

[224] R. Jain, L.M. Poisson, D. Gutman, L. Scarpace, S.N. Hwang, C.A. Holder, M. Wintermark, A. Rao, R.R. Colen, J. Kirby, J. Freymann, C.C. Jaffe, T. Mikkelsen, A. Flanders, Outcome prediction in patients with glioblastoma by using imaging, clinical, and genomic biomarkers: focus on the nonenhancing component of the tumor, Radiology 272 (2014) 484-493.

[225] L.A. Hunter, S. Krafft, F. Stingo, H. Choi, M.K. Martel, S.F. Kry, L.E. Court, High quality machine-robust image features: identification in nonsmall cell lung cancer computed tomography images, Med. Phys. 40 (2013) 121916.

[226] R.T. Leijenaar, S. Carvalho, E.R. Velazquez, W.J. van Elmpt, C. Parmar, O.S. Hoekstra, C.J. Hoekstra, R. Boellaard, A.L. Dekker, R.J. Gillies, H.J. Aerts, P. Lambin, Stability of FDG-PET Radiomics features: an integrated analysis of test-retest and interobserver variability, Acta Oncol. (Stockh.) 52 (2013) 1391-1397.

[227] C. Parmar, E. Rios Velazquez, R. Leijenaar, M. Jermoumi, S. Carvalho, R.H. Mak, S. Mitra, B.U. Shankar, R. Kikinis, B. Haibe-Kains, P. Lambin, H.J. Aerts, Robust radiomics feature quantification using semiautomatic volumetric segmentation, PLoS One 9 (2014), e102107.

[228] R. Buettner, J. Wolf, R.K. Thomas, Lessons learned from lung cancer genomics: the emerging concept of individualized diagnostics and treatment, J. Clin. Oncol. Off. J. Am. Soc. Clin. Oncol. 31 (2013) 1858-1865.

[229] F. Taguchi, B. Solomon, V. Gregorc, H. Roder, R. Gray, K. Kasahara, M. Nishio, J. Brahmer, A. Spreafico, V. Ludovini, P.P. Massion, R. Dziadziuszko, J. Schiller, J. Grigorieva, M. Tsypin, S.W. Hunsucker, R. Caprioli, M.W. Duncan, F.R. Hirsch, P.A. Bunn Jr., D.P. Carbone, Mass spectrometry to classify non-small-cell lung cancer patients for clinical outcome after treatment with epidermal growth factor receptor tyrosine kinase inhibitors: a multicohort cross-institutional study, J. Natl. Cancer Inst. 99 (2007) 838-846.

[230] S. Rizzo, F. Petrella, V. Buscarino, F. De Maria, S. Raimondi, M. Barberis, C. Fumagalli, G. Spitaleri, C. Rampinelli, F. De Marinis, L. Spaggiari, M. Bellomi, CT radiogenomic characterization of EGFR, K-RAS, and ALK mutations in non-small cell lung cancer, Eur. Radiol. (2015).

[231] R. Colen, I. Foster, R. Gatenby, M.E. Giger, R. Gillies, D. Gutman, M. Heller, R. Jain, A. Madabhushi, S. Madhavan, S. Napel, A. Rao, J. Saltz, J. Tatum, R. Verhaak, G. Whitman, NCI workshop report: clinical and computational requirements for correlating imaging phenotypes with genomics signatures, Transl. Oncol. 7 (2014) 556-569.

[232] A. Yaromina, M. Krause, M. Baumann, Individualization of cancer treatment from radiotherapy perspective, Mol. Oncol. 6 (2012) 211-221.

[233] J.C. Lindegaard, J. Overgaard, S.M. Bentzen, D. Pedersen, Is there a radiobiologic basis for improving the treatment of advanced stage cervical cancer? J. Natl. Cancer Inst. Monogr. (1996) 105-112.

[234] M. Krause, A. Yaromina, W. Eicheler, U. Koch, M. Baumann, Cancer stem cells: targets and potential biomarkers for radiotherapy, Clin. Cancer Res. 17 (2011) 7224-7229.

[235] A. Yaromina, M. Krause, H. Thames, A. Rosner, M. Krause, F. Hessel, R. Grenman, D. Zips, M. Baumann, Pre-treatment number of clonogenic cells and their radiosensitivity are major determinants of local tumour control after fractionated irradiation, Radiother. Oncol. 83 (2007) 304-310.

[236] D. Slonina, A. Gasinska, Intrinsic radiosensitivity of healthy donors and cancer patients as determined by the lymphocyte micronucleus assay, Int. J. Radiat. Biol. 72 (1997) 693-701.

[237] A. Menegakis, C. De Colle, A. Yaromina, J. Hennenlotter, A. Stenzl, M. Scharpf, F. Fend, S. Noell, M. Tatagiba, S. Brucker, D. Wallwiener, S. Boeke, U. Ricardi, M. Baumann, D. Zips, Residual gammaH2AX foci after ex vivo irradiation of patient samples with known tumour-type specific differences in radio-responsiveness, Radiother. Oncol. (2015)

[238] A. Menegakis, C. von Neubeck, A. Yaromina, H. Thames, S. Hering, J. Hennenlotter, M. Scharpf, S. Noell, M. Krause, D. Zips, M. Baumann, gammaH2AX assay in ex vivo irradiated tumour specimens: a novel method to determine tumour radiation sensitivity in patient-derived material, Radiother. Oncol. (2015).

[239] B. Fertil, E.P. Malaise, Intrinsic radiosensitivity of human cell lines is correlated with radioresponsiveness of human tumors: analysis of 101 published survival curves, Int. J. Radiat. Oncol. Biol. Phys. 11 (1985) 1699-1707.

[240] A. Menegakis, A. Yaromina, W. Eicheler, A. Dorfler, B. Beuthien-Baumann, H.D. Thames, M. Baumann, M. Krause, Prediction of clonogenic cell survival curves based on the number of residual DNA double strand breaks measured by gammaH2AX staining, Int. J. Radiat. Biol. 85 (2009) 1032-1041.

[241] T. Bjork-Eriksson, C. West, E. Karlsson, C. Mercke, Tumor radiosensitivity (SF2) is a prognostic factor for local control in head and neck cancers, Int. J. Radiat. Oncol. Biol. Phys. 46 (2000) 13-19.

[242] J. Kahn, T.J. Hayman, M. Jamal, B.H. Rath, T. Kramp, K. Camphausen, P.J. Tofilon, The mTORC1/mTORC2 inhibitor AZD2014 enhances the radiosensitivity of glioblastoma stem-like cells, Neuro-Oncology 16 (2014) 29-37.

[243] M.M. Chitnis, K.A. Lodhia, T. Aleksic, S. Gao, A.S. Protheroe, V.M. Macaulay, IGF-1R inhibition enhances radiosensitivity and delays double-strand break repair by both non-homologous end-joining and homologous recombination, Oncogene 33 (2014) 5262-5273. 
[244] S. Du, S. Bouquet, C.H. Lo, I. Pellicciotta, S. Bolourchi, R. Parry, M.H. Barcellos-Hoff, Attenuation of the DNA damage response by transforming growth factor-beta inhibitors enhances radiation sensitivity of non-small-cell lung cancer cells in vitro and in vivo, Int. J. Radiat. Oncol. Biol. Phys. 91 (2015) 91-99.

[245] C.M. West, S.E. Davidson, S.A. Roberts, R.D. Hunter, The independence of intrinsic radiosensitivity as a prognostic factor for patient response to radiotherapy of carcinoma of the cervix, Br. J. Cancer 76 (1997) 1184-1190.

[246] R.A. El-Awady, E. Dikomey, J. Dahm-Daphi, Radiosensitivity of human tumour cells is correlated with the induction but not with the repair of DNA double-strand breaks, Br. J. Cancer 89 (2003) 593-601.

[247] P.L. Olive, J.P. Banath, Phosphorylation of histone H2AX as a measure of radiosensitivity, Int. J. Radiat. Oncol. Biol. Phys. 58 (2004) 331-335.

[248] H. Bartelink, A. Begg, J.C. Martin, M. van Dijk, L.v.'t. Veer, P.v.d. Vaart, M. Verheij, Towards prediction and modulation of treatment response, Radiother. Oncol. 50 (1999) 1-11.

[249] M.W. van Gisbergen, A.M. Voets, M.H. Starmans, I.F. de Coo, R. Yadak, R.F. Hoffmann, P.C. Boutros, H.J. Smeets, L. Dubois, P. Lambin, How do changes in the mtDNA and mitochondrial dysfunction influence cancer and cancer therapy? Challenges, opportunities and models, Mutat. Res. Rev. Mutat. Res. 764 (2015) 16-30.

[250] A.C. Begg, Predicting recurrence after radiotherapy in head and neck cancer, Semin. Radiat. Oncol. 22 (2012) 108-118.

[251] K.M. Smits, V. Melotte, H.E. Niessen, L. Dubois, C. Oberije, E.G. Troost, M.H. Starmans, P.C. Boutros, M. Vooijs, M. van Engeland, P. Lambin, Epigenetics in radiotherapy: where are we heading? Radiother. Oncol. 111 (2014) 168-177.

[252] M. Hockel, K. Schlenger, B. Aral, M. Mitze, U. Schaffer, P. Vaupel, Association between tumor hypoxia and malignant progression in advanced cancer of the uterine cervix, Cancer Res. 56 (1996) 4509-4515.

[253] P. Vaupel, A. Mayer, Hypoxia in cancer: significance and impact on clinical outcome, Cancer Metastasis Rev. 26 (2007) 225-239.

[254] S. Chouaib, Y. Messai, S. Couve, B. Escudier, M. Hasmim, M.Z. Noman, Hypoxia promotes tumor growth in linking angiogenesis to immune escape, Front. Immunol. 3 (2012) 21.

[255] J.H. Kaanders, K.I. Wijffels, H.A. Marres, A.S. Ljungkvist, L.A. Pop, F.J. van den Hoogen, P.C. de Wilde, J. Bussink, J.A. Raleigh, A.J. van der Kogel, Pimonidazole binding and tumor vascularity predict for treatment outcome in head and neck cancer, Cancer Res. 62 (2002) 7066-7074.

[256] M. Nordsmark, J. Loncaster, C. Aquino-Parsons, S.C. Chou, V. Gebski, C. West, J.C. Lindegaard, H. Havsteen, S.E. Davidson, R. Hunter, J.A. Raleigh, J. Overgaard, The prognostic value of pimonidazole and tumour pO2 in human cervix carcinomas after radiation therapy: a prospective international multi-center study, Radiother. Oncol. 80 (2006) 123-131.

[257] K.M. Rouschop, T. van den Beucken, L. Dubois, H. Niessen, J. Bussink, K. Savelkouls, T. Keulers, H. Mujcic, W. Landuyt, J.W. Voncken, P. Lambin, A.J. van der Kogel, M. Koritzinsky, B.G. Wouters, The unfolded protein response protects human tumor cells during hypoxia through regulation of the autophagy genes MAP1LC3B and ATG5, J. Clin. Invest. 120 (2010) 127-141.

[258] L.J. Dubois, N.G. Lieuwes, M.H. Janssen, W.J. Peeters, A.D. Windhorst, J.C. Walsh, H.C. Kolb, M.C. Ollers, J. Bussink, G.A. van Dongen, A. van der Kogel, P. Lambin, Preclinical evaluation and validation of [18F]HX4, a promising hypoxia marker for PET imaging, Proc. Natl. Acad. Sci. U. S. A. 108 (2011) 14620-14625.

[259] S.G. Peeters, C.M. Zegers, A. Yaromina, W. Van Elmpt, L. Dubois, P. Lambin, Current preclinical and clinical applications of hypoxia PET imaging using 2-nitroimidazoles, Q. J. Nucl. Med. Mol. Imaging 59 (2015) 39-57.

[260] B.J. Krause, R. Beck, M. Souvatzoglou, M. Piert, PET and PET/CT studies of tumor tissue oxygenation, Q. J. Nucl. Med. Mol. Imaging 50 (2006) 28-43.

[261] J. van Loon, D. De Ruysscher, R. Wanders, L. Boersma, J. Simons, M. Oellers, A.M. Dingemans, M. Hochstenbag, G. Bootsma, W. Geraedts, C. Pitz, J. Teule, A. Rhami, W. Thimister, G. Snoep, C. Dehing-Oberije, P. Lambin, Selective nodal irradiation on basis of (18)FDG-PET scans in limited-disease small-cell lung cancer: a prospective study, Int. J. Radiat. Oncol. Biol. Phys. 77 (2010) 329-336.

[262] C.M. West, R.A. Cooper, J.A. Loncaster, D.P. Wilks, M. Bromley, Tumor vascularity: a histological measure of angiogenesis and hypoxia, Cancer Res. 61 (2001) 2907-2910.

[263] L. Goethals, C. Perneel, A. Debucquoy, H. De Schutter, D. Borghys, N. Ectors, K. Geboes, W.H. McBride, K.M. Haustermans, A new approach to the validation of tissue microarrays, J. Pathol. 208 (2006) 607-614.

[264] B. Maciejewski, H.R. Withers, J.M. Taylor, A. Hliniak, Dose fractionation and regeneration in radiotherapy for cancer of the oral cavity and oropharynx: tumor doseresponse and repopulation, Int. J. Radiat. Oncol. Biol. Phys. 16 (1989) 831-843.

[265] E.T. McKinley, G.D. Ayers, R.A. Smith, S.A. Saleh, P. Zhao, M.K. Washington, R.J. Coffey, H.C. Manning, Limits of [18F]-FLT PET as a biomarker of proliferation in oncology, PLoS One 8 (2013), e58938.

[266] C. Petersen, D. Zips, M. Krause, K. Schone, W. Eicheler, C. Hoinkis, H.D. Thames, M. Baumann, Repopulation of FaDu human squamous cell carcinoma during fractionated radiotherapy correlates with reoxygenation, Int. J. Radiat. Oncol. Biol. Phys. 51 (2001) 483-493.

[267] I. Turesson, J. Nyman, E. Holmberg, A. Oden, Prognostic factors for acute and late skin reactions in radiotherapy patients, Int. J. Radiat. Oncol. Biol. Phys. 36 (1996) 1065-1075.

[268] J. Johansen, S.M. Bentzen, J. Overgaard, M. Overgaard, Evidence for a positive correlation between in vitro radiosensitivity of normal human skin fibroblasts and the occurrence of subcutaneous fibrosis after radiotherapy, Int. J. Radiat. Biol. 66 (1994) 407-412.

[269] C.M. West, S.E. Davidson, S.A. Elyan, H. Valentine, S.A. Roberts, R. Swindell, R.D. Hunter, Lymphocyte radiosensitivity is a significant prognostic factor for morbidity in carcinoma of the cervix, Int. J. Radiat. Oncol. Biol. Phys. 51 (2001) 10-15.
[270] J. Peacock, A. Ashton, J. Bliss, C. Bush, J. Eady, C. Jackson, R. Owen, J. Regan, J. Yarnold, Cellular radiosensitivity and complication risk after curative radiotherapy, Radiother. Oncol. 55 (2000) 173-178.

[271] N.S. Russell, A. Grummels, A.A. Hart, I.J. Smolders, J. Borger, H. Bartelink, A.C. Begg Low predictive value of intrinsic fibroblast radiosensitivity for fibrosis development following radiotherapy for breast cancer, Int. J. Radiat. Biol. 73 (1998) 661-670.

[272] N.S. Russell, C.F. Arlett, H. Bartelink, A.C. Begg, Use of fluorescence in situ hybridization to determine the relationship between chromosome aberrations and cel survival in eight human fibroblast strains, Int. J. Radiat. Biol. 68 (1995) 185-196.

[273] C.L. Dileto, E.L. Travis, Fibroblast radiosensitivity in vitro and lung fibrosis in vivo: comparison between a fibrosis-prone and fibrosis-resistant mouse strain, Radiat. Res. 146 (1996) 61-67.

[274] A.E. Kiltie, A.J. Ryan, R. Swindell, J.B. Barber, C.M. West, B. Magee, J.H. Hendry, A correlation between residual radiation-induced DNA double-strand breaks in cultured fibroblasts and late radiotherapy reactions in breast cancer patients, Radiother. Oncol. 51 (1999) 55-65.

[275] D. Azria, Y. Belkacemi, G. Romieu, S. Gourgou, M. Gutowski, K. Zaman, C.L Moscardo, C. Lemanski, M. Coelho, B. Rosenstein, P. Fenoglietto, N.E. Crompton, M. Ozsahin, Concurrent or sequential adjuvant letrozole and radiotherapy after conservative surgery for early-stage breast cancer (CO-HO-RT): a phase 2 randomised trial, Lancet Oncol. 11 (2010) 258-265.

[276] S.M. Bentzen, Preventing or reducing late side effects of radiation therapy: radiobiology meets molecular pathology, Nat. Rev. Cancer 6 (2006) 702-713.

[277] H.P. Rodemann, M. Bamberg, Cellular basis of radiation-induced fibrosis, Radiother Oncol. 35 (1995) 83-90.

[278] C.N. Andreassen, J. Alsner, M. Overgaard, F.B. Sorensen, J. Overgaard, Risk of radiation-induced subcutaneous fibrosis in relation to single nucleotide polymorphisms in TGFB1, SOD2, XRCC1, XRCC3, APEX and ATM-a study based on DNA from formalin fixed paraffin embedded tissue samples, Int. J. Radiat. Biol. 82 (2006) 577-586.

[279] G.C. Barnett, D. Thompson, L. Fachal, S. Kerns, C. Talbot, R.M. Elliott, L. Dorling, C.E. Coles, D.P. Dearnaley, B.S. Rosenstein, A. Vega, P. Symonds, J. Yarnold, C. Baynes, K. Michailidou, J. Dennis, J.P. Tyrer, J.S. Wilkinson, A. Gomez-Caamano, G.A. Tanteles, R. Platte, R. Mayes, D. Conroy, M. Maranian, C. Luccarini, S.L. Gulliford, M.R Sydes, E. Hall, J. Haviland, V. Misra, J. Titley, S.M. Bentzen, P.D. Pharoah, N.G. Burnet, A.M. Dunning, C.M. West, A genome wide association study (GWAS) providing evidence of an association between common genetic variants and late radiotherapy toxicity, Radiother. Oncol. 111 (2014) 178-185.

[280] S.L. Kerns, H. Ostrer, R. Stock, W. Li, J. Moore, A. Pearlman, C. Campbell, Y. Shao, N. Stone, L. Kusnetz, B.S. Rosenstein, Genome-wide association study to identify single nucleotide polymorphisms (SNPs) associated with the development of erectile dysfunction in African-American men after radiotherapy for prostate cancer, Int. J Radiat. Oncol. Biol. Phys. 78 (2010) 1292-1300.

[281] S.L. Kerns, R. Stock, N. Stone, M. Buckstein, Y. Shao, C. Campbell, L. Rath, D. De Ruysscher, G. Lammering, R. Hixson, J. Cesaretti, M. Terk, H. Ostrer, B.S Rosenstein, A 2-stage genome-wide association study to identify single nucleotide polymorphisms associated with development of erectile dysfunction following radiation therapy for prostate cancer, Int. J. Radiat. Oncol. Biol. Phys. 85 (2013) e21-e28.

[282] S.L. Kerns, R.G. Stock, N.N. Stone, S.R. Blacksburg, L. Rath, A. Vega, L. Fachal, A Gomez-Caamano, D.D. Ruysscher, G. Lammering, M. Parliament, M. Blackshaw, M. Sia, J. Cesaretti, M. Terk, R. Hixson, B.S. Rosenstein, H. Ostrer, Genome-wide association study identifies a region on chromosome 11q14.3 associated with late rectal bleeding following radiation therapy for prostate cancer, Radiother. Oncol. 107 (2013) 372-376.

[283] S.L. Kerns, N.N. Stone, R.G. Stock, L. Rath, H. Ostrer, B.S. Rosenstein, A 2-stage genome-wide association study to identify single nucleotide polymorphisms associated with development of urinary symptoms after radiotherapy for prostate cancer, J. Urol. 190 (2013) 102-108.

[284] J. Chang-Claude, O. Popanda, X.L. Tan, S. Kropp, I. Helmbold, D. von Fournier, W. Haase, M.L. Sautter-Bihl, F. Wenz, P. Schmezer, C.B. Ambrosone, Association between polymorphisms in the DNA repair genes, XRCC1, APE1, and XPD and acute side effects of radiotherapy in breast cancer patients, Clin. Cancer Res. 11 (2005) 4802-4809.

[285] G.C. Barnett, C.E. Coles, R.M. Elliott, C. Baynes, C. Luccarini, D. Conroy, J.S. Wilkinson, J. Tyrer, V. Misra, R. Platte, S.L. Gulliford, M.R. Sydes, E. Hall, S.M. Bentzen, D.P Dearnaley, N.G. Burnet, P.D. Pharoah, A.M. Dunning, C.M. West, Independent validation of genes and polymorphisms reported to be associated with radiation toxicity: a prospective analysis study, Lancet Oncol. 13 (2012) 65-77.

[286] L. Fachal, A. Gomez-Caamano, G.C. Barnett, P. Peleteiro, A.M. Carballo, P. CalvoCrespo, S.L. Kerns, M. Sanchez-Garcia, R. Lobato-Busto, L. Dorling, R.M. Elliott, D.P. Dearnaley, M.R. Sydes, E. Hall, N.G. Burnet, A. Carracedo, B.S. Rosenstein, C.M. West, A.M. Dunning, A. Vega, A three-stage genome-wide association study identifies a susceptibility locus for late radiotherapy toxicity at 2q24.1, Nat. Genet. 46 (2014) 891-894

[287] S.C. Formenti, S. Demaria, Combining radiotherapy and cancer immunotherapy: a paradigm shift, J. Natl. Cancer Inst. 105 (2013) 256-265.

[288] P.G. Coulie, B.J. Van den Eynde, P. van der Bruggen, T. Boon, Tumour antigens recognized by T lymphocytes: at the core of cancer immunotherapy, Nat. Rev. Cancer 14 (2014) 135-146.

[289] T.N. Schumacher, R.D. Schreiber, Neoantigens in cancer immunotherapy, Science (New York, N.Y.) 348 (2015) 69-74.

[290] M.S. Rooney, S.A. Shukla, C.J. Wu, G. Getz, N. Hacohen, Molecular and genetic properties of tumors associated with local immune cytolytic activity, Cell 160 (2015) $48-61$. 
[291] I. Mellman, R.M. Steinman, Dendritic cells: specialized and regulated antigen processing machines, Cell 106 (2001) 255-258.

[292] S. Demaria, E.B. Golden, S.C. Formenti, Role of local radiation therapy in cancer immunotherapy, JAMA Oncol. (2015).

[293] E.B. Golden, A. Chhabra, A. Chachoua, S. Adams, M. Donach, M. Fenton-Kerimian, K Friedman, F. Ponzo, J.S. Babb, J. Goldberg, S. Demaria, S.C. Formenti, Local radiotherapy and granulocyte-macrophage colony-stimulating factor to generate abscopal responses in patients with metastatic solid tumours: a proof-of-principle trial, Lancet Oncol. 16 (2015) 795-803.

[294] N.A. Rizvi, M.D. Hellmann, A. Snyder, P. Kvistborg, V. Makarov, J.J. Havel, W. Lee, J. Yuan, P. Wong, T.S. Ho, M.L. Miller, N. Rekhtman, A.L. Moreira, F. Ibrahim, C. Bruggeman, B. Gasmi, R. Zappasodi, Y. Maeda, C. Sander, E.B. Garon, T. Merghoub, J.D. Wolchok, T.N. Schumacher, T.A. Chan, Cancer immunology. Mutational landscape determines sensitivity to PD-1 blockade in non-small cell lung cancer, Science (New York, N.Y.) 348 (2015) 124-128.

[295] E.B. Garon, N.A. Rizvi, R. Hui, N. Leighl, A.S. Balmanoukian, J.P. Eder, A. Patnaik, C. Aggarwal, M. Gubens, L. Horn, E. Carcereny, M.J. Ahn, E. Felip, J.S. Lee, M.D. Hellmann, O. Hamid, J.W. Goldman, J.C. Soria, M. Dolled-Filhart, R.Z. Rutledge, J. Zhang, J.K. Lunceford, R. Rangwala, G.M. Lubiniecki, C. Roach, K. Emancipator, L. Gandhi, Pembrolizumab for the treatment of non-small-cell lung cancer, N. Engl. J. Med. 372 (2015) 2018-2028.

[296] H. Cammann, K. Jung, H.A. Meyer, C. Stephan, Avoiding pitfalls in applying prediction models, as illustrated by the example of prostate cancer diagnosis, Clin. Chem. 57 (2011) 1490-1498.

[297] F. Legare, D. Stacey, N. Briere, S. Desroches, S. Dumont, K. Fraser, M.A. Murray, A. Sales, D. Aube, A conceptual framework for interprofessional shared decision making in home care: protocol for a feasibility study, BMC Health Serv. Res. 11 (2011) 23.

[298] G. Elwyn, A. O'Connor, D. Stacey, R. Volk, A. Edwards, A. Coulter, R. Thomson, A. Barratt, M. Barry, S. Bernstein, P. Butow, A. Clarke, V. Entwistle, D. Feldman-Stewart, M. Holmes-Rovner, H. Llewellyn-Thomas, N. Moumjid, A. Mulley, C. Ruland, K. Sepucha, A. Sykes, T. Whelan, Developing a quality criteria framework for patient decision aids: online international Delphi consensus process, BMJ 333 (2006) 417.

[299] G. Elwyn, S. Laitner, A. Coulter, E. Walker, P. Watson, R. Thomson, Implementing shared decision making in the NHS, BMJ 341 (2010) c5146.

[300] J.D. Tariman, D.L. Berry, B. Cochrane, A. Doorenbos, K. Schepp, Preferred and actual participation roles during health care decision making in persons with cancer: a systematic review, Ann. Oncol. 21 (2010) 1145-1151.

[301] S. Molenaar, M.A. Sprangers, F.C. Postma-Schuit, E.J. Rutgers, J. Noorlander, J. Hendriks, H.C. de Haes, Feasibility and effects of decision aids, Med. Decis. Mak. 20 (2000) 112-127.

[302] J.F. Kasper, A.G. Mulley Jr., J.E. Wennberg, Developing shared decision-making programs to improve the quality of health care, QRB Qual. Rev. Bull. 18 (1992) $183-190$

[303] A.M. O'Connor, A. Rostom, V. Fiset, J. Tetroe, V. Entwistle, H. Llewellyn-Thomas, M. Holmes-Rovner, M. Barry, J. Jones, Decision aids for patients facing health treatment or screening decisions: systematic review, BMJ 319 (1999) 731-734.

[304] L.M. Masya, J.M. Young, M.J. Solomon, J.D. Harrison, R.J. Dennis, G.P. Salkeld, Preferences for outcomes of treatment for rectal cancer: patient and clinician utilities and their application in an interactive computer-based decision aid, Dis. Colon Rectum 52 (2009) 1994-2002.

[305] S. Molenaar, M.A. Sprangers, E.J. Rutgers, E.J. Luiten, J. Mulder, P.M. Bossuyt, J.J. van Everdingen, P. Oosterveld, H.C. de Haes, Decision support for patients with earlystage breast cancer: effects of an interactive breast cancer CDROM on treatment decision, satisfaction, and quality of life, J. Clin. Oncol. Off. J. Am. Soc. Clin. Oncol. 19 (2001) 1676-1687.

[306] P. . Stalmeier, IJ. Unic LC. Verhoef, W. A. Van Daal, Evaluation of a shared decision making program for women suspected to have a genetic predisposition to breast cancer: preliminary results, Med. Decis. Mak. 19 (1999) 230-241.

[307] D. Stacey, F. Legare, N.F. Col, C.L. Bennett, M.J. Barry, K.B. Eden, M. Holmes-Rovner, H. Llewellyn-Thomas, A. Lyddiatt, R. Thomson, L. Trevena, J.H. Wu, Decision aids for people facing health treatment or screening decisions, Cochrane Database Syst. Rev. 1 (2014), CD001431.

[308] F. Andre, S. Delaloge, First-generation genomic tests for breast cancer treatment, Lancet Oncol. 11 (2010) 6-7.

[309] R.G. Gray, P. Quirke, K. Handley, M. Lopatin, L. Magill, F.L. Baehner, C. Beaumont, K.M. Clark-Langone, C.N. Yoshizawa, M. Lee, D. Watson, S. Shak, D.J. Kerr, Validation study of a quantitative multigene reverse transcriptase-polymerase chain reaction assay for assessment of recurrence risk in patients with stage II colon cancer, J. Clin. Oncol. Off. J. Am. Soc. Clin. Oncol. 29 (2011) 4611-4619.

[310] K.A. Ahmed, W.J. Fulp, A.E. Berglund, S.E. Hoffe, T.J. Dilling S.A. Eschrich, R. Shridhar, J.F. Torres-Roca, Differences between colon cancer primaries and metastases using a molecular assay for tumor radiation sensitivity suggest implications for potential oligometastatic SBRT patient selection, Int. J. Radiat. Oncol. Biol. Phys. 92 (2015) 837-842.

[311] S. Eschrich, H. Zhang, H. Zhao, D. Boulware, J.-H. Lee, G. Bloom, J.F. Torres-Roca, Systems biology modeling of the radiation sensitivity network: a biomarker discovery platform, Int. J. Radiat. Oncol. Biol. Phys. 75 (2009) 497-505.

[312] S.A. Eschrich, W.J. Fulp, Y. Pawitan, J.A. Foekens, M. Smid, J.W. Martens, M. Echevarria, V. Kamath, J.H. Lee, E.E. Harris, J. Bergh, J.F. Torres-Roca, Validation of a radiosensitivity molecular signature in breast cancer, Clin. Cancer Res. 18 (2012) 5134-5143.

[313] S.A. Eschrich, J. Pramana, H. Zhang, H. Zhao, D. Boulware, J.-H. Lee, G. Bloom, C. Rocha-Lima, S. Kelley, D.P. Calvin, T.J. Yeatman, A.C. Begg, J.F. Torres-Roca, A gene expression model of intrinsic tumor radiosensitivity: prediction of response and prognosis after chemoradiation, Int. J. Radiat. Oncol. Biol. Phys. 75 (2009) 489-496.

[314] C.J. Anker, J.Y. Wo, Personalized medicine in radiation oncology-a work in progress, Int. J. Radiat. Oncol. Biol. Phys. 92 (2015) 843-845.

[315] L. Hood, S.H. Friend, Predictive, personalized, preventive, participatory (P4) cancer medicine, Nat. Rev. Clin. Oncol. 8 (2011) 184-187.

[316] M.J. Khoury, M.L. Gwinn, R.E. Glasgow, B.S. Kramer, A population approach to precision medicine, Am. J. Prev. Med. 42 (2012) 639-645.

[317] A.D. Weston, L. Hood, Systems biology, proteomics, and the future of health care: toward predictive, preventative, and personalized medicine, J. Proteome Res. 3 (2004) 179-196. 